NBER WORKING PAPER SERIES

\title{
WHITHER POVERTY IN GREAT BRITAIN AND THE UNITED STATES? THE DETERMINANTS OF CHANGING POVERTY AND WHETHER WORK WILL WORK
}

\author{
Richard Dickens \\ David T. Ellwood \\ Working Paper 8253 \\ http://www.nber.org/papers/w8253 \\ NATIONAL BUREAU OF ECONOMIC RESEARCH \\ 1050 Massachusetts Avenue \\ Cambridge, MA 02138 \\ April 2001
}

The authors gratefully acknowledge the helpful suggestions of Richard Blundell, David Card, Richard Freeman, and all the participants at the conference Seeking a Premier League Economy, Centre for Economic Performance, LSE and seminar participants at the University of Kent, the Centre for the Analysis of Social Exclusion, LSE and the Policy Studies Institute. We are also grateful to Jayne Taylor, Howard Reed and Mike Brewer from the Institute for Fiscal Studies and to Steve Wilcox at the University of York for their invaluable advice. The Family Expenditure Survey is collected by the Office for National Statistics and made available by The Data Archive. The views expressed herein are those of the authors and not necessarily those of the National Bureau of Economic Research.

(C) 2001 by Richard Dickens and David T. Ellwood. All rights reserved. Short sections of text, not to exceed two paragraphs, may be quoted without explicit permission provided that full credit, including (C) notice, is given to the source. 
Whither Poverty in Great Britain and the United States?

The Determinants of Changing Poverty and Whether Work Will Work

Richard Dickens and David T. Ellwood

NBER Working Paper No. 8253

April 2001

JEL No. I3

\begin{abstract}
Scholars emphasize that poverty in Britain has risen sharply since the late 1970s. Meanwhile in the United States, both official figures and traditional poverty scholars report sharp declines in poverty. We seek to provide a comparison of poverty levels in Britain and the US based on a set of common definitions. We then proceed to ask what factors-demographic, economic, or policy-account for the observed changes in poverty in the two nations and what role could policy play in reducing poverty? We develop a procedure that allows one to trace out the relative impacts of altered demographics, rising wage inequality, work changes, and policy innovations in explaining changing poverty patterns. We find that the forces influencing poverty differ between nations and across absolute and relative poverty measures. Demographic and wage change is a dominant force in both nations. Britain has experienced a dramatic rise in workless households while the US has simultaneously had a sharp fall. These differences had a sizable impact on absolute poverty in both nations and a significant impact on relative poverty in Britain. Government benefits directly reduced relative and absolute poverty considerably in Britain over this period but had little impact in the US. However, changing patterns of benefits and work suggest that policy changes have significantly increased work in the US, particularly among single parents. In Britain, policy changes may have had the reverse effect, reducing work among many groups. The UK government has committed itself to reducing child poverty by half over the next 10 years and to its abolition within 20 years, largely through policy changes designed to make work pay. We conclude that any purely work-based strategy, which doesn't tackle demographics and wage dispersion, may not have a dramatic effect on relative poverty.
\end{abstract}

Richard Dickens

Centre for Economic Performance

London School of Economics

Houghton St., London, WC2A 2AE

United Kingdom

r.dickens@1se.ac.uk
David T. Ellwood

Kennedy School of Government

Harvard University

Cambridge, MA 02138

david.ellwood@harvard.edu 


\title{
Whither Poverty In Great Britain and the United States? The Determinants of Changing Poverty and Whether Work Will Work
}

\author{
By \\ Richard Dickens \\ and \\ David T. Ellwood
}

Scholars in the United Kingdom emphasize that poverty in Britain has risen sharply since the late 1970s. According to Goodman et al. (1997), after remaining steady at roughly $11 \%$ though the 60 s and falling to 8 or $9 \%$ in the 70 s, it has since doubled. Meanwhile in the United States, both official figures and traditional poverty scholars report sharp declines in poverty. Since reaching $15 \%$ in the early 1980 s, official poverty rates are now at $11 \%$. The black poverty rate and the rate for single parents are at their lowest level in the 40 years for which data is reported. ${ }^{1}$ What accounts for the apparent divergence? More importantly, what factors - demographic, economic, or policyaccount for the changes in poverty in the two nations? And what role could policy play in reducing poverty?

Of course a major reason for the differences in reported poverty trends is that the nations remain divided by a common language with a very uncommon set of definitions. In Britain and Europe, poverty is traditionally measured according to a relative scalefamilies are considered poor if their incomes fall below $60 \%$ of the (family size adjusted) median income. By contrast, in the US, poverty is measured against an absolute standard that is adjusted annually only for inflation. More subtle distinctions include the fact that in Britain poverty is typically based on weekly income net of taxes, while in the US it is based on gross annual income.

\footnotetext{
${ }^{1}$ U. S. Bureau of the Census (2000)
} 
In this paper, we work to create common measures of poverty in the two nations. We develop a procedure that allows one to more fully trace out the relative impacts of altered demographics, rising wage inequality, work changes, and policy innovations in explaining changing poverty patterns than the usual aggregate models allow. And we use this procedure to determine the forces shaping poverty in the two nations. Our basic methodological idea is straightforward if rather difficult to implement. For members of the sample in any given year, we estimate what each person's and family's work, wages, and benefits would have been if the structure of pay, employment, or aid had been equivalent to that of a base year. We can then estimate what poverty would have been if one or all of the base year conditions still prevailed.

Using this method, we find that the forces influencing poverty differ across nations and across absolute versus relative poverty measures. A number of important findings emerge from this paper:

- Britain and the US share some broad patterns in common - relative poverty has risen in both nations albeit much more so in Britain, and in recent years, absolute poverty has fallen in both.

- There are very sizable differences in the magnitudes and trends. By measures used here, the US has considerably higher relative poverty. But very importantly, relative poverty in Britain has risen far more sharply over the past 20 years, and the gap between the countries has closed considerably.

- In both nations demographic change and rising wage inequality played key roles in increasing relative poverty, but the impacts were far greater in Britain. Yet for absolute poverty, wage changes had almost no net effect in Britain, while they had a modest effect in the US.

- Britain has experienced a dramatic rise in workless households while the US has simultaneously had a sharp fall. In Britain this had a sizeable impact on relative and absolute poverty. In the US increasing work has had little impact on relative poverty but resulted in a sizable reduction of absolute poverty. 
- Ignoring any behavioural impacts, expanding government benefits reduced relative and absolute poverty considerably in Britain over this period. By contrast as compared to 1979, the impacts of US benefits were almost negligible.

- Both the level and structure of government aid differs enormously across the two nations. Government benefits for workless households are higher and have grown in Britain. In the US, government benefits for those with no earnings have been cut dramatically, while in recent years, benefits for those with low to moderate earnings have risen considerably.

- The changing patterns of benefits and work strongly suggest that in the US at least, policy changes have significantly influenced work behaviour, particularly by single parents, and thus altered poverty. In Britain the policy changes may have had the reverse effect, reducing work among many groups, though the evidence is far from conclusive.

- The relatively modest changes in incentives currently contemplated by UK policymakers will still leave Britain with a vastly different structure of benefits than the US. Based on the results of this paper, we suspect they will have a modest impact on work. Only a strategy that will dramatically increase work and significantly increase the incomes of lower paid workers will have a really sizable impact on relative poverty. And both of these will prove hard to achieve. Any purely work-based strategy which doesn't tackle demographics and wage dispersion, may not have a dramatic effect on relative poverty.

\section{Measuring Poverty in Britain and the US}

Our first goal is to create as common a set of poverty definitions across the two countries as possible. This involves recognizing different types of poverty standards, the definitions of income, and definitions of families.

\section{Relative Versus Absolute Poverty Standards}

Poverty is typically defined as a situation where family income falls below some poverty standard that varies by family size. But the way the standard is determined differs by country. 
There is no official poverty standard in Britain, but there is something of a conventional wisdom. Poverty has traditionally been defined as having net household income after taxes below half the mean (with appropriate adjustments for family size). However, more recently a relative measure based upon $60 \%$ of median income has gained prominence and has been adopted as the official poverty standard by Eurostat. ${ }^{2}$ These relative measures are based on the assumption that poverty is best understood as depending on where a family stands in comparison to others. If the income of disadvantaged families rises slightly, but the average income of families overall rises a great deal, poverty will increase using this measure.

The US does have an official poverty standard and it is widely used. The government defines poverty using an absolute standard that has been essentially unchanged $^{3}$ in real terms for 35 years. The absolute standard assumes that what matters is the absolute position of a family. If the income of disadvantaged families rises slightly, but the average income of families overall rises a great deal, poverty will decrease using this measure.

There is a large and energetic literature about the pros and cons of relative and absolute measures. Both have their virtues. The notion that a near poor family is no worse off if the standard of living of most other families rises considerably seems implausible. What were luxuries, such as telephones and indoor plumbing, become necessities as the society becomes more prosperous. A relative measure seems to come closer to capturing the larger notions of poverty which might involve a sense of connection or inclusion in the overall society.

\footnotetext{
${ }^{2}$ Note also that the UK government's commitment to eradicate child poverty is based on a poverty definition of $60 \%$ of median household income
} 
At the same time, it seems odd to assume that low income families would be worse off if their income rose $40 \%$ over a decade while the income of the average family rose by $50 \%$. An absolute measure captures the notion that having more food or better housing can be a benefit even if others do as well or even better.

Absolute standards pose another problem for international work- how should a common absolute standard be set? One possibility is to use a common standard adjusted for the exchange rate and differences in purchasing power. Since the US is somewhat wealthier by this standard than Britain, there will almost inevitably be more poverty in Britain. These issues do not arise with relative standards since each country is being measured relative to its mean or median income.

For purposes of this paper, we will examine both absolute and relative measures, though we will concentrate disproportionately on relative measures since this volume is focused on the British economy. For relative poverty we use $60 \%$ of median income and use the family size adjustment derived by McClements (1977), which is commonly used in Britain.

For absolute poverty standards we used slightly different procedures in each country. In Britain, we set the absolute standard for poverty equal to $60 \%$ of median income in 1979. Thus for 1979 in Britain, the measure of absolute and relative poverty is the same. After 1979 the relative poverty line rises or falls with median income, but the absolute measure remains unchanged (except for inflation adjustments).

We experimented with two different absolute poverty standards for the US. One was to use the $60 \%$ of median 1979 income in the US, just as was done for Britain. This

\footnotetext{
${ }^{3}$ There have been minor changes to definitions and family size adjustments over the years.
} 
yields a 1999 poverty standard of $\$ 32,652$ for a family of four ${ }^{4}$ - considerably above the US official standard of $\$ 17,356$. More importantly this procedure also yields an absolute poverty standard that is considerably higher in purchasing power parity terms for the US than for Britain because US average incomes were higher in 1979. If the 1999 US-UK purchasing power parity is applied to the $60 \%$ median 1979 income standard for Britain, the poverty line in the US would instead have been $\$ 20,047$ - much closer to the official US poverty line. Given the likely interest of US readers in the official poverty line, we report in the body of the text absolute figures for the US using the official US standards. We have done all calculations using both standards. The trends for the $60 \%$ median 1979 US income standard are virtually identical and Figure 7 which uses the official poverty line is reproduced using the $60 \%$ median 1979 standard as Appendix Figure A1.

\section{Definition of Income and Family/Household Unit}

Poverty is generally measured using large cross-sectional surveys in each country, but there are important differences in what the surveys measure. Successive waves of the Family Expenditure Survey (FES), based on interviews from roughly 10,000 households annually, are typically used to determine poverty levels. Income is a weekly measure. When poverty is measured, researchers generally count as income: earnings, dividends, interest, rent, pensions and government aid including nearly all Social Security benefits and housing. ${ }^{5}$ Taxes are deducted from income to give a sense of disposable income. Often the income is calculated both before and after housing costs to control for

\footnotetext{
${ }^{4}$ The poverty standard varies somewhat by the relationships of the four family members. This figure is the weighted average for all families with exactly 4 members.

${ }^{5}$ In Britain, virtually all non-housing aid is called Social Security benefits. To avoid confusion with the very different US Social Security system, which is primarily for the aged and disabled, we will generally refer to British Social Security benefits as "government aid" broadly to include these benefits along with housing.
} 
unmeasured inputted incomes of owner occupiers and because housing costs often vary greatly by region.

The issue of housing is further complicated in Britain by the provision of social housing. In 1980 about $33 \%$ of tenants were living in government provided housing with subsidised rents. A large proportion of the social housing stock was sold off to tenants through the "Right to Buy" policy of the Thatcher government. Furthermore, rents were deregulated and from 1983 housing aid was provided through Housing Benefit which covers housing costs for eligible claimants. As rents increased so did housing benefits. This resulted in a shift in housing aid from subsidized rents to cash support through benefit payments. The FES does collect information on cash support from Housing Benefits, and it reports whether people resided in social housing, but it has no estimate of the value of the subsidies to these residents. If one counts the value of the cash Housing Benefit but ignores the value of these social housing subsidies, one would show a sizable increase in housing aid that is partly the result of moving such aid from the uncounted social housing subsidy to the counted Housing Benefit. Because these subsidies are administered and funded at Local Authority level rather than household level, there is no reliable information with which to determine the exact subsidies that different families received over time. One can, however, get a measure of the aggregate subsidy from Local Authority Housing Revenue Accounts. And the FES does include a measure of the rent actually paid by housing tenants. After some experimentation, we imputed housing subsidy by applying the national percentage subsidy (expressed as a percentage of rent), to the rents reported by families and individuals in social housing. 
In official US statistics, the March Supplement of the Current Population Survey (CPS) is used. The March CPS collects information about income and work over the previous year from respondents in 40,000 - 50,000 households each year. For measuring poverty, income is based on gross annual income including earnings, rent, dividends, and interest, plus cash benefits from the government. Taxes are not deducted and so called "in-kind" benefits are left out. This excludes some very important sources of government aid such as the Earned Income Tax Credit ("taxes") and food stamps and housing aid ("in-kind benefits"). Numerous scholars, including a recent panel of the National Academy of Sciences, have called for revising this standard ${ }^{6}$ by ensuring that income is adjusted for taxes and most in-kind aid ${ }^{7}$, and work expenses.

We use the FES and CPS data for this study. We have no choice but to use weekly income in the FES and annual income in the CPS. Since weekly income is more volatile than annual income, we would expect British poverty would be lower if it were based on an annual measure. ${ }^{8}$ In the US data, we add the value of the Earned Income Tax Credit (EITC), food stamps, and housing benefits to other income for purposes of determining poverty. This correction should provide a more accurate picture of US gross income.

We cannot create after housing poverty measures for the US because information on housing expenditures is not collected in the CPS. Gross versus net income poses a different problem. Our methodology calls for estimating what each person and family would earn under different conditions in different years. As their income changes so too

\footnotetext{
${ }^{6}$ Citro and Michael (1995)

${ }^{7}$ The question of whether medical benefits should be included in income remains controversial.
} 
would their taxes owed. The structure of taxes is sufficiently complex, especially in the US, that it is far beyond the scope of this paper to estimate the new taxes for families under a variety of changed conditions. ${ }^{9}$

Figure 1 illustrates for Britain what difference the definition makes. It tracks relative poverty in Britain using gross and net income, with and without housing. Although the measures differ in their levels, they track each other almost perfectly over time. To facilitate comparisons and calculations, we will use poverty based on gross income before housing. It is intriguing that this measure is very close to one based on net income after housing. In the 1980s gross income before housing poverty is between 1.5 and 2 percentage points higher. This difference narrows somewhat in the 1990 s. Since our goal is to understand the key trends, we are convinced that our measure will perform quite well.

\section{Households, Families, and Filing Units}

Unfortunately the definition of families and households differ slightly between countries as well. In Britain, the economic unit is based on definitions comparable to benefit units for purposes of determining Social Security. This comes close to a household definition of an income unit. In particular, cohabiting couples are treated equivalently to married couples. Incomes are measured at the household level since this is how some benefits are determined. The US is based on families — defined as persons who are related by birth or marriage who are living together in the same household.

\footnotetext{
${ }^{8}$ Böheim and Jenkins (2000) show that income analysis based upon current monthly and annual incomes provide remarkably similar results, although there is some question over reliability of the annual income measure which is largely imputed from monthly data.

${ }^{9}$ In Britain, we have more hope. We have access to the IFS Taxben model which can calculate taxes and transfers for any family under any conditions. In later versions, we may use this model to estimate net income for Britain. We have no such model for the US. Though such models do exist for the US, of course, they are often quite massive and would be quite difficult to implement here.
} 
Unrelated adults in the same household are usually considered separate units. Thus cohabiting couples would appear as two separate units. In the past several years the CPS has refined its procedure to allow easier identification of cohabiting couples. Moreover, it is possible to infer cohabiting couples in earlier years. ${ }^{10}$ But we are also seeking to create units that are logically joined for benefit purposes since we estimate changes in benefits. Cohabiters are generally not included in the filing unit for benefits. Thus we choose to maintain the standard census definition of family where cohabiters are not included in the unit. There has been growth in cohabitation in recent years, but based on our previous work, we do not think treating cohabiters separately would change poverty trends much, though poverty would likely be slightly lower with a more inclusive definition of the unit.

\section{Young Versus Old}

In this study we have also chosen to limit our attention to families with household heads who are under 60 years of age. The work, retirement activity, and benefit structures are very different for older persons. Retirement patterns have changed over time in both countries. Britain has experienced a large growth in occupational pension schemes which have raised the incomes of pensioners. In both countries, pension benefits will be linked at least partly to past earnings which we cannot model or observe in this cross-sectional data. Thus we have chosen to limit our sample to households where the worker is unlikely to be retired or a pensioner.

\footnotetext{
${ }^{10}$ See Ellwood (2000) for a detailed description of how this can be done.
} 


\section{The Trends in Relative and Absolute Poverty in the US and UK}

Figure 2 shows the trends in relative poverty in Britain and the US between 1979 and 1999 using our gross income before housing, 60\% median income standard for households with a head under 60 .

- In 1979 , the countries were far apart in relative poverty. Poverty in Britain was $13 \%$; in the US it was over $26 \%$. In the following 20 years poverty grew in both countries. But poverty growth was much greater in Britain than the US. Between 1979 and 1999, poverty rose 11 percentage points in Britain, while rising "just" 4 points in the US.

The British trends are quite consistent with those reported by Goodman, Johnson and Webb (1997) and Department of Social Security (1999), as well as those reported for Britain and the US in Gottschalk and Smeeding (1997).

Figure 3 shows the measures of absolute poverty. It illustrates absolute poverty in both countries using the $60 \%$ median 1979 income absolute standard. And it shows poverty in the US using the official US measure.

- In contrast to the relative measures, absolute poverty in both countries mostly follow a rather clear cyclical path, rising during the recessions of 1982-83, falling in the mid 80s, rising again in 1992-93, and falling back sharply in recent years.

Not surprisingly the choice of poverty standard for the US makes a big difference in the level of absolute poverty. The vastly lower official standard leads to half the poverty rate that one might have projected otherwise.

- When one compares absolute US poverty using the official standard and absolute poverty in Britain using a 60\% median 1979 income standard, the poverty rates are much closer. The U.S. standard is somewhat lower ( $\$ 17,356$ in 1999 versus the purchasing power equivalent of $\$ 20,047$ for the absolute standard in Britain) and so poverty is somewhat lower in the US but the trends remain similar. 
Figures 2 and 3 reveal why it is important to be clear about whether one is comparing relative or absolute poverty. Using either measure the US does not perform very well, but relative poverty makes Britain's performance seem far worse than that of the US: poverty grew vastly more in Britain. Using absolute poverty, Britain has done as well or better than the US in recent years. As noted earlier, we will exclusively use the US official poverty standard in exploring absolute poverty for the US in the remainder of the paper.

What then explains the trends over time and, in particular, the differential performance in relative poverty? There are many possible explanations for these changes - a rise in single parent families, rising wage inequality, changing work patterns, or altered government aid. The challenge for this paper is to understand these trends.

\section{Possible Explanations for the Changing Patterns of Poverty}

The trends for Britain described above are relatively well known. A variety of important work has already been done exploring the role of demographic and economic factors. We summarise several explanations below.

\section{Changing Demographic Patterns}

Goodman, Johnson and Webb (1997), Davies and Joshi (1998) and many others document the changing mix of demographic characteristics among the poor. In both the US and Britain, a rising share of families are headed by women, and these families have far higher poverty rates than husband-wife families. Thus, in Britain for example, lone parents with children have risen from $5 \%$ of those in the bottom income quintile in the early 1960 s to $15 \%$ by the early 1990 s. 


\section{Changing Wage Patterns}

Real wages have risen in Britain over much of this period, but so too has wage dispersion. Machin (1999) reports that median male wages rose from $£ 6.13$ in 1980 to $£ 7.57$ in 1996. Yet during the same period the ratio of wages of men at the $90^{\text {th }}$ percentile of the hourly wage distribution to those at the $10^{\text {th }}$ percentile rose from 3.10 in 1975 to 3.96 in 1996. Similar changes occurred for women. Uniformly rising wages would have relatively little impact on relative poverty, but the widening dispersion would push such poverty up. (Of course if incomes in work are rising faster than incomes out of work then relative poverty will rise with growing earnings, even if wage dispersion did not grow, because median incomes would rise and more people without earnings would fall below the poverty standard.) By contrast, a uniform rise in wages would reduce absolute poverty (as more people are pulled above the fixed standard) but growing dispersion would work in the opposite direction. Since average wages grew in Britain and the dispersion widened, wage patterns seem likely to have pushed up relative poverty and had ambiguous impacts on absolute deprivation.

In sharp contrast to Britain, Mishel et al. (1999) report that median wages of men in the US fell from $\$ 14.37$ to $\$ 12.80$ between 1980 and 1998. But like Britain the 90/10 ratio rose over the period, from 3.62 to 4.51 . For women median wages actually rose from $\$ 9.13$ to $\$ 10.00$, but the $90 / 10$ ratio grew even more than it did for men, from 2.85 to 3.89. Thus it would seem that wage changes for men in the US would increase both absolute and relative poverty, while patterns for women would increase relative poverty at least.

Changing Employment and the Pattern of "Worklessness" 
Unemployment in Britain rose sharply over a large stretch of the recent period but has since fallen to a twenty year low of around 5\%. Nevertheless, the non-employment rate of men has remained high due to a large increase in inactivity, particularly among older, less skilled men. Furthermore, since the mid 1970s there has been a significant polarisation of work across households, so that by the late 1990s $17 \%$ of all households were without work as described in Gregg et al. (1999a) and Gregg and Wadsworth (2000). These households contain 4 million adults (13\%) and 2.6 million children (18\%). Some $70 \%$ of these workless households are poor and this rises to $90 \%$ where children are present. Ercolani and Jenkins (1998) use shift share analysis to show that the small increases in income inequality in the first half of the 1990s occur within and not between work rich and work poor households. We suspect that such polarisation may have been more important in influencing poverty in earlier periods and perhaps later periods as well.

By contrast in the US, employment levels seem to be high and growing in recent years. Unemployment rates are extremely low by US standards. A number of authors including Blank et al. (2000),Ellwood (2000), and Meyer and Rosenbaum (2000) have emphasized the sharp rise in work among single mothers in the US in recent years. There has been some decline in work among men over this period, a trend that some authors attribute to expanded disability benefits, though this conclusion remains quite controversial. ${ }^{11}$

\section{Social Policy Structures and "Reforms"}

Social policies are generally designed to mitigate hardships caused by low incomes that result from limited work, low pay, or single parenthood. Thus one would

\footnotetext{
11 See, for example, Bound and Waidmann (1992), DeLeire (forthcoming), Gruber and Kubik (1994), Haveman (1991).
} 
expect them to dampen the impact of the other factors cited above. In addition, social policies in Britain and the US have undergone repeated "reforms" over the past quarter century. Benefits have risen and fallen. New programmes have been added. Some have been eliminated and most recently in both countries, governments have moved toward a more work-oriented strategy, including expanded tax credits for workers, and at least some increase in work expectations. Policy changes obviously influence poverty both directly, by affecting the total income that individuals and families in a particular situation receive, and by altering behaviour. There is a sizeable body of work in both countries examining the role that social policies and incentives can have on work behaviour and poverty. ${ }^{12}$

All of these factors - demography, work, wages, and benefits - may have influenced policy in complex ways. We propose to extend the work of others on each of these individual topics by decomposing the altered patterns of poverty over time into the relative role that each of these factors may have played. The work of Goodman, Johnson and Webb (1997) offers the closest analogy, but their focus is primarily on inequality, and they seek to decompose the aggregate level of inequality into various components whereas we are more narrowly focussed on poverty and will do the decomposition on a more micro level. ${ }^{13}$

\footnotetext{
${ }^{12}$ See for example Blundell (2000), Blundell et al. (2000), Gregg et al. (1999b), Meyer and Rosenbaum (2000), Moffitt (1992).

${ }^{13}$ Goodman, Johnson and Webb (1997) do have a chapter on poverty, but they do not offer much decomposition of the trends in that segment.
} 


\section{Decomposing the Trends in Poverty among Families and Working Age Adults - \\ - Aggregate Methods and Micro Methods}

There are two different strategies one might pursue in seeking to parse the changing patterns of poverty--one using aggregate data at its heart and the other using micro data. While we always intended to rely primarily on the use of a time-series of cross-sectional micro data for our work, we initially tried estimating some aggregate models because their simplicity makes them relatively easy to perform and common in the literature.

\section{Aggregate Analyses}

Blank and Blinder (1986), Blank and Card (1993), and Cutler and Katz (1991) are among the chief contributors to the literature that seeks to explain variations in poverty using aggregate data in the U.S., while Gregg and Machin (1994) and Nolan (1986) have done key work for Britain. The basic strategy has typically been to regress aggregate poverty rates on factors such as unemployment rates, mean wages, inflation rates, GDP, demographic measures, government benefit levels, etc.

Unfortunately when we estimated such models we found them to be unstable and quite sensitive to specification. This should presumably come as no surprise given the time series nature of the data. Especially when we tried to separately identify wage levels, wage dispersion, unemployment, worklessness, and government benefits, we found that the results had no power at all. Aggregate methods by their very nature cannot do a very good job of distinguishing spurious from real effects. Thus we turned to micro methods for our analysis. 


\section{Micro Methodology}

The overall aim of this paper can probably best be represented with the question: what would the poverty rate have been today if the structure of wages, work or benefits had remained at some base year level? For example, since 1979 the distribution of wages has widened considerably, but employment, family structures, and benefit structures have changed as well. Thus a natural first question would be to ask how different the poverty rate would have been in 1999 had the distribution of wages been the same as in 1979 while everything else was at the actual 1999 level? This kind of experiment essentially requires that we assign each person who was working in 1999 a wage that an equivalent person would have earned in 1979, and then recalculate the poverty rate. A similar methodology can also be applied to work and benefit structures.

For all members of the sample in any given year, we estimate each person's and family's work, wages, and benefits given the structures of pay, employment, or benefits in a chosen base year. We can then estimate what poverty would have been if the base year conditions still prevailed. For this work we need to look at individual family income. A family is poor if their equivalised family income is below the poverty threshold.

Total Income $_{t}=\sum_{i=1}^{\text {nadults }}\left(\right.$ wage $_{i t} *$ hours $\left._{i t}\right)+$ govtben $_{t}+$ othinc $_{t}$

Where:

Total Income $_{t}=$ total family income for the family at time $\mathrm{t}$

Nadults $_{j}=$ number of adults in the family wage $_{i t}=$ wage of adult $\mathrm{i}$ at time $\mathrm{t}$ hours $_{i t}=$ hours worked by adult $\mathrm{i}$ at time $\mathrm{t}$ govtben $_{t}=$ government benefits received by family at time $\mathrm{t}$ othinc $_{t}=$ other income of the family at time $\mathrm{t}$ 
We would like to have a model of each of the key variables above--wages, hours, and government benefits--that would allow us to explore what might have happened had wage or work or government benefit patterns been different.

\section{Wages}

For each year we estimate the following wage equation:

$$
\begin{aligned}
& \text { wage }_{i t}=W_{t}\left(X_{i t}\right)+\varepsilon_{i t} \\
& \text { where: } \\
& X_{i t}=\text { measured characteristics of the person at time } \mathrm{t}
\end{aligned}
$$

In practice, we estimate separate wage equations for men and women in each year. The characteristics included vary somewhat across the UK and US. Both include age and education dummies and number of children. In the US we also include race dummies.

We will need a wage prediction for everyone (aged over 16) in the sample in each year $\mathrm{t}$ because under some assumptions more people will be working. This is relatively straightforward. We predict an individual's wage in year $\mathrm{t}$ based on their characteristics $X_{i t}$. For those with an observed wage we assign them their actual residual from the wage equation (the predicted wage in year $t$ is therefore the observed wage in that year for people who already work). For those who are not working we do not observe a residual and so randomly assign them a residual from the year $\mathrm{t}$ residual distribution. This gives us predicted wages in year $t$ for all individuals in the sample without changing the distribution. Of course if more people worked the distribution might change even beyond that predicted by the model. Those who did not initially work might be drawn from the lower tail of the wage distribution. Much of this is already accounted for in the base prediction which does depend on measured characteristics. We experimented with 
Heckman type selection models in this work. In principle nothing prevents their use. But we lacked a good selection instrument and found that including these selection equations did little to change our results. Thus we have chosen instead to maintain the original distribution.

We then want to predict an individual's wage in year $t$ given the wage structure of some base year s. To do this we need to account for the impact of the implicitly different returns to measured characteristics $X_{i t}$ in the base year s, but we also need to take account of the changed distribution of the error term between year s and year t. We predict wages using the following methodology:

$$
\overline{\overline{\text { wage }}}_{i t}^{s}=W_{s}\left(X_{i t}\right)+\varepsilon_{s}\left(\text { errorptile }_{i t}\right)
$$

where

$\overline{\overline{\text { wage }}}_{i t}^{s}=$ predicted wage for person $\mathrm{i}$ in year $\mathrm{t}$ using the wage distribtion of year $\mathrm{s}$ $X_{i t}=$ measured characteristics of the person at time $\mathrm{t}$ $\varepsilon_{s}=$ the observed residual distribution function in the wage equation for year $\mathrm{s}$ errorptile $_{i t}=$ the observed percentile of the residual of person $\mathrm{i}$ in the year $\mathrm{t}$ wage equation

We use each person's characteristics in year $t$ in the base year s wage equation. To determine what the predicted error would be in the base year equation, we assume that the person's percentile ranking in the unexplained variance of wages remains unchanged in the two time periods. Thus if the residual $\varepsilon_{i t}$ for the person $\mathrm{i}$ in the year $\mathrm{t}$ wage equation placed them in the $37^{\text {th }}$ percentile of the residual distribution, they would be assigned the residual of the $37^{\text {th }}$ percentile of the distribution in year s. This method thus preserves both the ranking of individual's unobserved components of earnings over time while adjusting for altered levels of unexplained variance in pay over time. 
A problem arises with those individuals for whom we do not observe a wage in year $\mathrm{t}$. We chose to randomly assign a residual for these individuals from the year $\mathrm{s}$ residual distribution. This methodology allows us to predict wages for all individuals in each year, whether they work or not, given the current year or base year wage equation.

Work

There are two components to our work specification; the participation decision and the choice of hours of work. We treat these separately. Firstly, we estimate an equation each year that describes whether an individual works on not:

$$
\begin{aligned}
& \text { work }_{i t}=L_{t}\left(X_{i t}, Z_{i t}\right)+v_{i t} \\
& \text { where } \\
& \text { work }_{i t}=\begin{array}{l}
1 \text { if person i working in year } \mathrm{t} \\
0 \text { if person i not working in year } \mathrm{t}
\end{array} \\
& X_{i t}=\text { measured characteristics of person } \mathrm{i} \text { at time } \mathrm{t} \text { as in the wage equation } \\
& Z_{i t}=\text { measured household characteristics of person } \mathrm{i} \text { at time } \mathrm{t}
\end{aligned}
$$

$X_{i t}$ is the same as specified above. $Z_{i t}$ includes the number of children, spouse's

education, and other non-labor, non-benefit income. And, for women in couples, we also include their partner's work status to account for covariance in work decisions of couples. We estimate this equation separately for men and women and for individuals in different household types (husbands or wives, single household heads with other household members, single heads with no other members and other household members).

We now want a prediction of the work status of person $\mathrm{i}$ in year $\mathrm{t}$ given the work specification of some base year s. Our aim here in predicting work status in year $\mathrm{t}$ given the work equation of year $\mathrm{s}$ is to change the status of as few people as possible from their actual status observed in year t. Clearly, to the extent there are aggregate changes in 
work we need to adjust the work status of at least some individuals. Hence we predict work status in the following way:

$$
\begin{aligned}
& \text { If } \text { work }_{i t}=0 \text { and } P(\text { work })_{i t}^{S}-P(\text { work })_{i t}^{t}>0 \text { and } U_{i}<\frac{P(\text { work })_{i t}^{S}-P(\text { work })_{i t}^{t}}{1-P(\text { work })_{i t}^{t}} \text { then } \bar{w}_{i t}^{S}=1 \\
& \text { If } \text { work }_{i t}=1 \text { and } P(\text { work })_{i t}^{S}-P(\text { work })_{i t}^{t}<0 \text { and } U_{i}<\frac{P(\text { work })_{i t}^{t}-P\left(\text { work }_{i t}^{S}\right.}{P\left(\text { work }_{i t}^{t}\right.} \text { then } \overline{\overline{\text { work }}}_{i t}^{S}=0
\end{aligned}
$$

Otherwise $\overline{\overline{\text { work }}}$ it ${ }_{\text {it }}$ work $_{\text {it }}$

$\overline{\overline{\text { work }}}$ it $=$ predicted work status of person i in year t given year s work specification

work $_{i t}=$ observed work status of person i in year $\mathrm{t}$

$P(\text { work })_{i t}^{S}=L_{S}\left(X_{i t}, Z_{i t}\right)$ is the predicted work probability of person i in year t

using the year $\mathrm{s}$ work equation

$P(\text { work })_{i t}^{t}=L_{t}\left(X_{i t}, Z_{i t}\right)$ is the predicted work probability of person $\mathrm{i}$ in year $\mathrm{t}$

using the year $\mathrm{t}$ work equation

$U_{i}$ is a uniformly distributed random number for person $\mathrm{i}$

Thus to construct the predicted work status of person $i$ in year $t$ under the year $s$

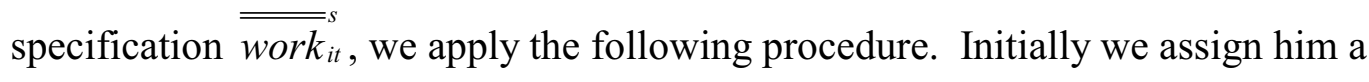
predicted work status that is equal to his observed work status. We then compare his predicted probability of work in year $\mathrm{t}$ under the year t equation, $P(\text { work })_{i t}^{t}$ with that predicted by the year s equation, $P(\text { work })_{i t}^{S}$. If for an individual, his $P(\text { work })_{i t}^{S}>$ $P(\text { work })_{i t}^{t}$ and the person is already working, we do nothing as predicted the odds of working have increased. If the person is not now working (and 1-P(work) ${ }_{i t}^{t}$ of such individuals will not be working), then there is some chance the person would in fact have 
gone to work. To assure that the fraction working matches the predicted probabilities, we need to randomly assign some of the individuals who are not working into work based on the difference in their predicted work probabilities and the odds that the person is not now working. This can be done on an individual basis using the equations above.

However, if $P(\text { work })_{i t}^{S}<P(\text { work })_{i t}^{t}$ then we need to assign some individuals who are working out of work. Again we randomly assign a proportion of these workers out of work. These proportions are specified such that the overall proportion in work in year $\mathrm{t}$ under the year s specification corresponds to that predicted by the year s work equation given year $\mathrm{t}$ characteristics.

\section{Hours}

Secondly, we estimate an hours equation for each year for those individuals with positive hours of work:

$$
\text { hours }_{i t}=H_{t}\left(X_{i t}, Z_{i t}\right)+\eta_{i t}
$$

where:

hours $_{i t}=$ hours worked by person $\mathrm{i}$ in year $\mathrm{t}$ (for those with positive hours)

$X_{i t}=$ measured characteristics of the person at time $\mathrm{t}$

$Z_{i t}=$ measured household characteristics of person $\mathrm{i}$ at time $\mathrm{t}$

Again we estimate this equation separately for men and women and for different household types (as discussed above). In order to obtain a prediction of the work hours of person $\mathrm{i}$ in year $\mathrm{t}$ under the base year s equation we apply the same method as employed with wages. 
${\overline{\overline{\text { hours }_{i t}}}}_{\text {it }}=H_{s}\left(X_{i t}\right)+\eta_{s}\left(\right.$ errorptile $\left._{i t}\right)$

where

${\overline{\text { hours }_{i t}}}_{\text {it }}=$ predicted hours for person $\mathrm{i}$ in year $\mathrm{t}$ using the hours distribtion of year $\mathrm{s}$ $X_{i t}=$ measured characteristics of the person at time $\mathrm{t}$

$Z_{i t}=$ measured household characteristics of person $\mathrm{i}$ at time $\mathrm{t}$

$\eta_{s}=$ the observed residual distribution function in the hours equation for year $\mathrm{s}$ errorptile $_{i t}=$ the observed percentile of the residual of person $\mathrm{i}$ in the year $\mathrm{t}$ hours equation

We use each person's individual and household characteristics in year $t$ in the base year s hours equation. To determine what the predicted error would be in the base year equation, we assume that the person's percentile ranking in the unexplained variance of hours remains unchanged in the two time periods. For those who are not working in year $\mathrm{t}$ we randomly assign a residual from the year s residual distribution.

Benefits

In our benefit specification we need to predict both whether a household is in receipt of benefits and the amount received. Ideally we would like to have access to a benefit model that uses observed household characteristics to predict the amount of benefit entitlement. In the absence of such a model we employ a regression based approach, using observed individual and household characteristics to predict benefit receipt. As with work there are two components to our benefit specification. Firstly we need to model whether the household is in receipt of benefits and then the benefit amount.

We estimate a benefit receipt equation for each household head i as follows: 


$$
\begin{aligned}
& \text { benp }_{i t}=R_{t}\left(X_{i t}, Y_{i t}\right)+\xi_{i t} \\
& \text { where } \\
& \text { benp }_{i t}=1 \text { if household } \mathrm{i} \text { is receiving benefits in year } \mathrm{t} \\
& 0 \text { if household } \mathrm{i} \text { is not receiving benefits in year } \mathrm{t} \\
& X_{i t}=\text { measured characteristics of household head i at time } \mathrm{t} \\
& Y_{i t}=\text { measured characteristics of household } \mathrm{i} \text { at time } \mathrm{t}
\end{aligned}
$$

We estimate this equation separately for our different household types (see above). $Y_{i t}$ includes own education dummies, spouse's education dummies, own hours of work, spouse's hours of work, number of adults, number of children, household earnings dummies, and non-wage income dummies. For the US we also include the State maximum AFDC level, whether the head has a disability, and whether the head was a widow.

We wish to predict the benefit participation of households in year $t$ given a base year s benefit participation equation. We employ an analogous methodology to that described above in terms of work participation. 
If benp $_{i t}=0$ and $P(\text { benp })_{i t}^{S}-P(\text { benp })_{i t}^{t}>0$ and $U_{i}<\frac{P(\text { benp })_{i t}^{S}-P(\text { benp })_{i t}^{t}}{1-P(\text { benp })_{i t}^{t}}$ then $\overline{\overline{b e n p}}_{i t}^{s}=1$ If benp $_{i t}=1$ and $P(\text { benp })_{i t}^{S}-P(\text { benp })_{i t}^{t}<0$ and $U_{i}<\frac{P(\text { benp })_{i t}^{t}-P(\text { benp })_{i t}^{S}}{P(\text { benp })_{i t}^{t}}$ then $\overline{\overline{\text { benp }}}_{i t}^{S}=0$

Otherwise $\overline{\overline{\text { benp }}}_{i t}^{s}=$ benp $_{i t}$

$\overline{\overline{\text { benp }}}_{\text {it }} S=$ predicted benefit status of household head $\mathrm{i}$ in year $\mathrm{t}$ given year $\mathrm{s}$ benefit specification

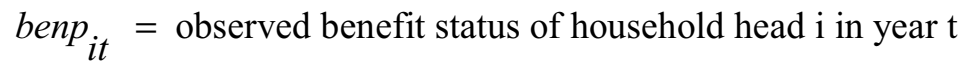

$P(\text { benp })_{i t}^{S}=R_{S}\left(X_{i t}, Z_{i t}\right)$ is the benefit participation probability of household head i in year $\mathrm{t}$ using the year s benefit equation

$P(\text { benp })_{i t}^{t}=R_{t}\left(X_{i t}, Z_{i t}\right)$ is the benefit participation probability of household head $\mathrm{i}$ in year $\mathrm{t}$ using the year $t$ benefit equation $U_{i}$ is a uniformly distributed random number for household head $\mathrm{i}$

\section{Benefit Amounts}

Lastly we require a prediction of the monetary amount of benefit receipt for each year. Our goal is to model as nearly as possible the mechanical relationship between a family's earnings and other characteristics and the amount of benefits they receive. Clearly the decision to work and the level of earnings that people have will be endogenous. But conditional on work and earnings benefits are not endogenous, they are a function of the rules of the benefit regime. In later work for Britain, we may use the IFS Taxben model to get more accurate estimates of benefit entitlement. But we do not have such a model for the US and we seek to have as comparable a model as possible between the two countries. We run the following regression for each household head separately for our different household types and also separately for households with and without children: 


$$
\text { benefits }_{i t}=B_{t}\left(X_{i t}, Y_{i t}\right)+\psi_{i t}
$$

where

benefits $_{i t}=$ benefit receipt of household head $\mathrm{i}$ at time $\mathrm{t}$

$X_{i t}=$ measured characteristics of household head $\mathrm{i}$ at time $\mathrm{t}$

$Y_{i t}=$ measured characteristics of household $\mathrm{i}$ at time $\mathrm{t}$

In order to obtain a prediction of benefit receipts of household head $\mathrm{i}$ in year $\mathrm{t}$

under the base year s equation we apply the same method as employed with wages and hours above.

${\overline{\text { benefits }_{i t}}}^{s}=B_{s}\left(X_{i t}, Y_{i t}\right)+\psi_{s}\left(\right.$ errorptile $\left._{i t}\right)$

where

$\overline{\text { benefits }}_{\text {it }}^{s}=$ predicted benefits for hosehold head i in year $\mathrm{t}$ using the benefits distribtion of year s $X_{i t}=$ measured characteristics household head i at time $\mathrm{t}$

$Z_{i t}=$ measured household characteristics at time $\mathrm{t}$

$\psi_{s}=$ the observed residual distribution function in the benefits equation for year $\mathrm{s}$

errorptile $_{i t}=$ the observed percentile of the residual of household head $\mathrm{i}$ in the year $\mathrm{t}$ benefits equation

We use each household head's individual and household characteristics in year $t$ in the base year s benefits equation. To determine what the predicted error would be in the base year equation, we assume that the household's percentile ranking in the unexplained variance of benefits remains unchanged in the two time periods. For those who are not in benefit receipt in year $\mathrm{t}$ we randomly assign a residual from the year s distribution.

We now have a predicted wage, work status, hours, benefit status and receipt for every person in our sample in each year $\mathrm{t}$. In addition, we have a prediction in each year $\mathrm{t}$ given the wage, work and benefits specification of the base year s. This allows us to 
answer questions such as; what would household income, and hence poverty, be in year $t$ given the wage, work or benefit specification and residuals from year $s$.

\section{Results: The Forces Shaping Poverty in Great Britain and the United States}

With this methodology we can pose a blistering array of hypothetical "what-if" scenarios. What would happen to poverty if wages had remained as they were in 1979 (or in 1984 or any other year) but demographic, work, and benefit patterns had all evolved as they did in actuality? What if the demographics only had changed? We have chosen 1979 as our base year partly because it just precedes most of the burst of inequality and policy change in both countries. We could have selected any year. Our basic question is straightforward: what factors caused the sharp changes in poverty?

We settled on an additive approach to understanding the changes. We start with everything as it was in 1979, and add in one change at a time. We begin by projecting what poverty would have been had demographic changes alone occurred. Methodologically, this involves estimating what work, wages, and benefits would have been in every year applying 1979 models (with their residuals) to the actual characteristics of the population in each year. Because family structures, education, and ages would have changed over time, work, wages, and benefits would have changed somewhat and poverty would have been changed as well. The change in poverty created by this model is the estimated impact of demographics. Next we projected poverty with wages and demographics set to their actual levels while work and benefits were kept at their 1979 level. ${ }^{14}$ The change in poverty from the previously measured impact of

\footnotetext{
${ }^{14}$ For most persons we use their actual wage multiplied by their predicted work hours if conditions had remained as in 1979. If some people were projected to work in a particular year who were not projected to work in 1979, we use an imputed wage for them.
} 
demographics alone indicates the impact of altered wage patterns. Next we calculated poverty allowing demographics, wages, and work to change, but still keeping government benefits at their 1979 base level. ${ }^{15}$ The net change in poverty now is the work effect. Finally the change from this to actual poverty is the impact of changes in benefits.

This type of decomposition involves several critical assumptions. The most obvious is that each change is being treated as though it were exogenous. But, of course, demographic changes may, in part, be the result of wage or benefit changes. Wage changes may be influenced by the fraction of people working. Work patterns will surely be influenced by wage and benefit patterns. These results thus must be seen as partial effects - not capturing any behavioural impacts. The place where this is most at issue is the potential impact of government benefits on work and worklessness. In the later sections of this paper, we shall confront this issue directly. Here we do adjust benefits for altered earnings, but not vise versa.

The other obvious feature of using this additive approach is that the decomposition it yields is somewhat path dependent. Depending on the order we added changes, the fraction attributed to various factors could differ. In our experiments, the order makes surprisingly little difference, though the order in which work or wage changes are added makes some difference in the UK because slightly more people are affected by wage changes when work levels are kept at 1979 levels.

Because we estimate changed outcomes for every member of our sample,

\footnotetext{
${ }^{15}$ We actually estimated two effects. First the projected poverty if benefits remained exactly at the level we predicted each family would have received in 1979 had their work and wages been as predicted using models for 1979. Then we projected poverty after allowing for the fact that under 1979 rules, benefits would have adjusted to the changed economic situation. This is the income stabilization effect of the benefit systems. In these charts, the lines are shown assuming benefits were set at the 1979 levels when work and wages were also set in 1979. Thus when we change wages or work we get the pure impact on poverty, not net of a stabilization effect.
} 
we can report on a very wide range of impacts. In each nation, we can look at effects on any possible measure of poverty for any demographic or family group. Here we have chosen to report on relative and absolute poverty overall, and for four family subgroups: couples with children, couples without children, singles with children, and singles without children. Note the "singles without children" is not necessarily a household with only one member (for example, in a small number of cases it includes grown children or other adults). With two nations, two poverty measures, and four family groupings, we have 16 different combinations to report about — and for each there is a different impact of demographics, wages, work, and public aid. Obviously we will not be able to comment fully on each of these, and many detailed results are relegated to an appendix or available from the authors.

Figure 4 illustrates the various impacts on relative poverty in Britain. It shows how each change would have altered poverty. The impacts are also summarized in the first column of the top panel of Table 1. The figure and table reveal a very straightforward and reasonable story.

- Demographics, wage change, and increased worklessness all contributed considerably to growing relative poverty in Britain throughout the 1979 to 1999 period. Demographic changes alone pushed poverty from roughly $13.0 \%$ up to $18.4 \%$. Wages moved the rate up another 4.6 points to $23.0 \%$. Worklessness raised poverty another 5.1 points to $28.1 \%$. On the other hand, government benefits expanded over the period and, ignoring any behavioural impacts, reduced poverty to $24.4 \%$-- 3.7 points lower than it would have been in the absence of expansion.

We should point out that much of the increase in benefits was in the form of increased housing benefit arising from increased rents. This is subject to interpretation and we will return to this below. Also, it is worth noting that the role of worklessness 
was larger during the mid 1980s and mid 1990s when overall levels of unemployment were much higher. ${ }^{16}$

Figure 5 and the second column of Table 1 shows the same information for absolute poverty, and a rather different picture emerges.

- In sharp contrast to relative poverty, neither demographic nor wage changes had a large net impact on absolute poverty. Demographic changes alone would have pushed up absolute poverty from $13.0 \%$ to $14.2 \%$. Wage changes had a small impact of 0.7 points. On the other hand, work changes had a very large impact on absolute poverty, pushing it up from $15 \%$ to over $21 \%$. Indeed the only reason absolute poverty did not rise much over this period was a large increase in government aid which pushed absolute poverty down by almost 7 points below what it would have been.

Figures 6 and 7 and the last two columns of Table 1 show similar decompositions

of poverty for the US. A very different pattern emerges.

- Demographic and wage changes in the US had smaller impacts on relative poverty than in Great Britain. On the other hand wages played a slightly larger role in raising absolute poverty in the US than in Britain.

- And in very sharp contrast to Britain, work changes significantly reduced absolute poverty and slightly reduced relative poverty in the US. And the direct effects of changes in government aid were almost negligible by 1999. (Figure 7 actually shows that in the mid 1980s policies increased poverty slightly, in the early 1990s they reduced it, and by 1999, the impact was roughly zero).

In interpreting these results, one must again remember that what is being measured is the effect of benefit (or wage or work) changes on poverty changes. The zero impacts for government benefits in Table 1 for the US does not mean that the level of government aid did not reduce poverty below what it would have been, only that

16 When we use the more standard definition of relative poverty based upon half mean contemporary income in Britain we find the role of work diminished and a larger impact from wages and demographic change. Since mean wages have risen faster than median wages this will raise this alternative poverty threshold by more. 
changes in aid relative to 1979 did not affect changes in poverty. And indirect effects through behavioural changes remain to be considered.

The bottom four panels of Table 1 display a plethora of results showing the impact of various types of changes on poverty among sub-groups. Even more detail is available in Appendix Tables A1-A4. In reading these results, it is important to remember that the experiment being contemplated is changing demographics or wages for everyone, not just the sub-group. A factor can have an effect on relative poverty of a group even if it does not affect the income of the group if it changes mean incomes overall and thus the poverty line. Thus the change in wages has large effects on relative poverty of single mothers (who do not work a great deal) because the higher overall mean wages result in a higher relative poverty standard which in turn leads more single mothers to be counted as poor.

The many results in Table 1 are too numerous to summarize, but a few key points do stand out.

- Among couples in Britain, work and pay changes are the big story: Wage changes pushed up relative poverty significantly, work declines pushed up relative poverty somewhat and absolute poverty quite considerably.

- Among couples in the US, work and wages are the story also, but in a different way. Wage changes did push up relative and absolute poverty somewhat, but work changes diminished both relative and absolute poverty.

- For single parents, the most striking findings involve work and benefits. In Britain, falling work pushes up poverty, especially absolute poverty while rising aid dramatically cuts poverty - reducing absolute poverty by an astonishing 27 percentage points. In the US, rising work of single parents apparently reduced absolute poverty a great deal, though this was partly offset by government benefit cuts. But intriguingly the changes in work have virtually no impact on relative poverty. 
- For singles without children, in the UK, the story is again one of reduced work being offset by higher benefits. In the US, neither of these factors appear to be important.

- What seems to emerge overall, then, is a story where:

$>$ Demographic change pushed up poverty in both nations, but far more for relative than absolute poverty.

$>$ Changing wages pushed up relative poverty in both nations, but had a small impact on absolute poverty in Britain and only a modest negative impact on absolute poverty in the US.

$>$ Changing work patterns increased poverty in Britain and reduced it in the US, but in both countries the impacts are larger on absolute than relative poverty.

$>$ The direct effect of changing government benefits since 1979 was to reduce poverty considerably in Britain while having essentially no impact in the US.

\section{Understanding How Demographic, Wage, and Work Changes Influenced Poverty}

These somewhat divergent results are actually quite plausible and fairly easy to understand. We examine each factor in turn briefly.

\section{Demographics}

There were two major types of demographic change in both countries. On the one hand two parent families diminished in proportion, being replaced by lone parents and singles without children. The number of single parent households increased from about $5 \%$ to $12 \%$ in Britain and from about $12 \%$ to $15 \%$ in the US between 1979 and 1999. As poverty rates are much higher in these settings, both absolute and relative poverty would be expected to rise as the mix shifted.

At the same time education levels rose significantly over the period. The increased education would have been expected to push up wages and work (and our models do project modest rises if 1979 work models had remained in place). This improvement in earnings would tend to reduce absolute poverty as more people moved 
above a fixed threshold. But its impact on relative poverty is ambiguous at best, since it raises incomes across the board. Indeed educational change could act to increase relative poverty both because education rises could have been greater in the upper percentiles and because low percentile families are far less likely to be working and thus would not see the impact of any wage rise associated with higher education.

- Changing demographics pushed up relative poverty due to altered family structures and rising education. But demographic effects on absolute poverty reflect the partially offsetting forces of changing family structures and rising education.

\section{Wages}

The picture for wages in Britain has much the same flavor, unambiguous increases in relative poverty, offsetting forces for absolute deprivation. Figures 8 and 9 show the well-known trends in wages for men and women in Great Britain using the FES. Mean and median hourly wages rose sharply, but the distribution also spread considerably. The striking fact on these figures is that wages for men and women in the $10^{\text {th }}$ percentile rose only slightly over this period, particularly for men. Relative poverty essentially measures inequality, so the widening distribution increased poverty regardless of the growth of the mean. And since absolute poverty captures what is happening to incomes of people at the bottom, the fact that wages were essentially unchanged at the lower tail left absolute poverty essentially untouched. In effect the beneficial effects of rising mean pay were offset by the negative impacts of a widening pay distribution.

As shown on Figures 10 and 11, in the US, pay distributions also widened, but for men at least, there was no concomitant rise in mean pay. Indeed the pay of men in the $10^{\text {th }}$ percentile fell from $\$ 7.06$ to $\$ 5.91$ in 1993 , before recovering somewhat to $\$ 6.36$ by 
1999. Such a change inevitably pushed up absolute poverty. Women's pay rose somewhat, but not enough at the bottom to offset the negative impacts of male earnings.

- Rising wage inequality in both countries played a leading role in raising relative poverty. But at the bottom of the distribution, stagnant pay in Britain and falling pay in the US meant that the absolute level of deprivation was unaffected in the former nation and worsened in the latter.

\section{Work}

Figure 12 plots the oft-cited rise in worklessness ${ }^{17}$ in the UK-reproducing the results of Gregg, Hansen and Wadsworth (1999a) and others. For every family type worklessness has risen rather considerably since 1979. This rise is quite remarkable since the unemployment rate is back down to where it had been in 1979 (as are overall employment rates) and wages are on average considerably higher. Worklessness rose from $35 \%$ of single parent households in 1979 to $56 \%$ in 1999 . Among couples with children the rise was from $4.5 \%$ up to $7.3 \%$, down from it's peak of nearly $12 \%$ in 1992 , but still considerably higher than previously. In absolute terms the rises were greatest for single parents, but in percentage terms the rises were especially high for couples.

The story for couples is somewhat more complex than it first appears. On the one hand men in couples are working considerably less than they did in 1979-non-work has risen from 7 to $13 \%$, even among men with children. Simultaneously work among women has grown even more dramatically. The fraction of mothers working outside the home has jumped from $59 \%$ to $71 \%$. Figure 13 shows that while worklessness has risen, so too has the frequency of both men and women working within couples. Gregg, Hansen and Wadsworth (1999a) report this redistribution of work into work rich and 
work poor households. Bifurcation of work within couples almost certainly contributed to a widening family income distribution.

In many respects it is a puzzle that work changes did not increase poverty more, especially relative poverty. Altered work did have large effects on absolute poverty. It appears that a large share of the newly workless poor would have previously been the working poor when one uses the higher relative poverty standard.

Nothing like this occurred in the US. Figure 14 shows that worklessness ${ }^{18}$ is on the decline, particularly among single mothers. Less than $5 \%$ of husband-wife families with children are workless. Among single parents, worklessness has fallen from a peak of $44 \%$ in 1982 to its current level of $27 \%$. Naturally these patterns are relevant in explaining poverty patterns.

Note, however, one very important fact — the impact of rising work in the US is felt mainly in absolute not relative poverty. Increasing work by single parents sharply reduced absolute poverty, but had no impact on relative poverty. The obvious reason must be that the move to work pushed single parent incomes up somewhat, but not high enough to get above the much higher relative poverty line. From the vantage point of relative poverty, in the US large numbers of single parents have gone form the nonworking poor to the working poor.

- Work patterns were radically different in Britain and the US. Worklessness is on the rise in all types of households in Britain, while it is falling sharply in the US, especially among single parents. Interestingly, changes in work have large effects on absolute poverty in both countries, but much smaller impacts

\footnotetext{
${ }^{17}$ For comparability with the US where young adults often live at home and work, we define worklessness as being where neither the household head nor the partner (if present) works.

${ }^{18}$ In all calculations relating to work and worklessness, we use whether or not the person was working at the March survey date. If we defined work based on annual work hours (which drives our model for the US) it would not be comparable to FES data which is for a survey week.
} 
on relative poverty. Moving people to work apparently moves their incomes up somewhat, but often not enough to avoid relative poverty.

\section{The Role of Social Policies}

It is evident that in Britain and the US benefits changed over time. These clearly influenced poverty, and they may be linked to changes in behaviour. One would like to compare the benefit structures, but past efforts at comparison have illustrated just how difficult that can be. The US has a set of overlapping programs often targeted to only a select group of beneficiaries, such as single parents (AFDC-TANF), the unemployed (UI), the disabled (SSI), working parents (EITC), widows (SSA-Survivors), as well as one fairly general support program called Food Stamps. In Britain, though there are important distinctions between aid for the unemployed or disabled or for housing, the variations among these are quite small in comparison to the US.

Comparison is further complicated by the fact that much of what influences benefit receipt and participation, especially in the US, has to do with administrative procedures and the treatment of clients. Benefit levels have not been cut dramatically in the US in recent years, but by all accounts the attempt to deter potential recipients from getting some forms of aid (in hopes of keeping them working) and the stigma of getting aid have increased significantly. Sanctions have grown and other administrative tightening seems omnipresent.

How then are we to compare the nature of support in the two nations over time? Our benefit model provides a rather straightforward conceptual way of comparison. For each country and for each family type, we can observe over time the amount of aid a family/household actually receives conditional on their earnings. Thus one can see how 
much aid a couple with zero earnings receives in 1979, in 1989, in 1999 and compare the levels and trends across countries. Similarly, one can compare the aid of couples with earnings of $£ 1-£ 150$, or earnings of $£ 151-£ 300$, etc. Of course this is not perfect, because the households in each category are in part a selected group, so there is an element of endogeneity. It is important to remember we are conditioning on earnings, and asking whether someone of a given earnings gets more benefits across countries and over timecertainly a well-defined question. Still, persons who have some condition we do not capture in the model or observe in the data that allows them to qualify for added aid may be more likely to be workless, and thus the method could not fully reflect the true potential benefit that another worker without this unobserved condition would get. ${ }^{19}$ Nonetheless country differences and trends over time should be quite revealing.

Let us begin be comparing the patterns for single parents because the differences are so striking. Figure 15 shows the amount of benefits a single parent received on average by weekly earnings category. For someone with zero earnings, benefits were roughly flat at $£ 130$ during most of the 1980 s, then rose significantly during the 1990 s to nearly $£ 170$ in 1999 . As noted before about $65 \%$ of this increase was due to rising housing aid. For someone earning from $£ 1$ to $£ 150$ per week, benefits averaged $£ 95$ and rose to $£ 120$ by 1999 .

Compare this to the benefits in the US as shown in Figure 16. In deriving these and the other charts for the US, we have excluded the disabled and widows who have

\footnotetext{
${ }^{19}$ The extreme example of this situation would be a disability program which paid vastly higher benefits to the disabled, but that others could not qualify for. Failing to control for disability might lead one to inappropriately predict that all persons with zero earnings would get high benefits, when in reality, only those with disabilities would. Such a disability program does exist in the US. However, we control for disability status in our model. And there is a bias in the other direction. Some people with zero earnings actually do not qualify for aid, either because the do not meet asset tests or because their zero earnings
} 
quite generous programs of support, and who would distort the comparisons.

Comparison between weekly benefits in pounds in Britain and annual benefits in dollars in the US can be tricky. In purchasing power parity terms, if one multiplies weekly benefits in pounds by roughly 80 , one gets annual dollars. Figure 16 is scaled so that the range is roughly equivalent in annual dollars of purchasing power parity to that of the British benefits. Thus visual comparisons between them give a sense of generosity.

Several facts stand out immediately in the US. First, benefits for zero earners have fallen throughout this period, and the fall has been particularly dramatic in the past five years. This trend can be traced first to the fact that AFDC benefits were not indexed to inflation, and then to the effects of welfare reforms at both the state and national levels in the early to mid 1990s.

Second, benefits for those with moderate earnings — $\$ 7,500$ to $\$ 15,000$ — dipped considerably in the early 1980 s, were flat until the early 1990s, and then rose sharply in recent years. These former changes are the result of Reagan era cutbacks in aid to working poor families on AFDC, the latter the effects of the dramatic expansions in the Earned Income Tax Credit. There is one mild puzzle here. Benefits have begun to drift down again. This appears to be the result of reductions in food stamp and other benefits, for there have not been any statutory cuts at the national level. In any case, by 1999, the difference in benefits for someone with zero earnings and someone earning up to $\$ 15,000$ were small.

Of particular relevance to the factors influencing poverty, the benefits for zero earnings are now considerably lower than in Britain, even though wages are often much

represent measurement error in the data. These persons would get zero benefits which would tend to pull the projected benefits for zero earners downward. 
higher in the US. In purchasing power weekly equivalents, the US benefit for a zero earner is only $£ 65$ per week. ${ }^{20}$ Even the benefits of the 1980 s were only the equivalent of $£ 100$. Thus,

- The benefit structures for single parents and the trends over time look dramatically different in the US and Britain. In the US, benefits received by zero earning single parents have fallen dramatically in recent years and benefits to those with low to moderate incomes have risen sharply. By contrast in Britain, benefits (largely due to rises in housing aid) have risen sharply for zero earning single parents and incentives for work have if anything worsened.

- The average benefit for a zero earner single parent as a fraction of the current relative poverty standard for a family of three in Britain was $62 \%$ in 1999 and $92 \%$ as a fraction of the absolute standard. In the US, this observed benefit for a zero earning single parents is now just $19 \%$ of the relative poverty line and only $36 \%$ of the US absolute poverty line. With British benefits far closer to the poverty lines, especially for absolute poverty, it should come as no surprise that benefit expansions had a relatively large impact on single parent poverty, particularly absolute poverty, in Britain, while benefit changes had much smaller impacts on poverty rates in the US.

Given the sharp difference in the trends in benefits and incentives between the two nations, it is at least plausible that benefit structures are influencing the divergent patterns of work, and we consider that issue in the next section.

But before looking at the question of behavioural impacts, we examine benefit patterns for other groups. Figures 17 and 18 show benefits for couples with children in Great Britain and the US. The British patterns show a rise in benefits for those with zero and low earnings in the early 80 s, then a flattening in the mid 80 s, perhaps because the indexing system was changed. Whereas previously benefit increases were indexed to

\footnotetext{
${ }^{20}$ The sharp decline in the number of persons with zero earnings in the US probably causes this figure to be exaggeratedly low. Some of the zero earners are probably data errors, or people with sizable assets who qualify for no aid. In the extreme case where one ignores all those getting zero benefits, the average benefit for a zero earner is $\$ 7200$ down from $\$ 9,000$ in the 80 s, still vastly lower than the British benefit.
} 
wage increases or price rises they were now tied to only price increases — and thus just kept pace with inflation. In the late 80 s a variety of housing benefit changes were implemented that reduced such aid. In particular, a capital limit of $£ 6000$ was introduced before an individual could qualify. See Evans (1996) for an excellent review. These probably account for the benefit falls of the mid to late 80s. Finally in 1986 the Social Security Act introduced wide-ranging reforms to the benefit system. The aim was to simplify the benefit system and to provide greater rewards to work. Supplementary Benefit was replaced by the simpler Income Support, which varied by just age and family structure. Family Credit replaced Family Income Supplement in providing a supplement for low income working families with children and was more generous than its predecessor. During this period benefits begin to rise again — about half due to housing aid expansion as rents rose and capital limits were increased.

In the US benefits for couples are far lower and show far less change over time, though the changes vaguely mimic the patterns for single parents in that less and less aid is available for those with zero earnings and more is being offered for those with low to moderate earnings. Still the striking feature of this figure is just how much lower benefits are for couples in the US. One seeming peculiarity in the US data can be readily explained. In years of recession the average benefits received by zero and low earning couples tends to jump up. That is because a group of former workers becomes unemployed and then quality for short term (26-38 weeks) unemployment benefits.

- Benefits for couples differ considerably between the US and Britain as well. British aid for low and zero earning families is considerably more generous and has become more so over time. In the US, even couples with zero earnings average just $\$ 4,000-\$ 5,000$ in aid or the purchasing power

Moreover, one would generally expect a strong potential bias in the other direction among those getting aid. Persons who could get the highest benefits should be more likely to have zero earnings. 
equivalent of $£ 50-65$ per week. In Britain, couples with zero earnings now average $£ 160$ per week. It seems no wonder that in Britain, expanding aid has had a far larger role in reducing poverty.

The patterns of US/British differences persist when we examine aid for single adults (not shown):

- In Britain benefits for single adults with zero earnings have also risen significantly over time. And in the US, aid to non-disabled single adults is almost non-existent.

We now turn to the most difficult question. What if any effects have these benefit structures had on behaviour?

\section{Behavioural Effects of Aid}

There are several strategies that are commonly followed to determine the impact of benefits and benefit changes on work. The first is to attempt to try to calculate the actual level of benefits for which each family could qualify using measures of benefit levels, eligibility rules, effective tax rates and the like and treat these parameters as exogenous. One would then use these in a structural model of labor supply behaviour. There is a long history of such modeling in work in both Britain and US. ${ }^{21}$

The difficulty of such methods when examining overall poverty patterns is that the wide range of often interacting benefits is difficult to model. Moreover, elements such as stigma, administrative complexity, and hostility/supportiveness of providers that sharply influence take-up rates severely complicate structural models. In the US the recent changes have proven particularly hard to model (Ellwood (2000).

A second strategy is to include a variety of measures of the structure of benefits, such as maximum benefit amounts, tax rates, indicators of sanction regimes or time

\footnotetext{
${ }^{21}$ See for example Bingley and Walker ), Blundell et al. (1999), Attanasio and MaCurdy (1997), and Moffitt (1986).
} 
limits, and the scope of the EITC in a reduced form labor supply equation along with wages. Meyer and Rosenbaum (1999), Eissa and Hoynes (1999), and Meyer and Rosenbaum (2000) all offer good recent examples in the US.

A final strategy is compare behaviour over time of groups of people whose incentives have been differentially affected by altered policy. Typically this work uses difference in difference techniques to look for evidence that the policy had an impact. This strategy or variations on it have been used by Eissa and Liebman (1996) and many others. One variation on this technique used by Ellwood (2000) is to examine the changed incentives and track the work behaviour of people at different parts of a predicted wage distribution. Often policies only affect low potential earners, and thus differential work behaviour can be tied to changes in policy.

Our imprecise methods for estimating benefits and the enormous differences across countries largely preclude our use of the first two strategies. But we can at least use the models to gain a rough sense of how work incentives have changed over time in each country for people in different family settings who have differing potential wages and compare these to changes in work.

This methodology is discussed in detail in Ellwood (2000), so we will only briefly describe it here. We begin by predicting wages - this time without residuals-for everyone in our sample according to the 1979 wage model. We then use these predicted wages to break people into thirds in each year, separately for men and women. Thus regardless of whether people worked or not we have a predicted wage third. We can then track incentives and work for people in those thirds. Wage thirds make more sense than say, educational levels, because the fraction with a given educational level changes 
considerably over time. We use the 1979 model for creating the wage thirds in each year to ensure that we really are tracking a comparable group over time, not following different people as returns to education and other variables shift.

Simple economic theory suggests that two factors ought to influence work decisions: first the level of income/benefits the person would get in the absence of work - a pure income effect, and the gain they would get by working - a substitution effect. We have already observed what happens to the benefits of persons and families with zero earnings: They rose over time in Britain for all family types, and benefits were considerably higher than in the US. In the US benefits for non-workers fell over time, particularly for single parents. Thus based on the income effect alone one would expect work to fall in Britain and rise in the US. But the substitution effect - the gain to working also matters. Wages have risen in Britain (although less so in entry jobs), and benefit structures changed. It is possible that the gains to working have increased considerably as wages have gone up.

We used our model to get a rough sense of how the gains to work may have changed over time and across countries. For each person in the sample, we first predicted their potential wage if they worked using the wage equation of their sample year. Once again we do not project residuals to avoid some forms of selection bias. We then use our benefits models to predict what benefits the household would get if the person did not work, and what would be received if the person worked full time at the predicted wage. ${ }^{22}$ To simplify this analysis, we looked only at work behaviour of the heads and partners for

\footnotetext{
${ }^{22}$ Note the predicted wage used to determine benefits is based on the equation for that year. The predicted wage used to classify people into potential wage thirds is based on the 1979 model.
} 
this work - the income of others was taken as given. For couples, we estimated benefits under a variety of joint work assumptions. ${ }^{23}$

Finally we calculated a very simple predicted gain to work from earnings less benefit changes. We did so by adding the gain in earnings to the predicted benefits given this level of earnings and then subtracting the benefits they would have gotten had they not worked. This gain to work is decidedly not a full measure of the returns to working. We take no account of child care costs, work expenses, or income or payroll taxes in the two countries. But we do at least have a sense of how the gains from work due to earnings plus benefit offsets have changed over time.

Single Parents-We again start by looking at single parents. We have already seen that benefits for those with zero earnings rose quite significantly over time in Britain and fell precipitously in the US. What happened to the gains to work from earnings less benefit changes? Figures 19 and 20 show the results for Britain and the US by predicted wage third. Once again we see large differences:

- $\quad$ For British single mothers, the predicted gain in earnings less benefit changes from entering work has risen over time somewhat, primarily because of rising wages. But the gain from work for women in the bottom third of predicted wages has risen from just $£ 57$ to $£ 89$ per week. And this ignores the costs of child care, work expenses, and taxes. Even for single mothers in the top third, the gains from work average $£ 200$ per week - or the US equivalent of less than $\$ 16,000$ per year.

- For single mothers in the US the gains in earnings less benefit changes from working are significantly higher and they have risen dramatically. In percentage terms gains were particularly great for single mothers in the lowest third, though in absolute terms they were greater for women in the top

\footnotetext{
${ }^{23}$ Note that this methodology could over-predict the potential wage for those who do not actually work since those not working are more likely to have a negative wage residual. Gregg, Johnson and Reed 1999 use "entry wages" for different groups of workers to model the expected wage. But since we are looking at potential gains to work for workers at different levels of education and age, the entry level wage is not appropriate for use here. Additionally, entry jobs have increasingly become part time, and many of these would not be entry level workers if they worked.
} 
third. The gain (from earnings and benefits alone) for single mothers in the bottom third rose roughly $\$ 4,500$ since 1993 (British equivalent of $£ 60$ per week). Single mothers in the top third stand to gain nearly $\$ 30,000$.

Again we emphasize that these gains are not the whole story. But adding other elements would if anything make things more dramatic. In the US, Ellwood (2000) calculates that the returns to working after taking out child care costs and taxes and adding in other benefits such as aid for child care, has risen from under $\$ 2,000$ to over $\$ 7,000$. The change in returns is quite close to what is predicted here, but the starting levels are lower due to accounting for other expenses.

Combining the effects of vastly higher benefits when not working and continuing low returns to work, one would presumably expect work to decline among single mothers in Britain, especially at the bottom. In the US one would expect to see the reverse. Figures 21 and 22 show that the predictions are borne out, though not perfectly.

- Consistent with changed work incentives, single parents in Britain are working less, those in the US working more. Consistent with theory, gains in work are particularly great among low wage single parents in the US. One puzzle, however, is that in Britain, work declines were about as large for people in all three wage thirds. One would generally expect social policies to have their greatest impact for those with the least earning potential.

Couples-The work incentives for couples are a bit more complicated because there are four different combinations of work and non-work for the partners-more if one allows for part-time work. Rather than focus on all of these, we shall present only two: the gains in earnings plus benefit changes if the man goes to work full time and the woman is not working, and the gains from work if the woman works full time when the husband is already working full time. Obviously the other combinations are plausible too, but this gives the rough incentives for families considering sending one or two people into the labor market. 
Figures 23 and 24 show the gains to sending the man into full time work in an otherwise workless household in Britain and the US. Once again we find striking differences. As always, scales are roughly equilibrated to purchasing power equity.

- There are very large differences by country in the gains to working for a man if he is to be the only worker in a joint household. In the US even someone in the bottom wage third can expect to see gains in earnings and benefits of close to $\$ 17,000$ per year ( $£ 217$ per week) and this has risen somewhat in recent years. In Britain the gain is just $£ 82$ per week and this amount has fallen sharply since the early 1990s. Even those in the middle third stand to gain just $£ 130$ (US \$10,200) from a full time job. In the US, with lower benefits and higher median wages, workers in the middle stand to gain nearly $\$ 25,000$ in earnings less any benefit changes.

Given the rising aid for those not working and low and declining returns for those in the bottom third, one would anticipate declines in work by men in Britain and if anything increases in work in the US. Figures 25 and 26 show the actual patterns.

- Work by men in couples is clearly cyclical, but consistent with altered incentives, work declined overall among men in Britain, particularly among men in the lowest third. And work among husbands with children rose in the US. ${ }^{24}$ Still we again see the result that declines in work were sizable even among those in the highest wage categories in Britain.

One puzzle in the British data is why work by female partners is rising rapidly while work by male partners is declining. Figures 27 and 28 give some hint as to why that might be occurring. If most of the women entering the labor market are in homes where the man is already working, these are families already getting relatively low benefits, so the decision to work is primarily a question of what can be earned net of child care and work expenses.

- In Britain, the gains from sending a second worker into the labor market are much higher than for sending the first worker. Whereas a man in the bottom tercile who is the first earner in a household gained just £82, a woman who is the second earner in such settings would gain over $£ 150$ per week even

\footnotetext{
${ }^{24}$ The rise in work in the US is all the more remarkable since disability programs expanded and work by men overall did diminish somewhat.
} 
though her gross pay is lower. In the US a comparable woman in the bottom third would gain perhaps $\$ 14,000$ (£180). Women in higher wage thirds gain considerably more and the gains have been growing over time.

Actually this example does illustrate some limits to our admittedly rather imprecise methodology. Others have shown that returns to work for women at the bottom have fallen somewhat in recent years due to the Earned Income Tax Credit whereas this analysis shows things to be unchanged.

Figures 29 and 30 indicate work patterns of women in couples.

- Consistent with observed incentives, women in couples are working more in both nations. In Britain the rise is particularly notable among women at the bottom - in contrast to the increasing worklessness for all other groups. By contrast, work by US wives in the bottom third leveled off in the late 1980s and early 1990s, unlike the pattern for wives in higher wage categories. Both of these patterns are roughly consistent with observed changes in incentives.

Of course there are many other reasons why women may be working more, including changing attitudes and expectations. Still what is striking is that trends among women in couples in the Britain and the US are broadly similar, but differ in specifics in ways consistent with incentives. In Britain, the lowest wage women increased work the most. In the US, they increased it the least. And in both cases, their behaviour defies the patterns of all other low wage groups in the country. In Britain where all other low skill workers are working less, low skill wives are working more. In the US, where others are working more, low skill wives have not increased their work. The results reinforce findings from Gregg, Hansen and Wadsworth (1999a) which suggest that the increasing polarization of work within couples in Britain may be related to features of the social benefit system that create weak work incentives among families with no workers, and relatively strong incentives for a second earner when one person is already working. 
Singles Without Children-Finally we examined work incentives and work behaviour in the two nations (not shown).

- In general the returns to working seem to have changed little for single adults in the two nations. But the sharp rise in benefits for those with no earnings (the income effect) in Britain coupled with no change in the gains to working would be expected to reduce work by singles in the bottom third. That is precisely the pattern on finds in the British data.

Conclusions Regarding Behavioural Results--Our examination of the broad trends in work incentives suggest that they may explain an important part of the divergent trends in the US and Britain.

- In general, incentives to work were always stronger in the US, and particularly for single parents they have recently become much stronger. By contrast incentives for work in Britain have generally weakened over timebenefits for non-workers have risen, gains to work have fallen in some cases and been stable in others. There is one exception: gains to work by second earners have increased somewhat. And wives are the only group working more in Britain. Still declining work even among the highest potential wage group suggests that more than just work incentives are operating here.

\section{Reducing Poverty: Potential and Limits of Work Based Strategies}

Prime Minister Tony Blair's government committed itself to reducing child poverty by half over the next 10 years and to its abolition within 20 years. A central element of this effort has included a series of policy initiatives designed to encourage work and to "make work pay." The main changes in Britain are the introduction of the Working Families Tax Credit (WFTC), which provides generous support for low income working families and includes a, potentially very generous, child care element, the National Minimum Wage, reform of the National Insurance system, the introduction of a $10 \%$ starting rate of income tax and the National Childcare Strategy. These policies have been combined with various New Deal policies, most of which impose participation in 
work or training as a condition of benefit receipt. Furthermore, benefits to all families with children, regardless of work status, have become more generous with real increases in child benefit and income support and the introduction of the Child Tax Credit.

Table 2 helps to illustrate the larger themes of this paper, and points to the potential and the limits of work-based policies as a central element in reducing child poverty. The table shows the distribution of poor children by total work hours of everyone in the household. The first column shows that currently over half of poor children are in homes where no one is working, and only a third are in homes where people are working 30 hours or more.

- Unless demographic, economic, or policy change induces more parents of children to work, the only way to reduce poverty by $50 \%$ would be to reduce poverty among non-working families. Absent behavioural change, added support for working families will still leave the majority of poor children poor.

The chart also shows what would happen to child poverty if one could magically return to the work levels of 1979, but retained the wage and demographic patterns of 1999. The percentage of children in poverty in the current setting and under this scenario can be seen in the second and fourth columns. The overall poverty rate would fall from $34.5 \%$ to $29.1 \%$. Impressively the share of all children who are poor and in homes where no one is working would fall from $17.6 \%$ to $11.0 \%$. But overall poverty would not fall as much because the number of children in working poor families would rise. One can see that the percentage of all children who are poor and living in families with more than 30 work hours, would rise from $11.3 \%$ to $14.5 \%$.

- Work changes alone are unlikely to dramatically reduce poverty of chilren. Even if work levels could be restored to those of 1979, continuing low pay would leave many children poor. Many families would move from being the 
workless poor to the working poor. Poverty would only fall by 5 percentage points (out of $35 \%)^{25}$

But if many more people were induced to work and work were made to pay, the goal of reducing child poverty by half might be achieved. In the fourth column of Table 2, one can infer that if work were at the 1979 levels and if those who would otherwise be poor in families with 30 hours of work or more were removed from poverty, only $14.6 \%$ of all children would remain poor (the $11.0 \%$ in families that would still not be working and the $3.6 \%$ in families with 1-29 work hours).

- If work could be increased back to the 1979 levels, and if work was made to pay sufficiently so that no family with 30 hours of work was left poor, then poverty among children could fall from its current level of roughly $35 \%$ to approximately $15 \%$, achieving the goal of a $50 \%$ reduction in poverty. If the make work pay policies reduced poverty among those who were working part time as well, poverty could fall still further.

Thus, at least theoretically, a work based strategy could significantly reduce poverty among children. Still this table assumed that work levels that prevailed in the late 1970 s could somehow be restored and that work really could be made to pay enough to keep families out of poverty. Is that level of change really feasible?

Clearly the U.S. has successfully raised work among low income families, notably single parents. But the differences in the US and UK benefit systems are enormous. Single parents in Britain with zero earnings get benefits equivalent to just $62 \%$ of the relative poverty standard. The US pays just 19\%! Two parent families and single adults without children get even less. To mimic the financial work incentives in the US, benefits for non-working families would have to be cut enormously for all families while

\footnotetext{
${ }^{25}$ Other evidence in support of this conclusions comes from the US experience where rising work had very small effects on relative poverty. It did have large effects on absolute poverty, because the absolute poverty standard is so much lower in the US.
} 
maintaining aid for working ones. And of course, cuts in benefits for non-workers will surely raise poverty or increase hardship among those with little or no earnings.

Alternatively, aid for working families could be expanded dramatically, while maintaining support for non-working families. This would also help in ensuring that working families avoid poverty. Dilnot and McCrae (1999) show that WFTC is well targeted as a redistributive tool, with most gains going to households in the $2^{\text {nd }}$ decile of the income distribution. Unfortunately increases in in-work benefits of the sort enacted to date with the WFTC seem unlikely to change work incentives to the extent seen in the US, especially if the change in policy is largely offset by housing benefit changes, as Blundell and Hoynes (this volume) seem to suggest. The gap in income for workers and non-workers is simply too limited, and the recent increases in benefits to all families with children may induce adverse income effects on labour supply. If the WFTC were greatly expanded, costs may rise sharply or benefits will need to be phased-out so rapidly for working families above the poverty line that this will create another set of adverse incentives. Still, that may be a promising domain for further reforms.

The US example may again be instructive. The US spends more now on in-work benefits than it ever did on cash based benefits for the non-working poor. The gain from going to work has increased considerably. Benefits paid are large enough to pull families with 4 or fewer members and a full-time minimum-wage worker over the US absolute poverty line of $\$ 17,356$. But benefits are nowhere near enough to push people above a relative poverty line that exceeds $\$ 30,000$. In Table 1 we saw that increased work lead to reduced absolute poverty, but little change in relative poverty. Some observers believe it will be difficult fiscally and politically to increase in-work benefits a great deal more in 
the US, and economists are increasingly worried about the adverse incentives created as benefits phase-out when people move toward the middle class.

Of course if the underlying pattern of wages could be made more equal, work might increase and poverty would fall. Altering the underlying distribution of wages would require rapid and effective intervention to narrow differences in skills and opportunity—and even that may not narrow wages too much. ${ }^{26}$

One might hope that moving people into the labor market will lead to rising experience and with that higher wages and ultimately to less relative poverty. Keeping people working steadily rather than episodically might narrow the wage distribution somewhat. But recent work by Burtless (forthcoming), Gottschalk (2000) and others suggests that wages rise even less with experience for low skill workers than for others. Dickens (2000) work on mobility and Stewart (1999) on the low pay - no pay cycle offer a similar caution. Indeed, individuals are likely to require some form of in-work support or training that enables them to progress into better jobs.

The final strategy would be to find some way to reverse some of the demographic changes, particularly in family structure. Here the US has virtually no lessons to offer. There are few clear policy strategies that successfully reduce the incidence of single parent families. Although there are some signs that recent increases in work among single parents in Britain may be partly due to a changing composition of this group.

And difficult as it might be to halve poverty through work based strategies, it will be even harder to move toward complete elimination. Under almost any plausible scenario, a great many workless households will still remain, so even dramatic expansions of in-work benefits will probably not pull down poverty rates enough to meet 
the governments goal of halving poverty. One could also seek to raise benefits for all low income families with children with larger child credits and similar schemes. Piachaud and Sutherland (2000) argue that measures of this type introduced by the Blair government are likely to have a significant impact on non-working poor families. The difficulty with this strategy is that one is likely to dampen down the increased work incentives . Such a policy of increasing support to non-working families, while creating strong incentives may prove to be very costly, since it inevitably runs into the basic dilemma of reform — a high guarantee and strong work incentives implies a very high break-even point so benefits are collected by a very large portion of the population.

There are other ways to increase work beyond the use of financial incentives. In the US and to a lesser degree in the UK, there is a move towards requiring work (in government subsidised jobs if necessary) as a condition of aid for some persons, while providing more generous aid to those not expected to work in an attempt to deal with this dilemma. But such policies raise difficult value laden issues of determining who is expected to work and determining penalties when they do not do so. We suspect that the changed attitudes and expectations of welfare workers and the public at large has had every bit as much to do with the rise in work among single parents as financial incentives have in the US. British policymakers may need to pursue both sharp improvements in incentives and various administrative policies if they are really determined to increase work and reduce poverty.

This discussion should not be seen as pessimistic about the potential for work based strategies to reduce poverty. But only a combination of strategies that dramatically increase work and increase the pay of low wage parents seems likely to change things

\footnotetext{
${ }^{26}$ See Devroye and Freeman (2000).
} 
dramatically. And absent ways to narrow wage differentials or change family structures, sharply reducing poverty will prove a formidable and expensive challenge.

\section{Concluding Thoughts}

This paper has provided a strategy for decomposing the factors influencing poverty in Britain and the United States. Striking similarities and differences are at work in the two nations. Demographic and wage change is a dominant force in both nations. Work is falling among many low wage groups in Britain but rising on the other side of the Atlantic. Social policies increased incomes but may have reduced work in Britain, and they may have done the opposite in the US.

The paper also suggests the potential for detailed cross-national examinations. The notion that the economic incentives built into policy are influencing outcomes within a nation are reinforced in this paper by the fact that when incentives differ in the two countries, so too do work patterns. And one can see far more clearly than most casual observers realize that social policies are often profoundly different. Ultimately, the hard work of policy analysis will probably remain a within-border affair. But understanding the larger forces shaping poverty in several nations helps to illustrate both the potential and the limits of policies to reduce it. 


\section{References}

Attanasio, Orazio, and Thomas MaCurdy. "Interactions in Family Supply and their Implications for the Impact of the EITC." Stanford University, Mimeo, 1997.

Bingley, P., and Ian Walker. "The Labour Supply, Unemployment and Participation of Lone Mothers in In-Work Transfer Programs.” Economic Journal. 107 (1997): 1375-90.

Blank, Rebecca, and Alan Blinder. "Macroeconomics, Income Distribution, and Poverty." in Fighting Poverty: What Works and What Doesn't, edited by Sheldon H. Danziger and Daniel H. Weinberg, 180-208. Cambridge, MA: Harvard University Press, 1986.

Blank, Rebecca, and David Card. "Poverty, Income Distribution, and Growth: Are They Still Connected?" Brookings Papers on Economic Activity. 2 (1993): 285325.

Blank, Rebecca, David Card, and Philip Robbins. "Financial Incentives for Increasing Work and Income Among Low-Income Families." in Finding Jobs: Work and Welfare Reform, edited by Rebecca Blank and David Card. New York: Russell Sage, 2000.

Blundell, R., A. Duncan, and C. Meghir. "Evaluating In-Work Benefit Reform: The Working Families Tax Credit in the UK." University College London, Mimeo, 1999.

Blundell, Richard. "Work Incentives and In-Work Benefit Reforms: A Review." Oxford Review of Economic Policy. 16 No. 1 (2000).

Blundell, Richard, A. Duncan, J. McCrae, and C. Meghir. "The Labour Market Impact of the Working Families' Tax Credit.” Fiscal Studies. 21 No. 1 (2000).

Böheim, René, and Stephen P. Jenkins. "Do Current Income and Annual Income Measures Provide Different Pictures of Britain's Income Distribution?" Institute for Economic and Social Research Working Paper No. 16. London: 2000.

Bound, John, and Timothy Waidmann. "Disability Transfers, Self-reported Health, and the Labor Force Attachment of Older Men: Evidence from the Historical Record." Quarterly Journal of Economics. (1992): 1393-1419.

Burtless, Gary. “The Employment Experiences and Potential Earnings of Welfare Recipients." in Welfare Reform: 1996-2000. Is There a Safety Net?, edited by Robert Morris and John E. Hansan. Westport, Connecticut: Greenwood, forthcoming. 
Citro, Constance F., and Robert T. Michael (Eds.). Measuring Poverty: A New Approach. Washington, D.C.: National Academy Press, 1995.

Cutler, David M, and Lawrence F. Katz. "Macroeconomic Performance and the Disadvantaged." Brookings Papers on Economic Activity. 2 (1991): 1-74.

Davies, H., and H. Joshi. "Gender and Income Inequality in the UK 1968-1990: The Feminization of Earnings or of Poverty?" Journal of the Royal Statistical Society. 161 No. 1 (1998): 33-61.

DeLeire, Thomas. "The Wage and Employment Effects of The Americans with Disabilities Act." Journal of Human Resources. (forthcoming).

Department of Social Security. "Households Below Average Income: 1994/5 - 1997/8." London: HMSO, 1999.

Devroye, Dan, and Richard Freeman. "Does Inequality in Skills Explain Inequality in Earnings Across Countries." Harvard University, Mimeo, 2000.

Dickens, Richard. "Caught in a Trap? Wage Mobility in Great Britain: 1975-95." Economica. 67 No. 268 (November 2000).

Dilnot, A., and J. McCrae. "Family Credit and the Working Families Tax Credit." Institute for Fiscal Studies Briefing Note No. 3. London: Institute for Fiscal Studies, 1999.

Eissa, Nada, and Hilary Hoynes. "The Earned Income Tax Credit and the Labor Supply of Married Couples." University of California at Berkeley, Mimeo, 1999.

Eissa, Nada, and Jeffrey B. Liebman. "Labor Supply Response to the Earned Income Tax Credit." Quarterly Journal of Economics. 112 No. 2 (May 1996): 605-637.

Ellwood, David T. "The Impact of the Earned Income Tax Credit and Social Policy Reforms On Work, Marriage, and Living Arrangements." National Tax Journal. 53 No. 4 (Part 2) (December 2000): 1063-1106.

Ercolani, M. , and Steven Jenkins. "The Polarisation of Work and the Distribution of Income in Britain." Discussion Paper. Institute for Labour Research, 1998.

Evans, M. "New Inequalities: The Changing Distribution of Income and Wealth in the United Kingdom.” edited by J. Hills. Cambridge, UK: Cambridge University Press, 1996.

Goodman, Alissa, Paul Johnson, and Steven Webb. Inequality in the UK.Oxford, England: Oxford University Press, 1997. 
Gottschalk, Peter. "Early Labor Market Experience: Dead-end Jobs or Stepping-stones for Less-skilled Workers?" Boston College, Mimeo, 2000.

Gottschalk, Peter, and Timothy Smeeding. "Cross-National Comparisons of Earnings and Income Inequality.” Journal of Economic Literature. 35 (June 1997): 633687.

Gregg, P., and S. Machin. "Is the UK Rise in Inequality Different?" in The UK Labour Market, edited by R. Barrell. Cambridge, UK: Cambridge University Press, 1994.

Gregg, Paul, Kristine Hansen, and Jonathan Wadsworth. "Economic Inactivity." in The State of Working Britain, edited by Paul Gregg and Jonathan Wadsworth. Manchester, UK: Manchester University Press, 1999a.

Gregg, Paul, P. Johnson, and H. Reed. "Entering Work and the British Tax and Benefit System." London: Institute for Fiscal Studies, 1999b.

Gregg, Paul, and Jonathan Wadsworth. "Two Sides to Every Story. Measuring Worklessness and Polarisation at the Household Level." Centre for Economic Performance Discussion Paper No. 1099. London: 2000.

Gruber, Jonathan, and Jeffrey D. Kubik. "Disability Insurance Rejection Rates and the Labor Supply of Older Workers." Journal of Public Economics. 64 No. 1 (1994): 1-23.

Haveman, Robert, Philip de Jong, and Barbara Wolfe. "Disability Transfers and the Work Decision of Older Men." The Quarterly Journal of Economics. (1991): 939-949.

Machin, Steven. "Wage Inequality in the 70s, 80s and 90s." in The State of Working Britain, edited by P. Gregg and J. Wadsworth. Manchester, UK: Manchester University Press, 1999.

McClements, D. "Equivalence Scales for Children." Journal of Public Economics. 8 (1977): 191-210.

Meyer, Bruce D., and Dan T. Rosenbaum. "Welfare, the Earned Income Tax Credit, and the Labor Supply of Single Mothers." NBER Working Paper No. W7363. Cambridge, MA: National Bureau of Economic Research, 1999.

Meyer, Bruce D., and Dan T. Rosenbaum. "Making Single Mothers Work: Recent Tax and Welfare Policy and its Effects." National Tax Journal. 53 No. 4 (Part 2)

(December 2000): 1027-1062. 
Mishel, Lawrence, Jared Bernstein, and John Schmitt. The State of Working America 1998-1999. Armonk, New York: M. E. Sharpe, 1999.

Moffitt, Robert. "The Econometrics of Piecewise-Linear Budget Constraints: A Survey and Exposition of the Maximum Likelihood Method." Journal of Business and Economic Statistics. 4 (1986): 317-327.

Moffitt, Robert. "Incentive Effects of the U.S. Welfare System: A Review." Journal of Economic Literature. 30 (March 1992): 1-61.

Nolan, B. "Unemployment and the Size Distribution of Income." Economica. 53 (1986): 421-446.

Piachaud, D., and H. Sutherland. "How Effective is the British Government's Attempt to Reduce Child Poverty?" CASE Working Paper No. 38. London: 2000.

Stewart. "Low Pay in Britain." in The State of Working Britain, edited by P. Gregg and J. Wadsworth. Manchester, UK: Manchester University Press: Manchester University Press, 1999.

U. S. Bureau of the Census. "Poverty in the United States: 1999." Current Population Reports, P-60, No. 210. Washington, D.C.: U.S. Government Printing Office, 2000 . 
Figure 1

Alternative Measures of Relative Poverty in Britain Households Headed by Someone Under 60

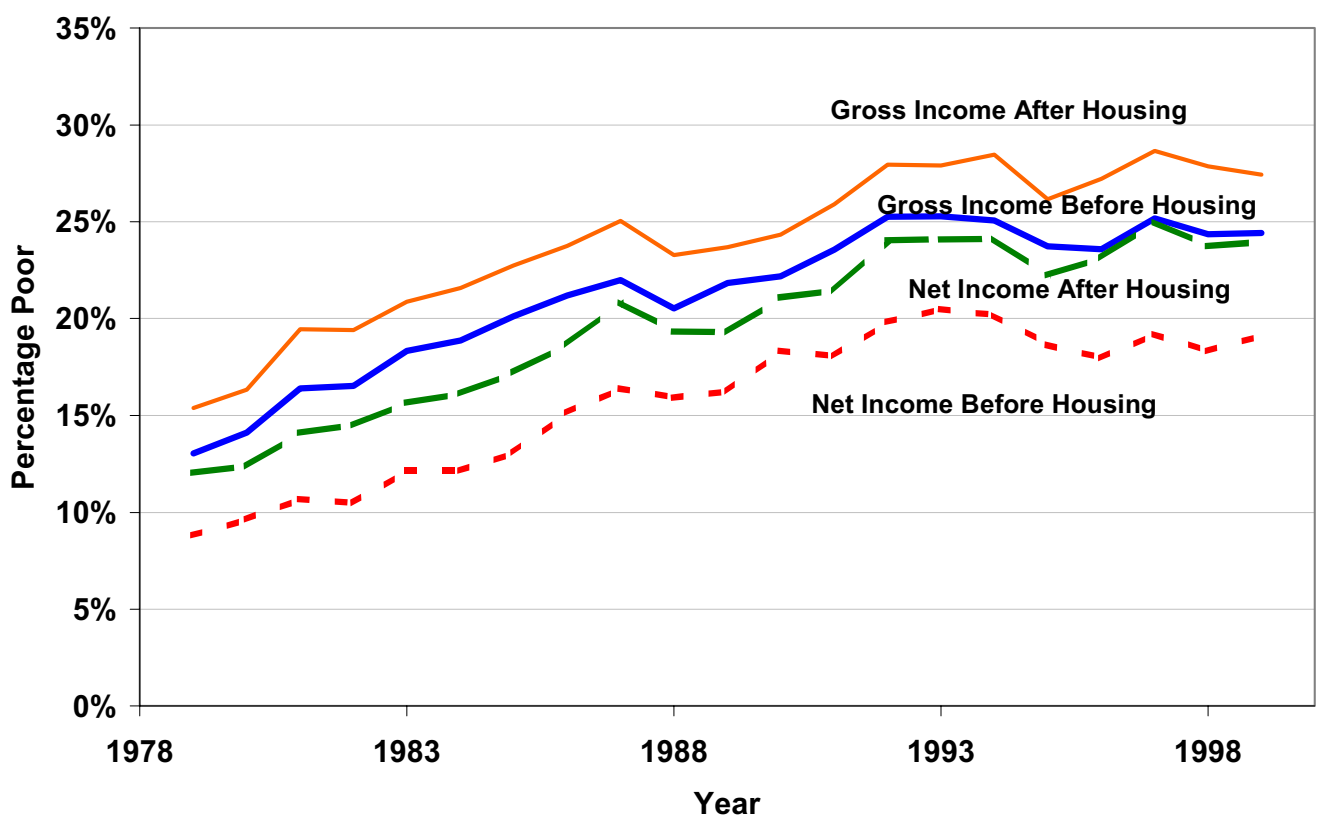


Figure 2

Relative Poverty in Britain and US

Households Headed by Someone Under 60

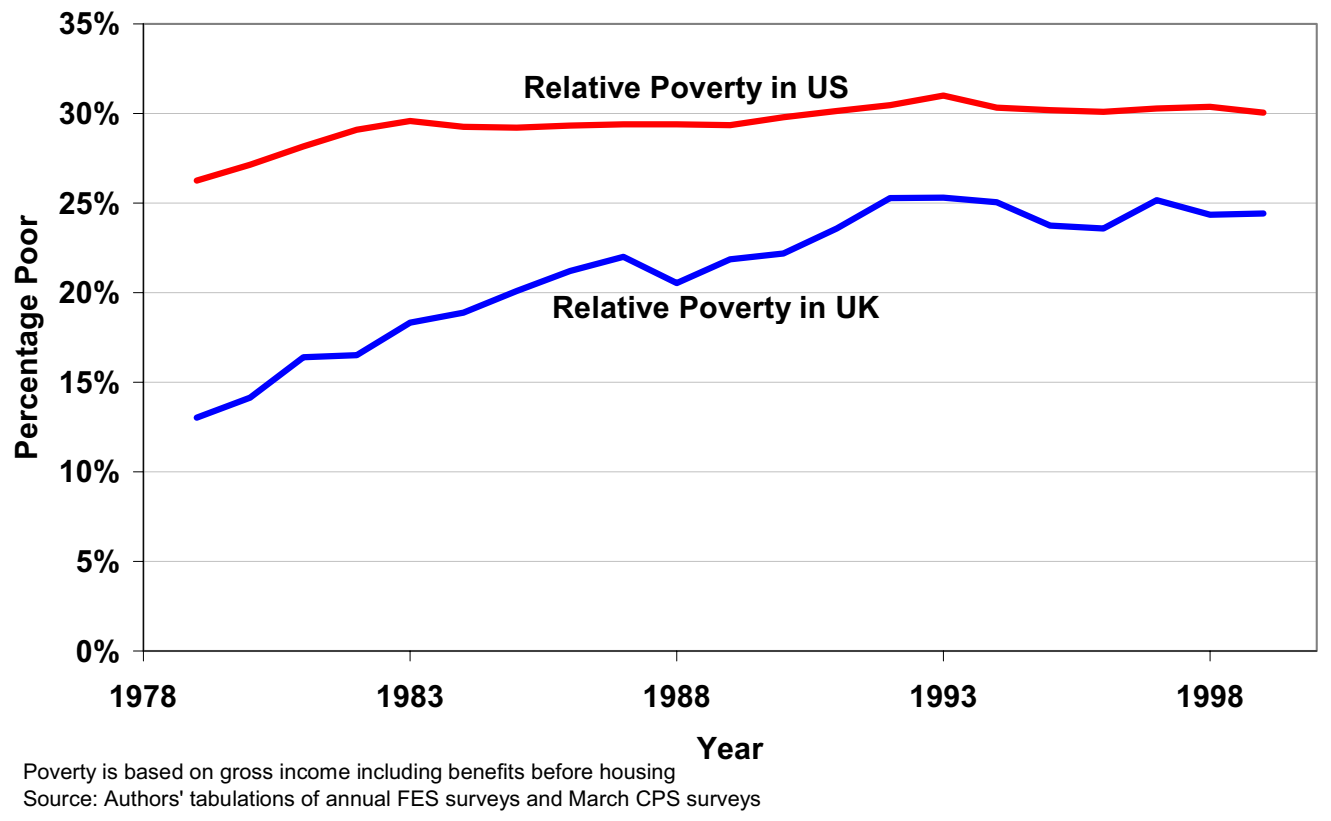

Figure 3

Absolute Poverty in Britain and US

Households Headed by Someone Under 60

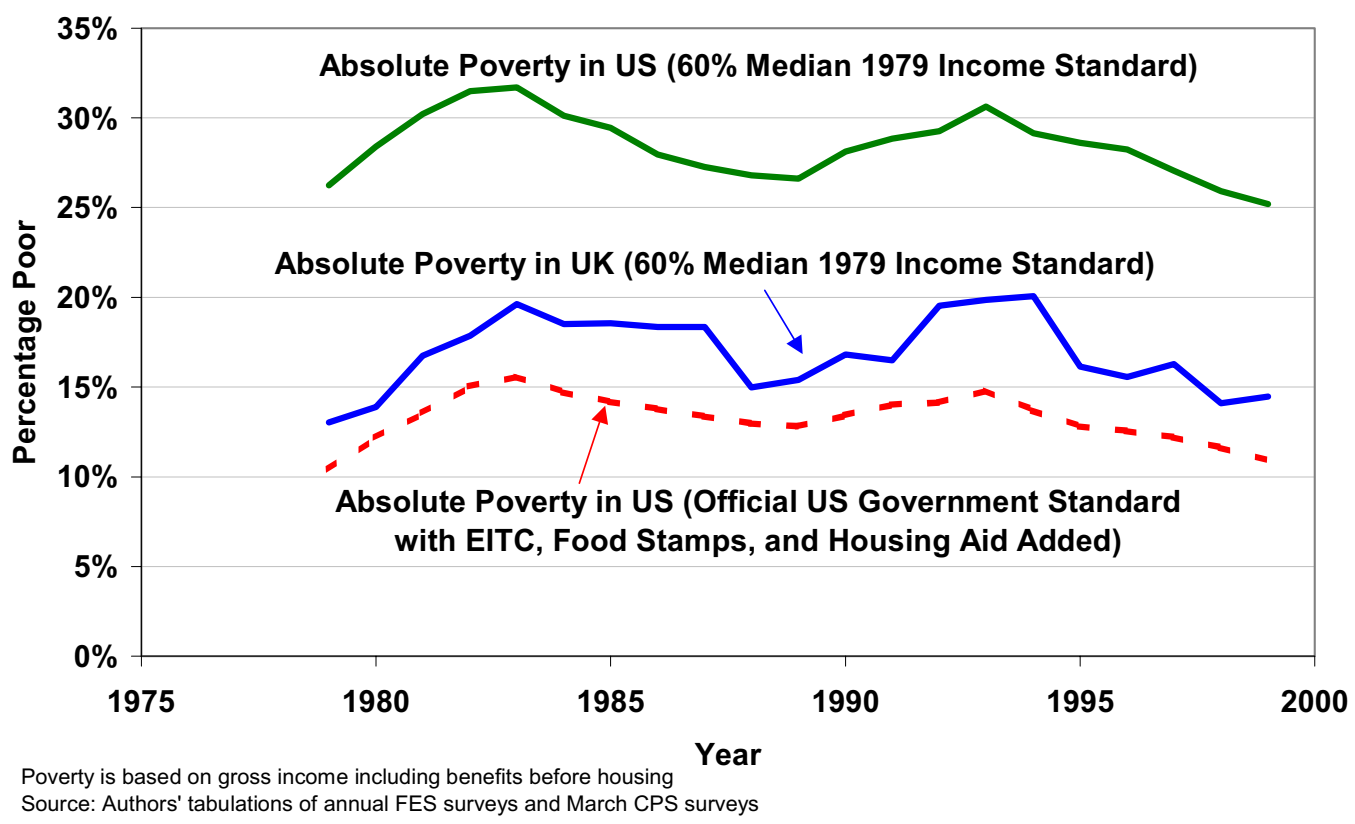


Figure 4

Components of Change in Relative Poverty in Britain Since 1979

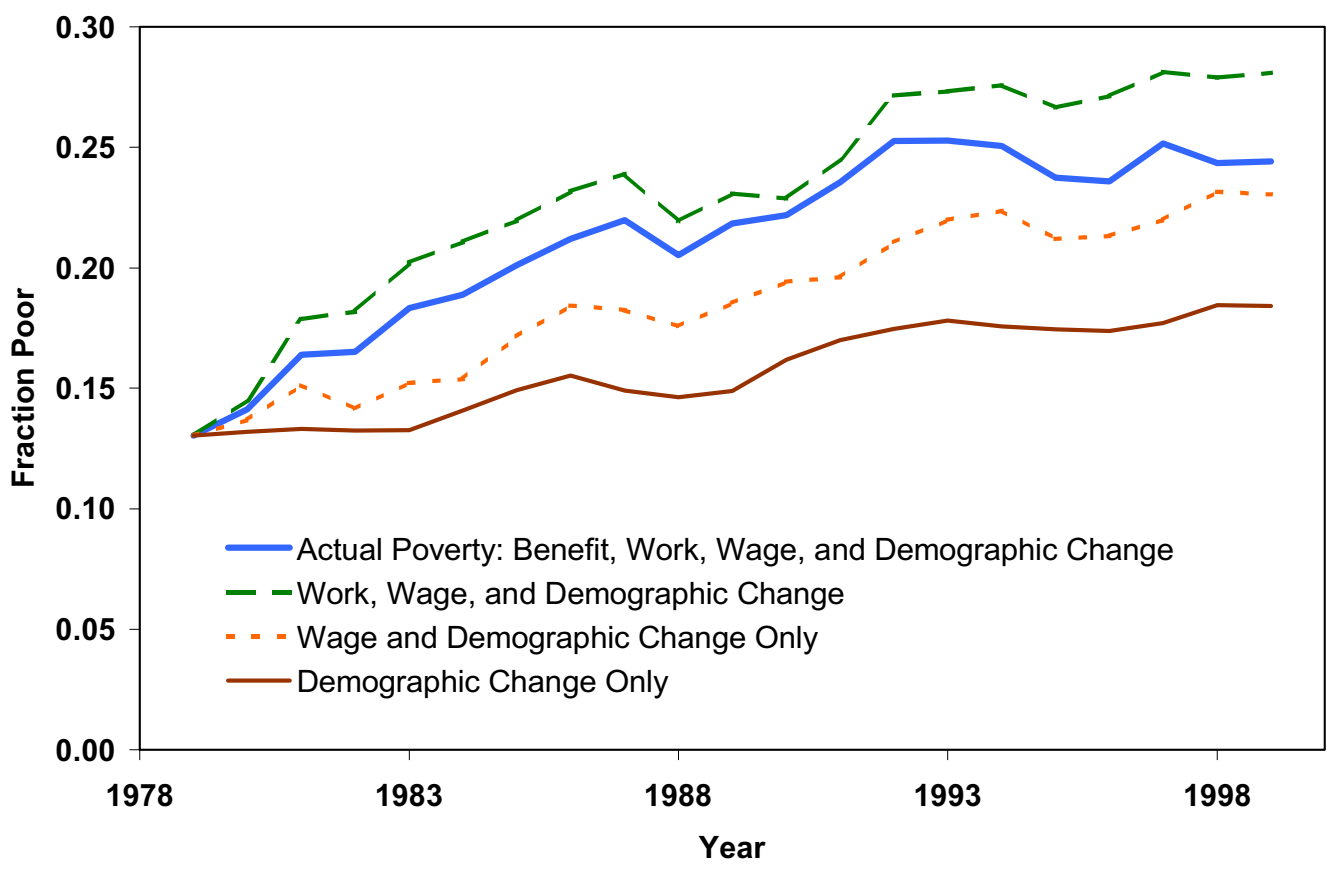

Figure 5

Components of Change in Absolute Poverty in Britain Since 1979

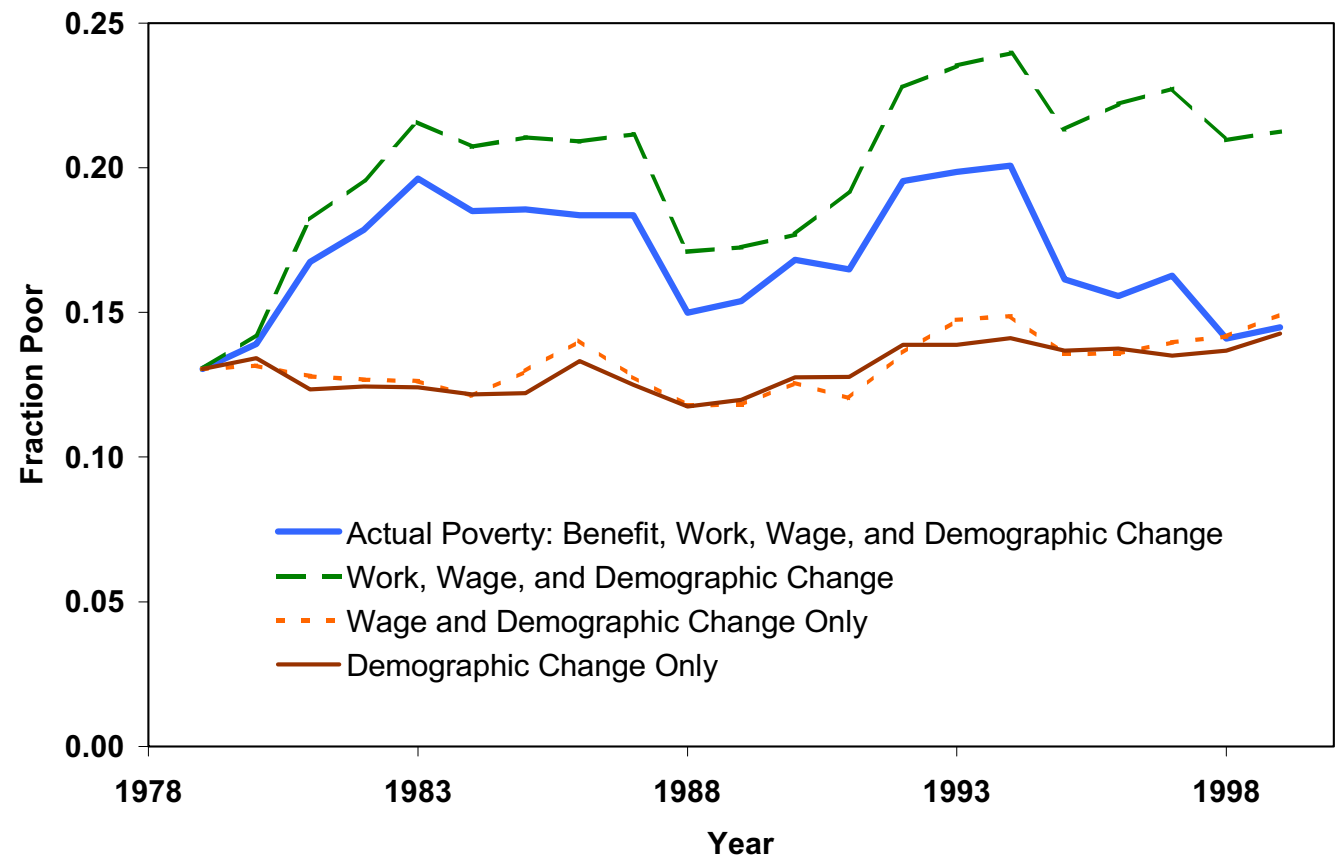


Figure 6

Components of Change in Relative Poverty in the US Since 1979

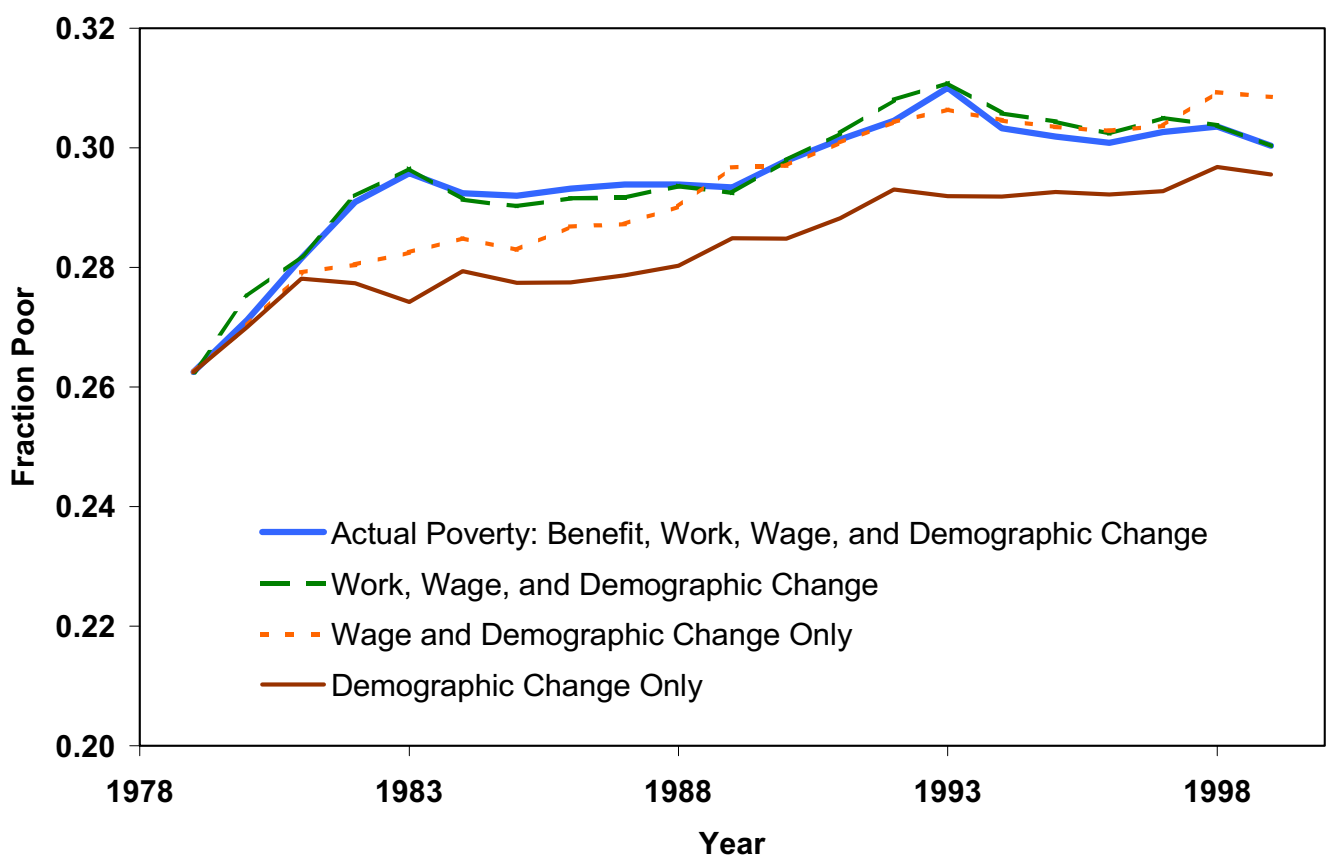

Figure 7

Components of Change in Absolute Poverty in the US Since 1979

Using Official Standard

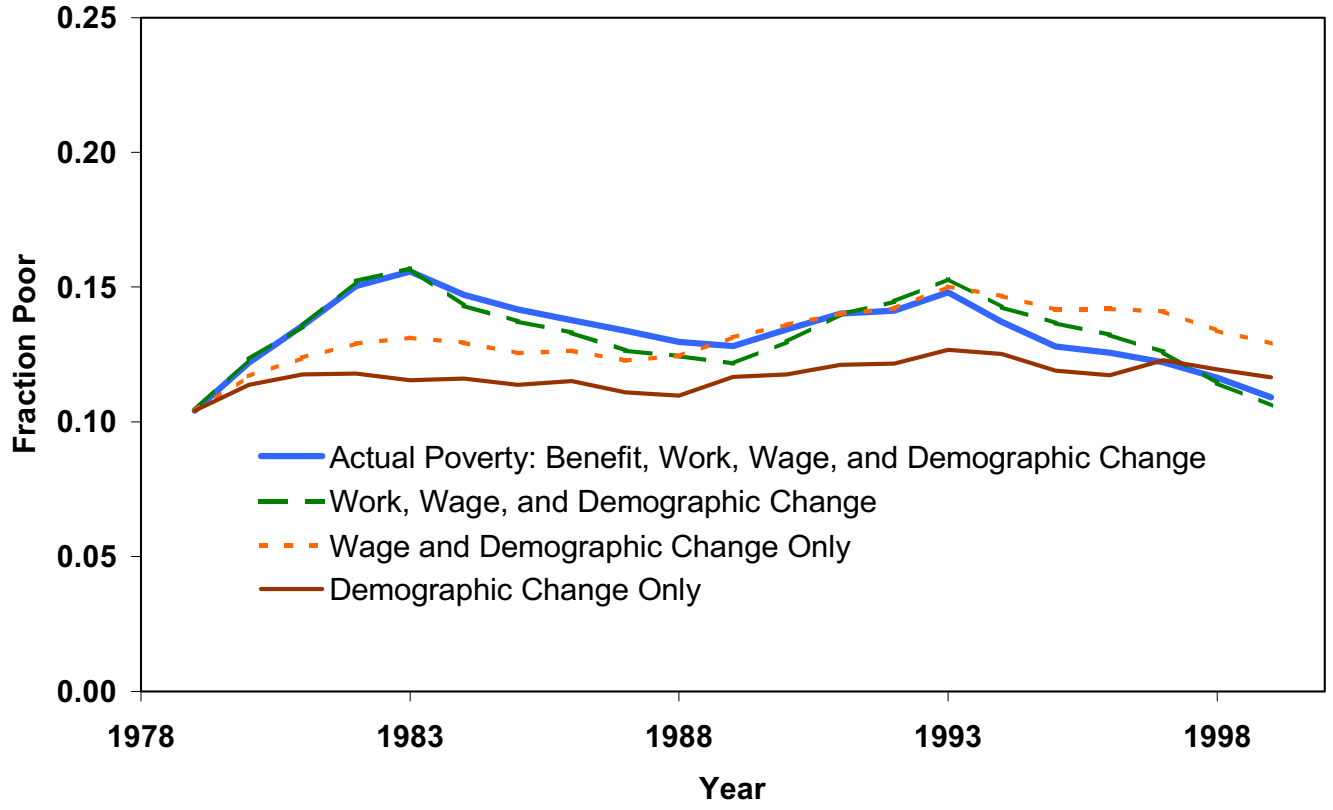


Figure 8

Real Wages in Britain for Males Working at Least Half Time

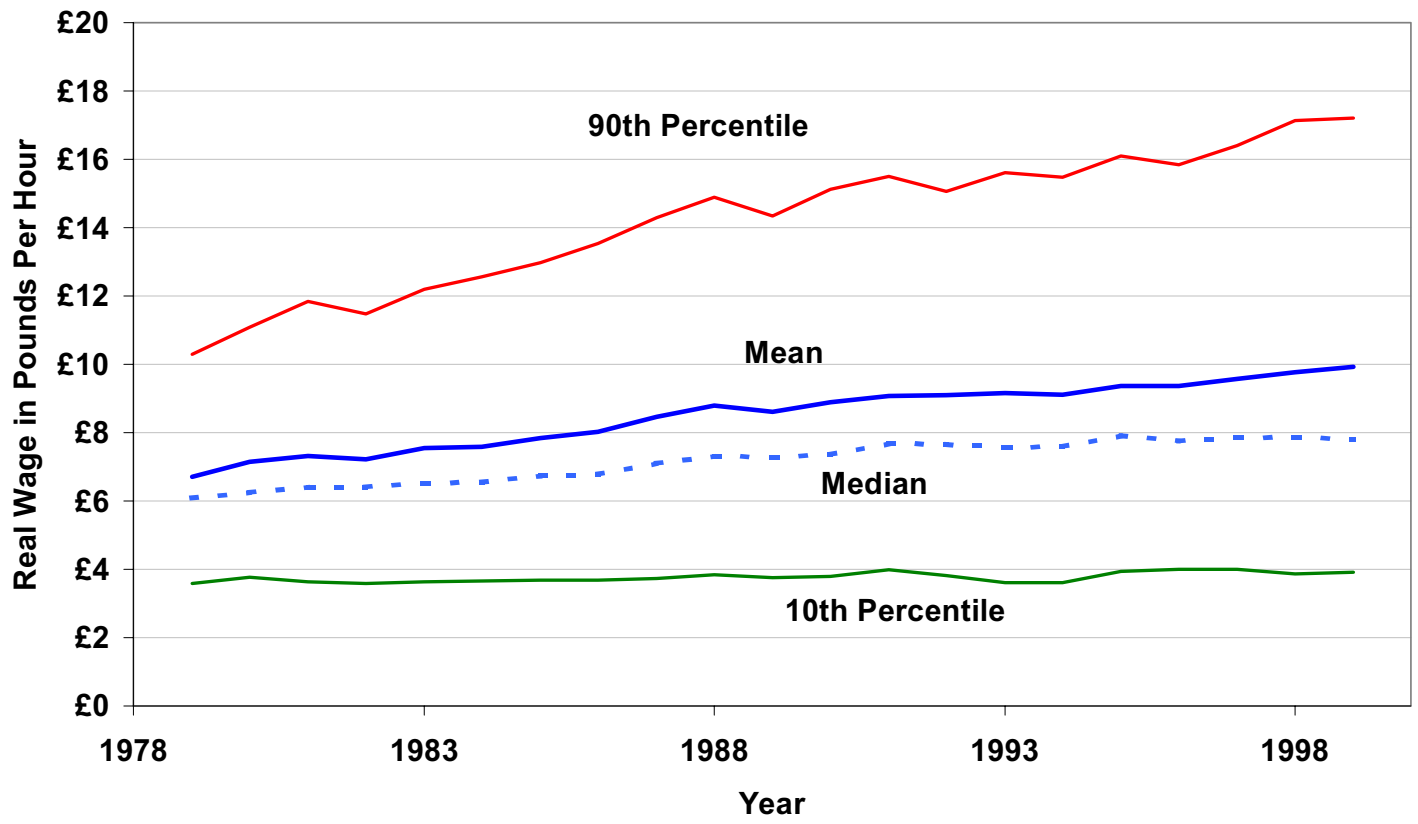

Figures 9

Real Wages in Britain for Females Working at Least Half Time

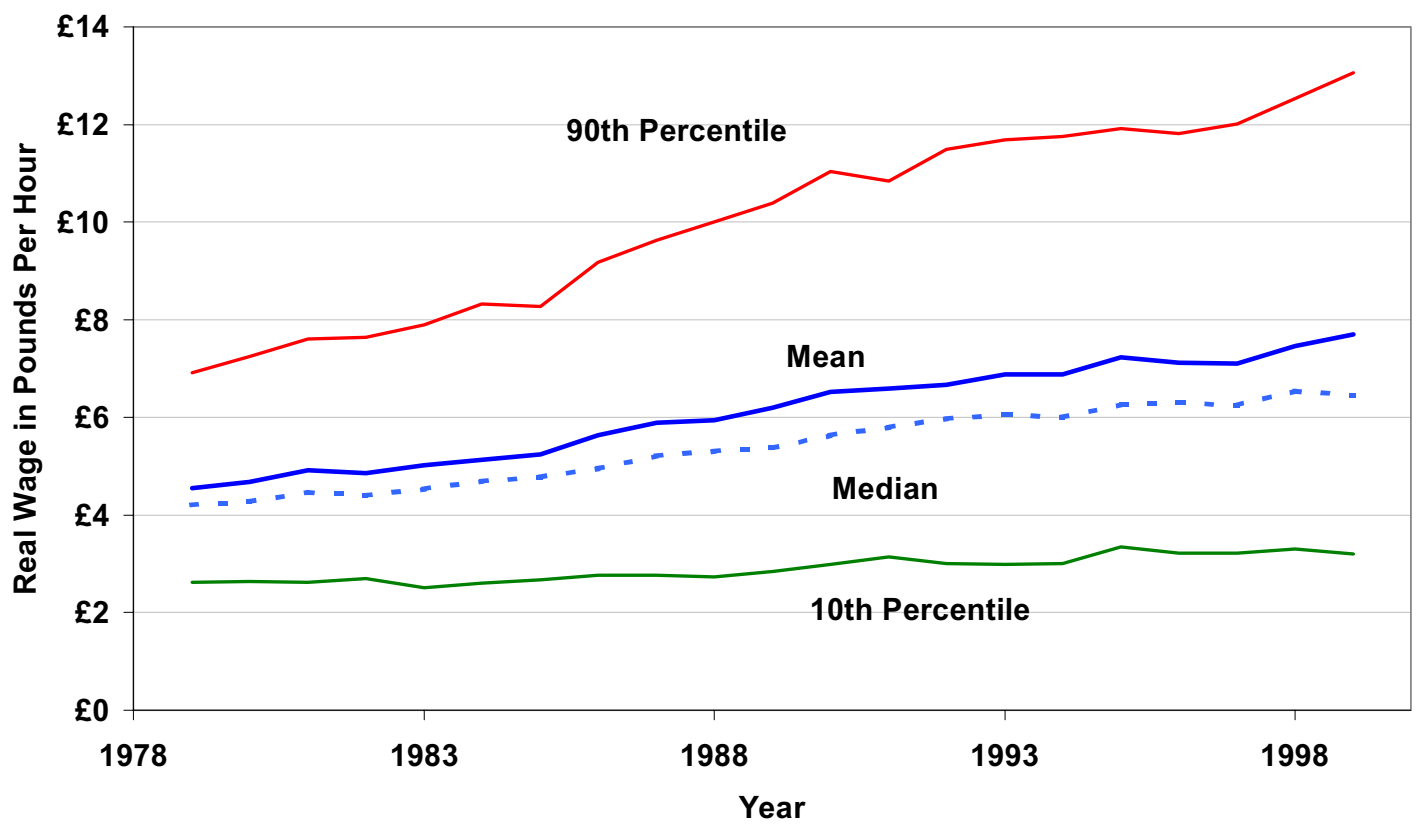


Figure 10

Real Wages in the US for Males Working at Least Half Time

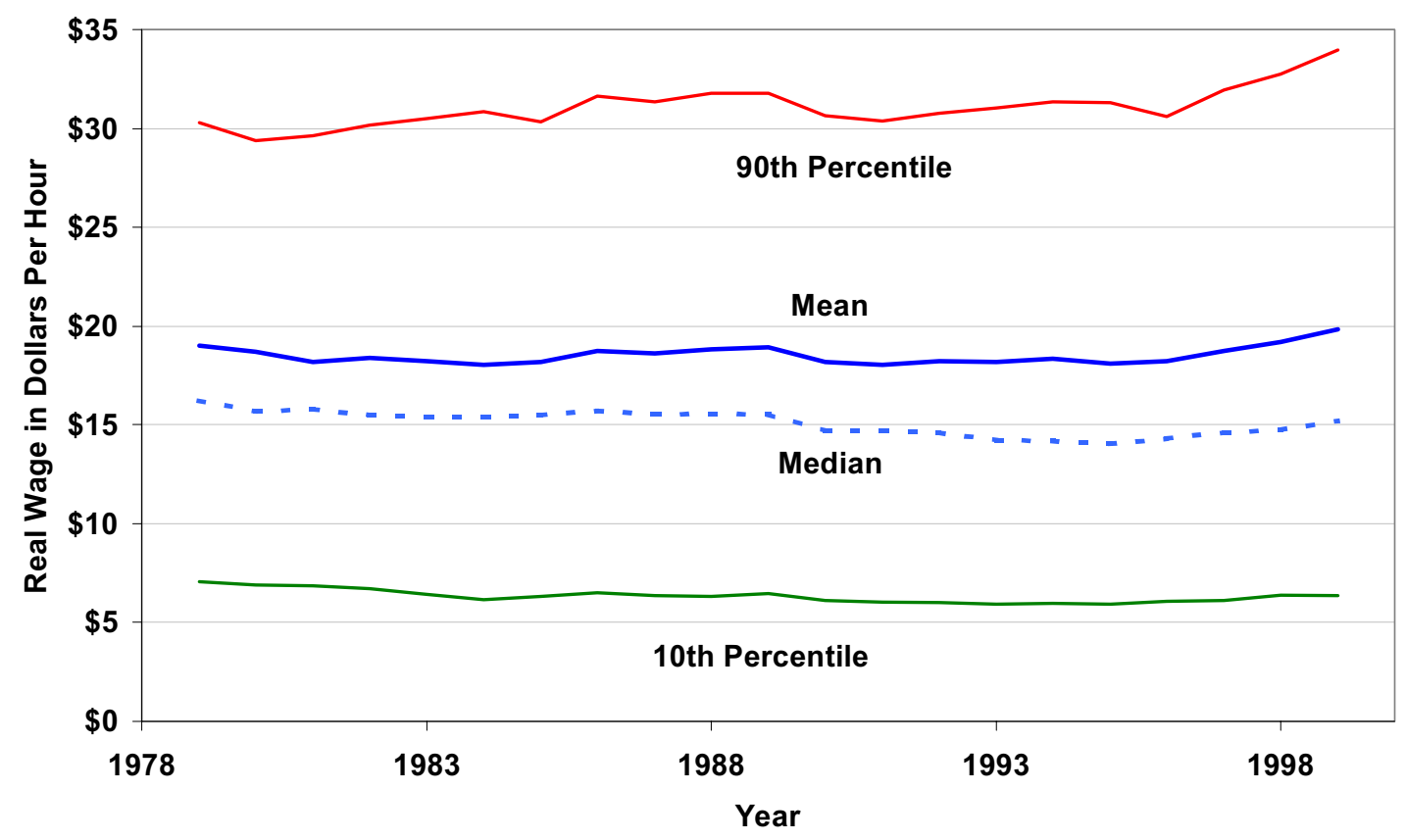

Figure 11

Real Wages in the US for Females Working at Least Half Time

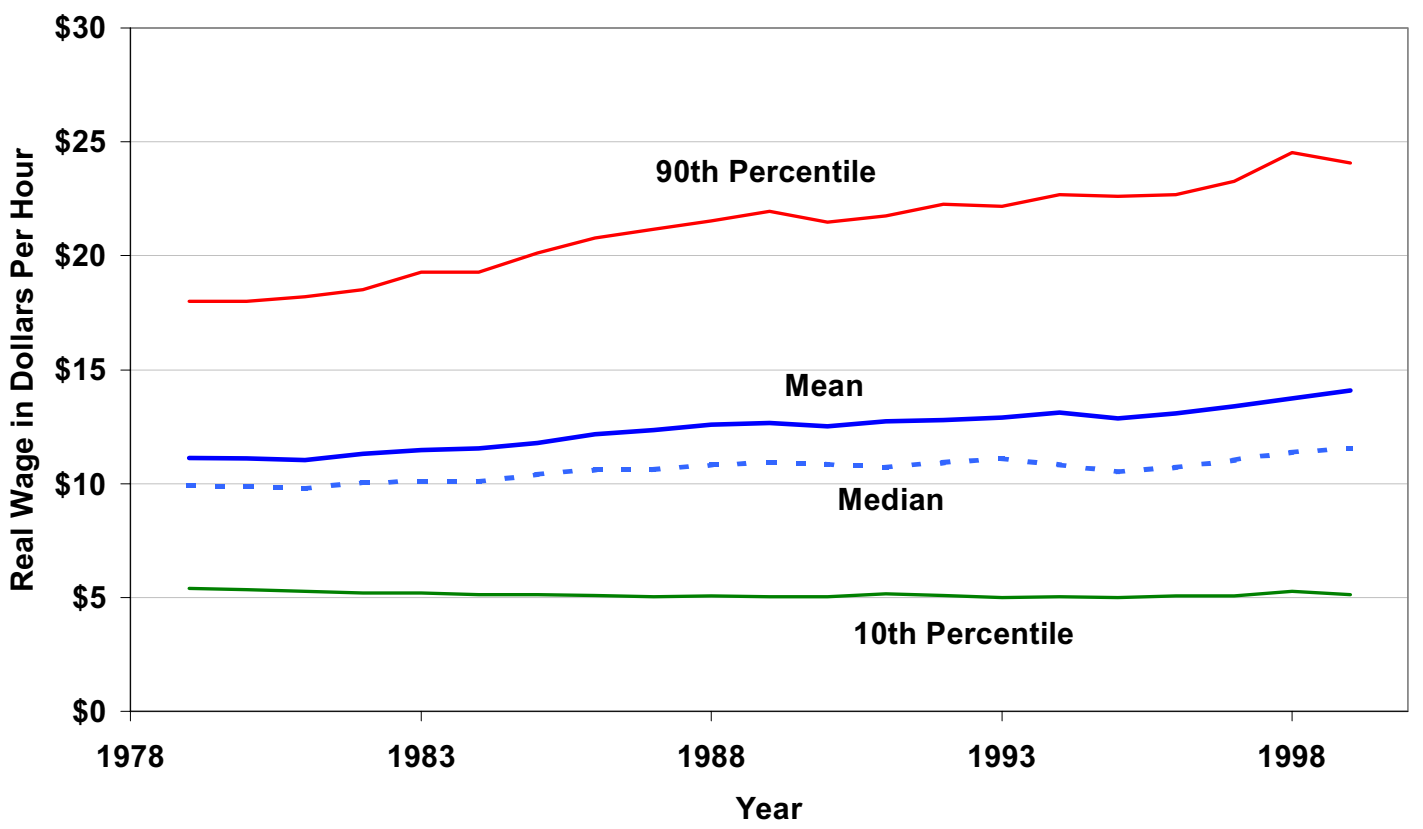


Figure 12

Percent Workless Households in Britain

By Type Of Household

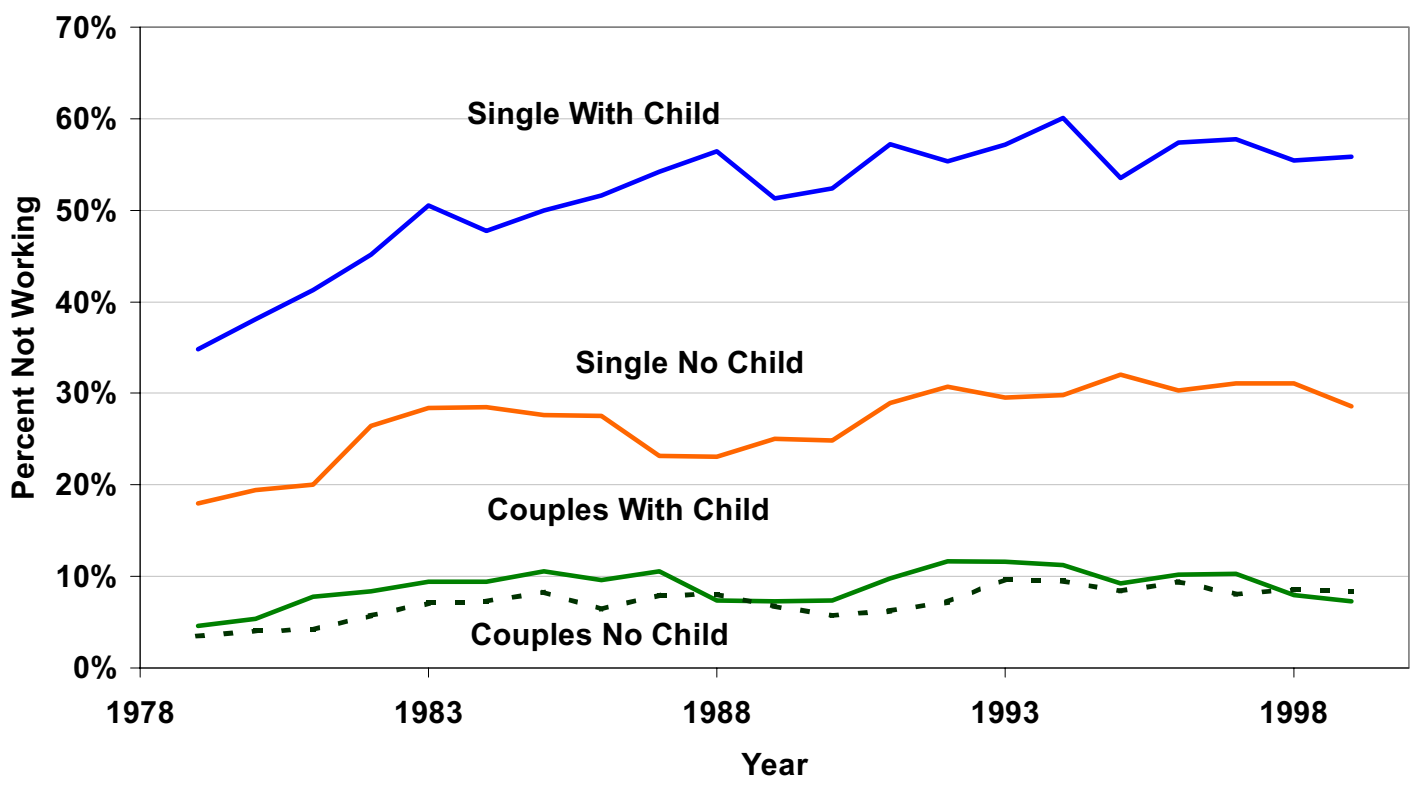

Figure 13

Work Patterns of Men and Women in Couples in Britain

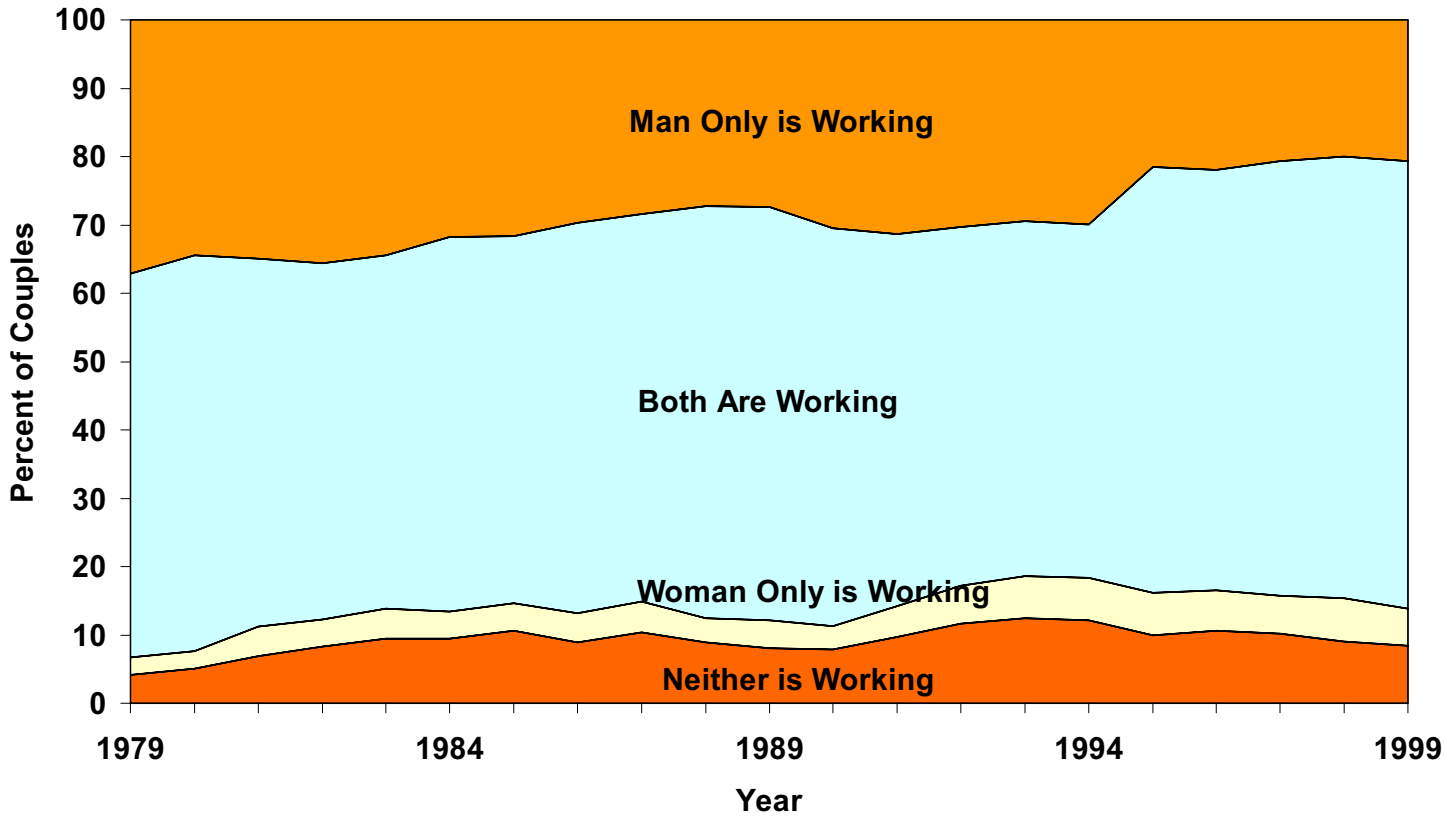


Figure 14

Percent Workless* Households in the US

By Type Of Household

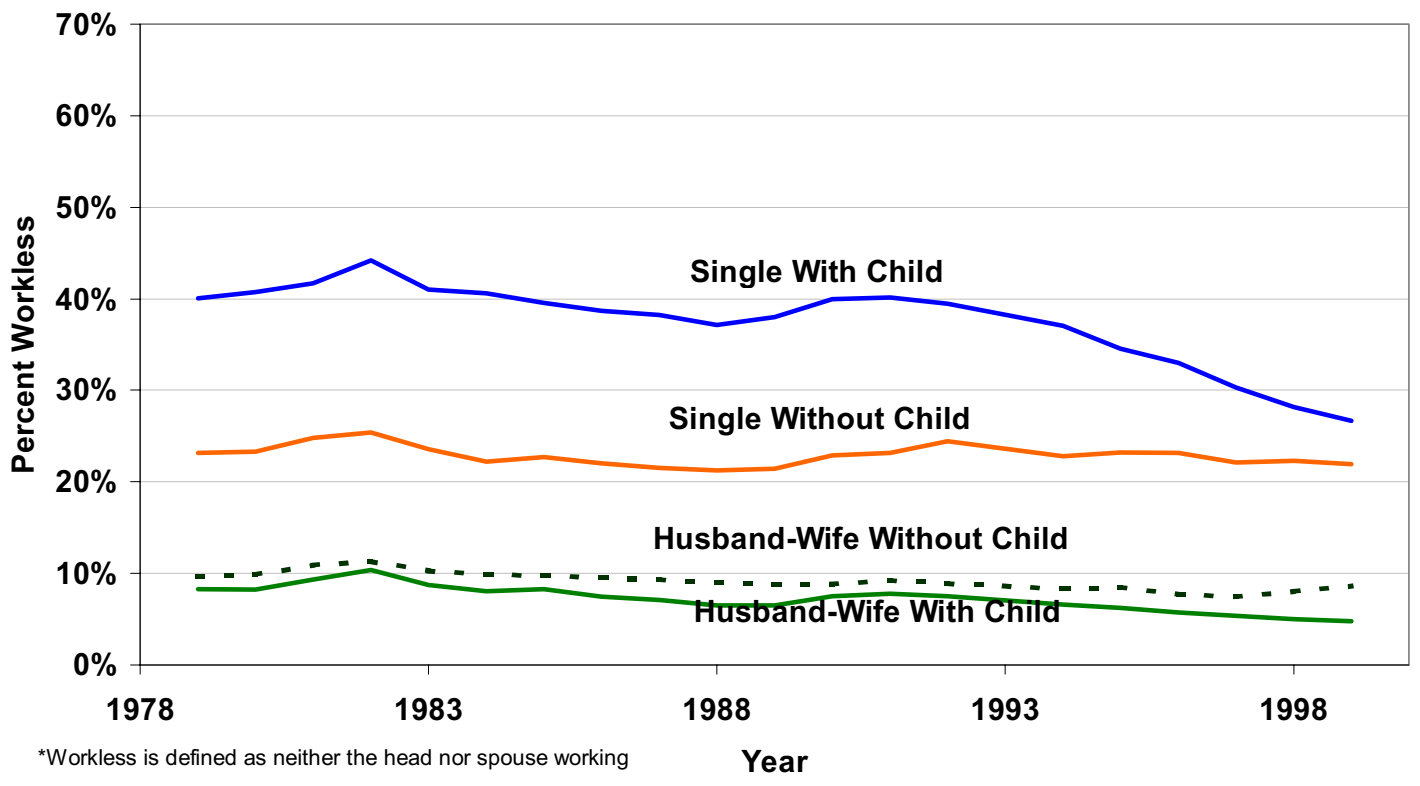


Figure 15

Benefits for Singles With Children in Britain

By Weekly Earnings Category

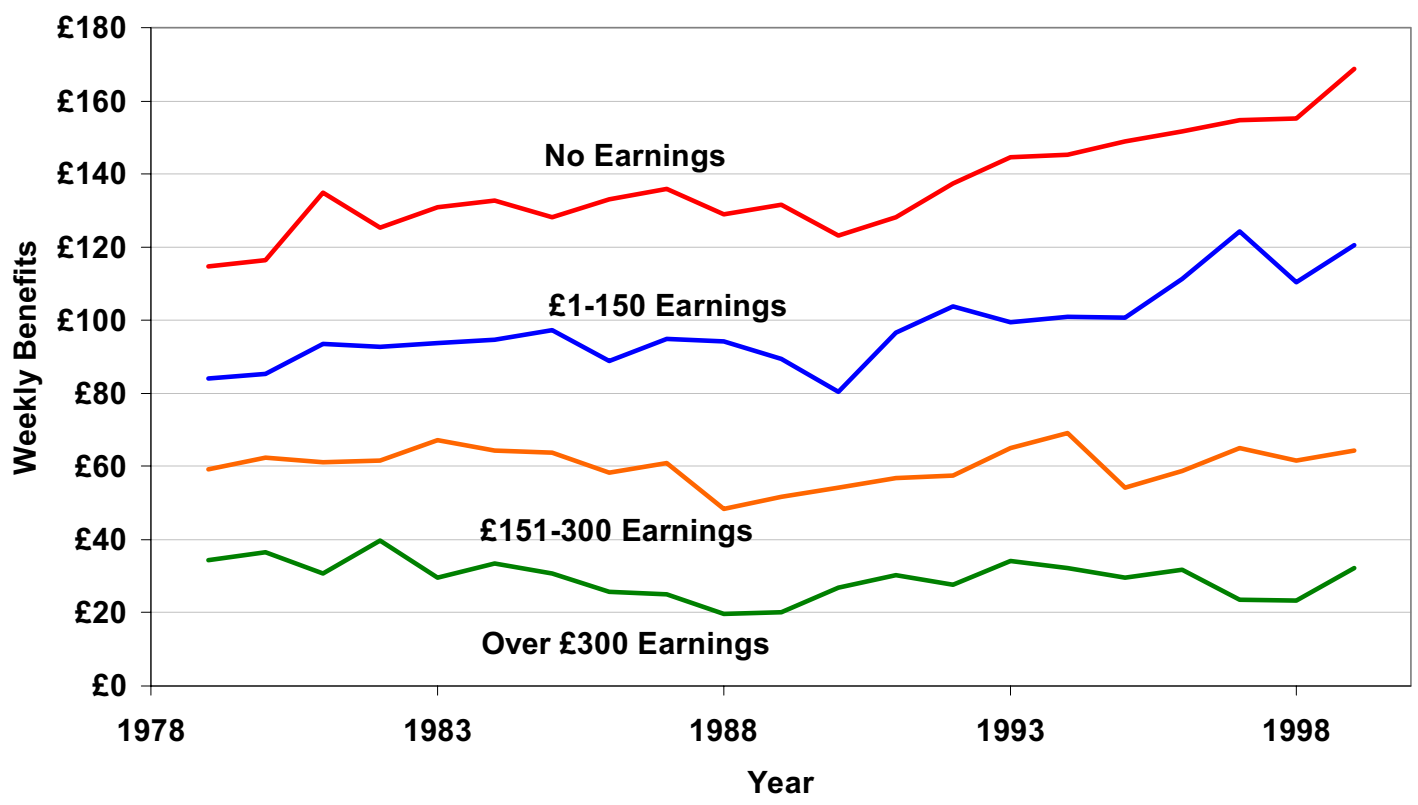

Figure 16

Benefits for Single Adult Headed Households in the US

(Non-disabled, Non-widowed) By Annual Earnings Category

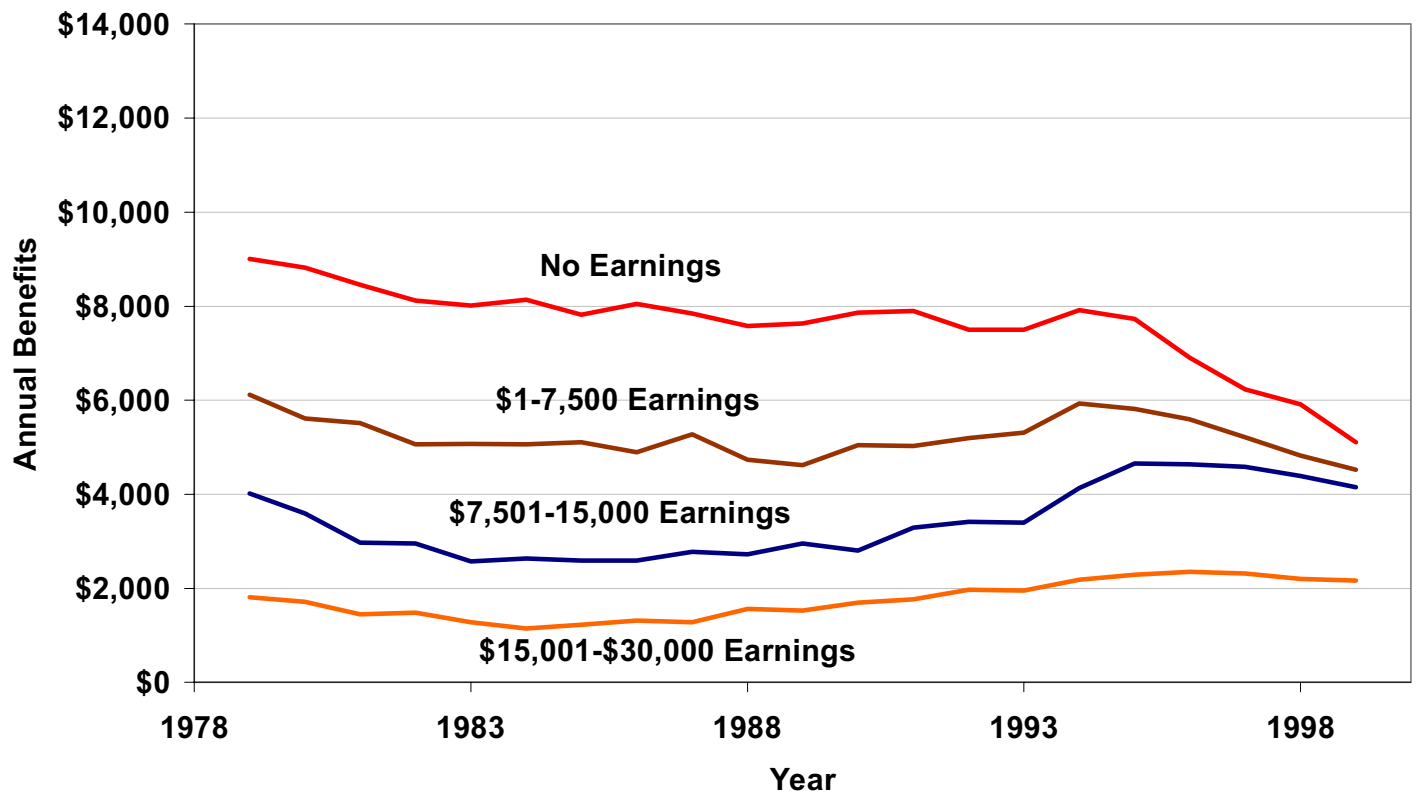


Figure 17

Benefits for Couples With and Without Children in Britain

By Earnings Category

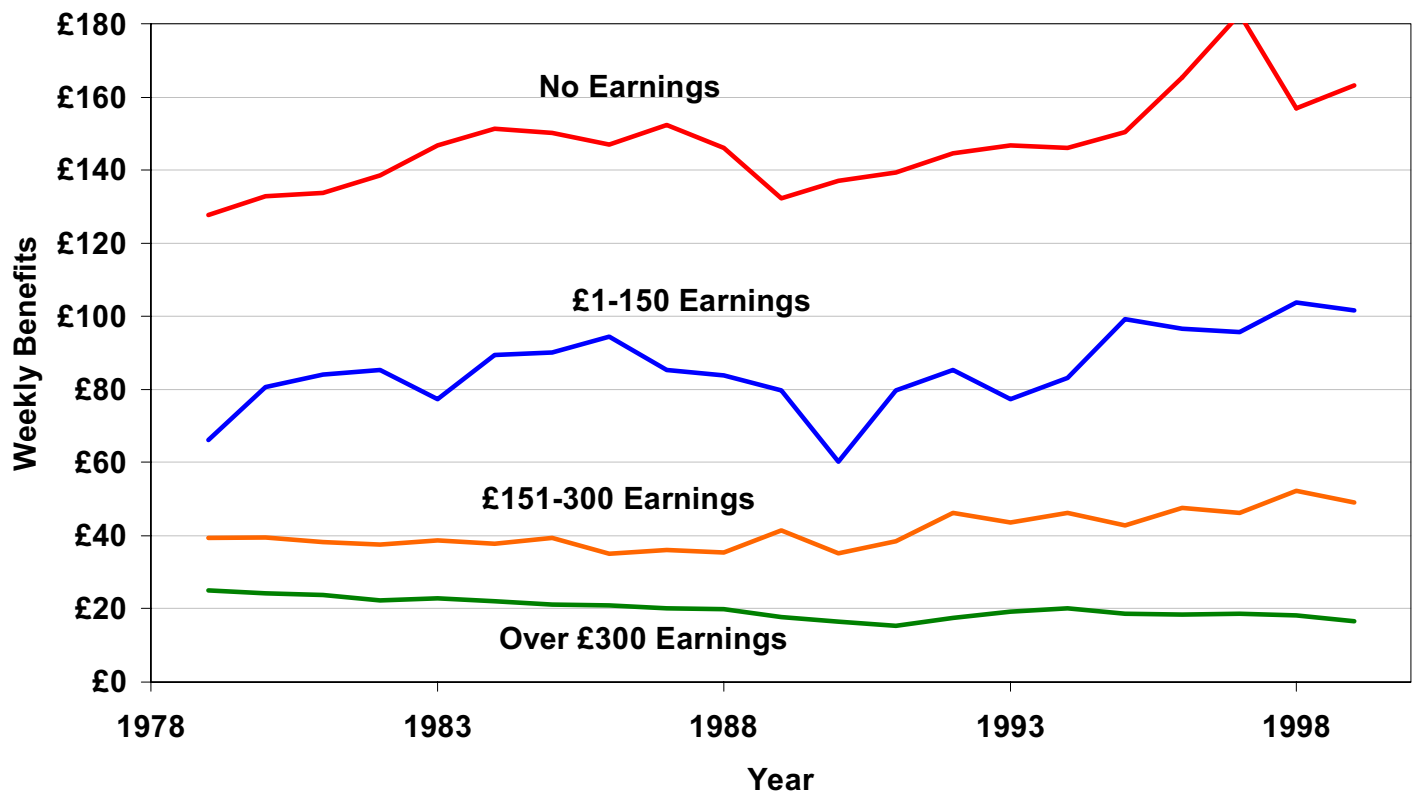

Figure 18

Benefits for Husband Wife Households in the US (Non-disabled, Non-widowed)

By Annual Earnings Category

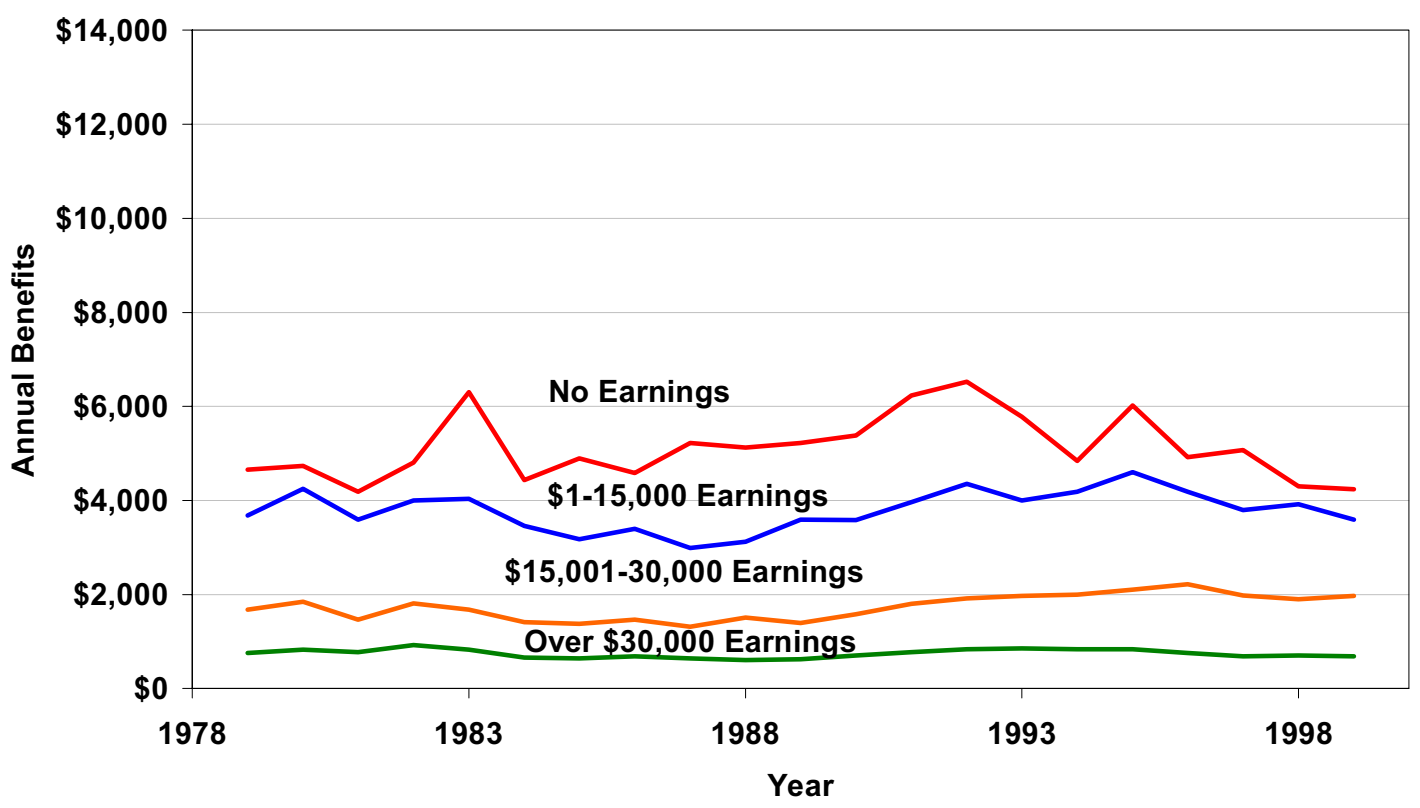


Figure 19

Predicted Gain in Earnings Less Benefit Changes for Full-Time Work:

Single Parents in Britain By Predicted Wage Class*

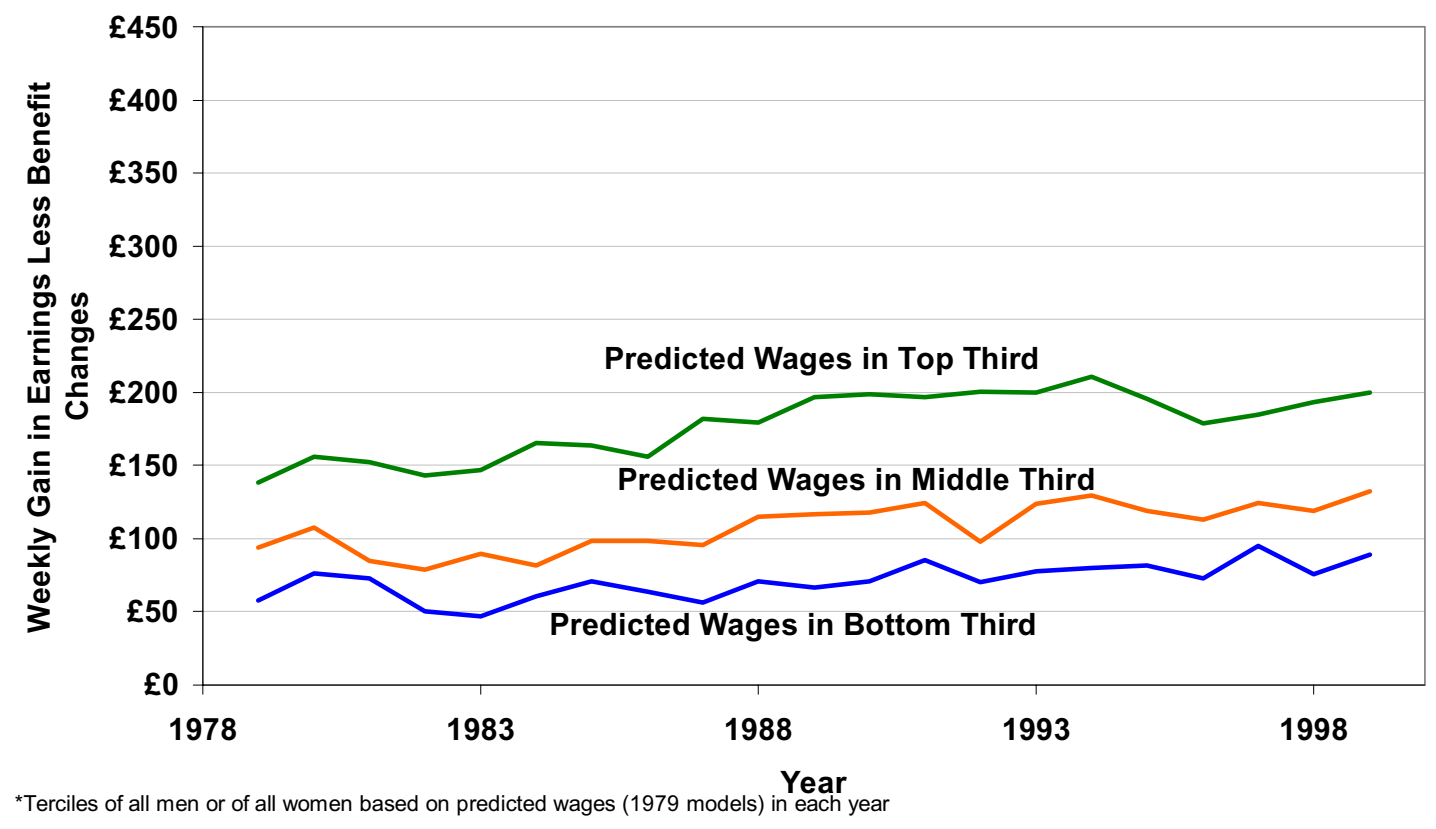

Figure 20

Predicted Gain in Earnings Less Benefit Changes for Full-Time Work: Single Parents in the US By Predicted Wage Class*

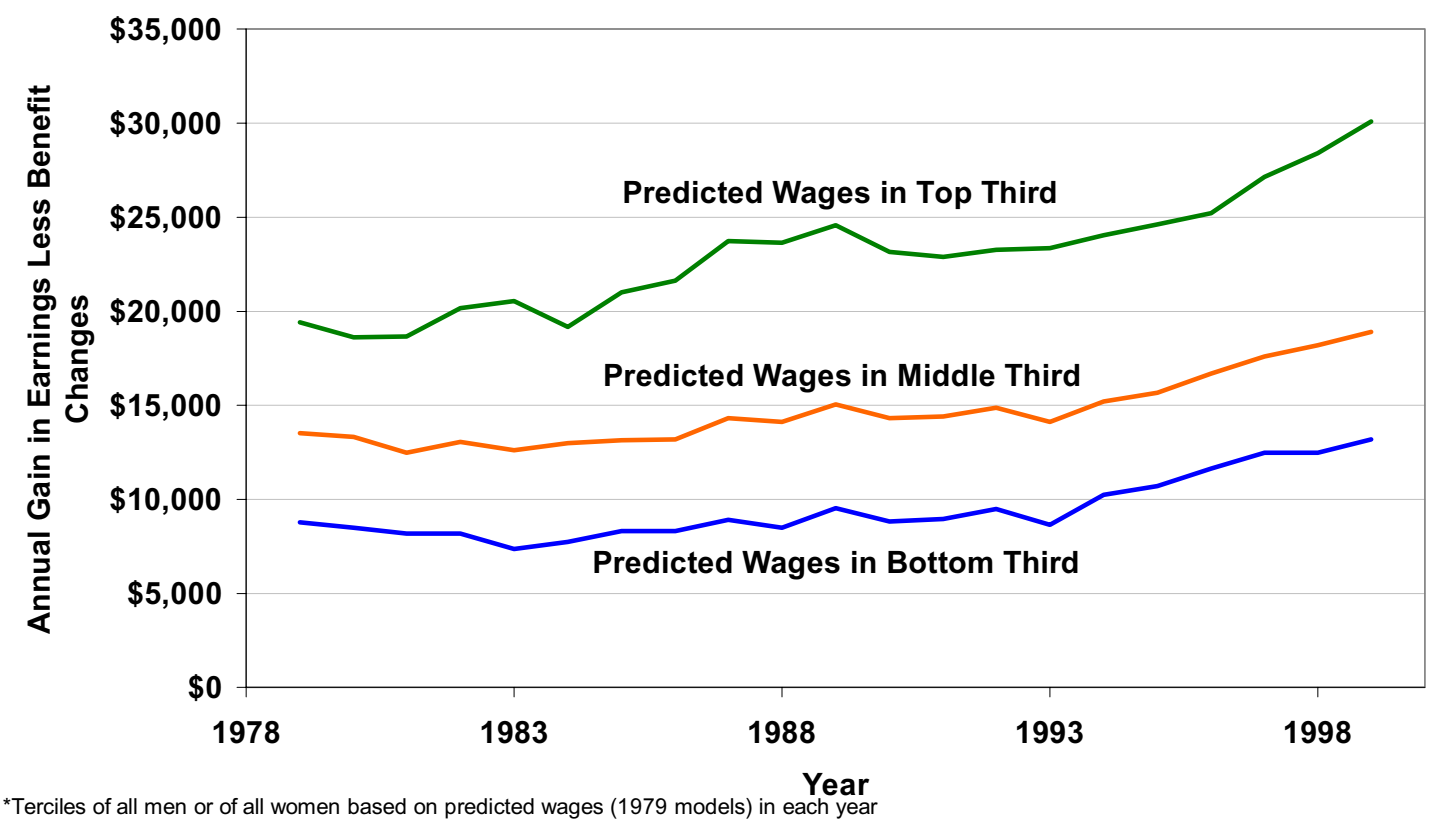


Figure 21

Percentage Working Among Singles With Children in Britain

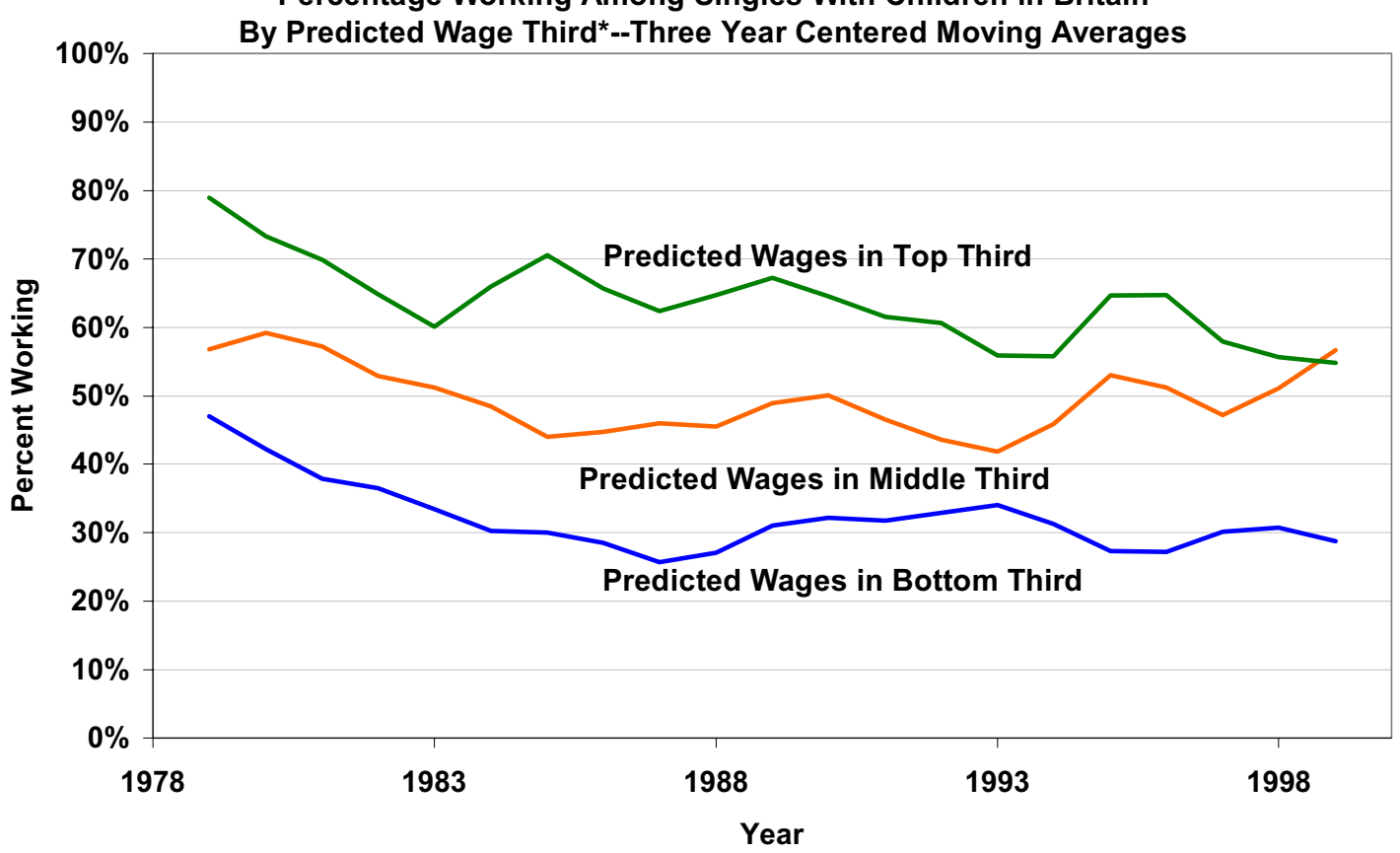

*Terciles of all women based on predicted wages (1979 models) in each year

Figure 22

Percentage Working Among Singles With Children in the US

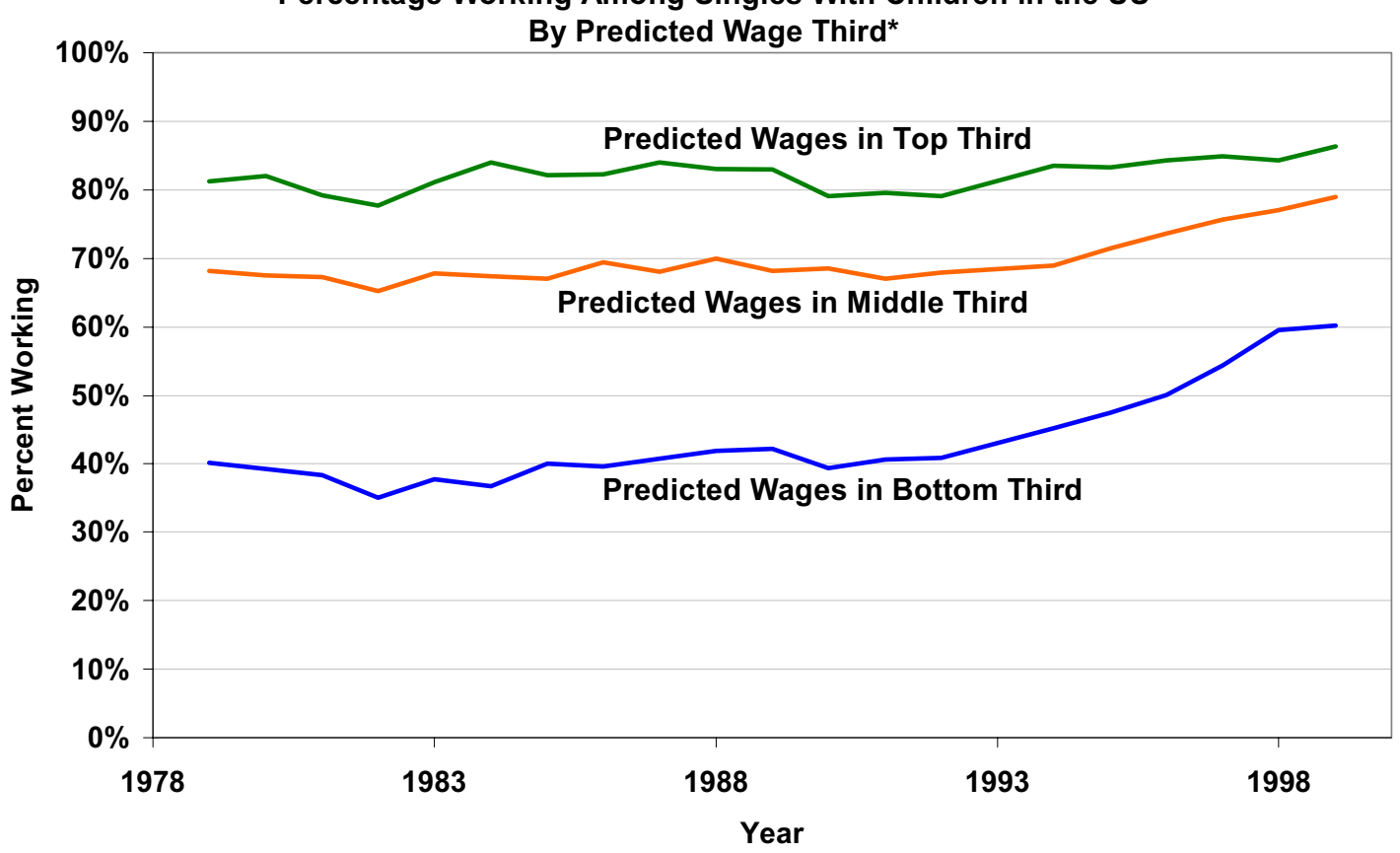

${ }^{*}$ Terciles of all women based on predicted wages (1979 models) in each year 
Figure 23

Predicted Gain in Earnings Less Benefit Changes for Full-Time Work: Men in Couples with Children in Britain By Predicted Wage Class* Assuming Their Partner is Not Working

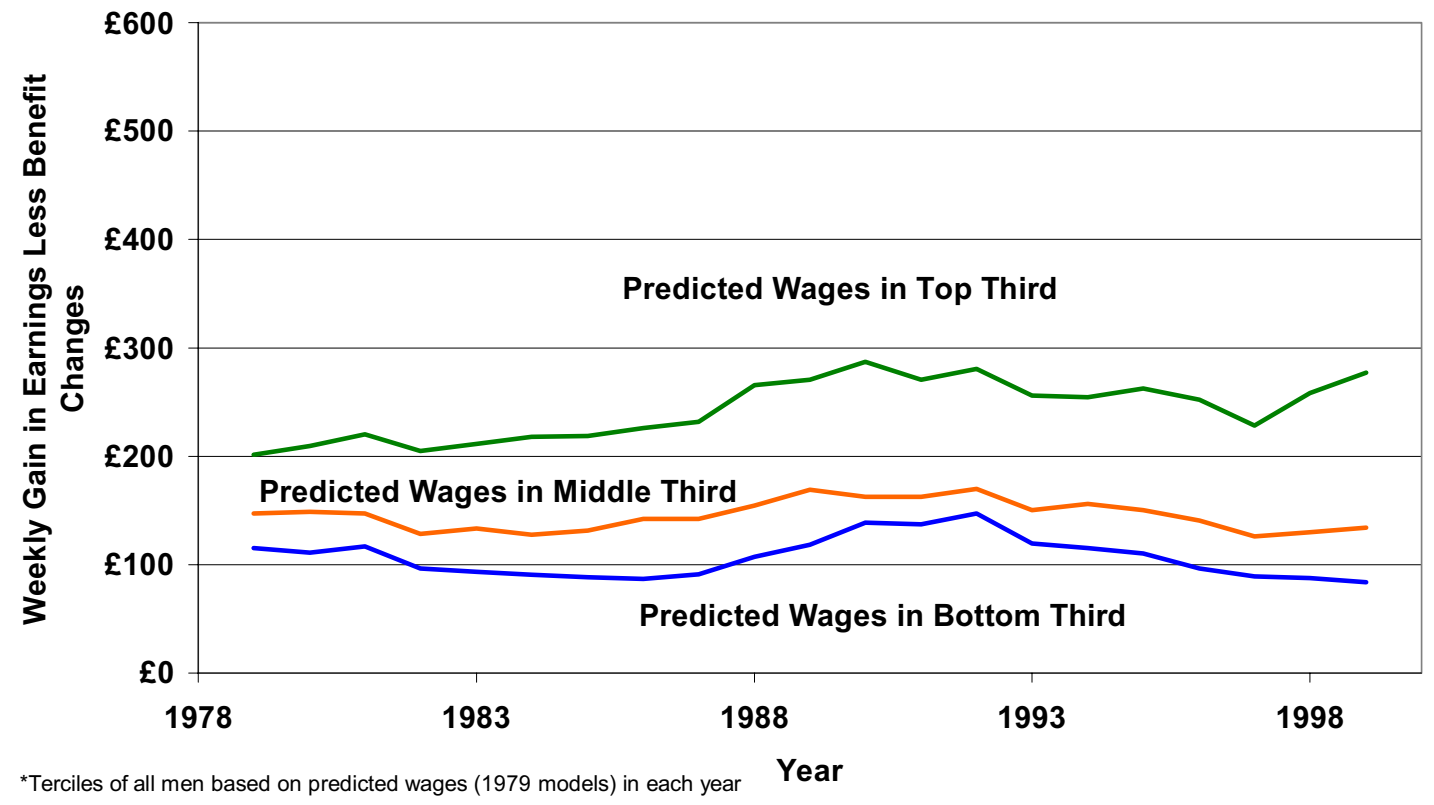

Figure 24

Predicted Gain in Earnings Less Benefits Changes for Full-Time Work: Husbands with Children in the US By Predicted Wage Class*

Assuming the Wife is Not Working

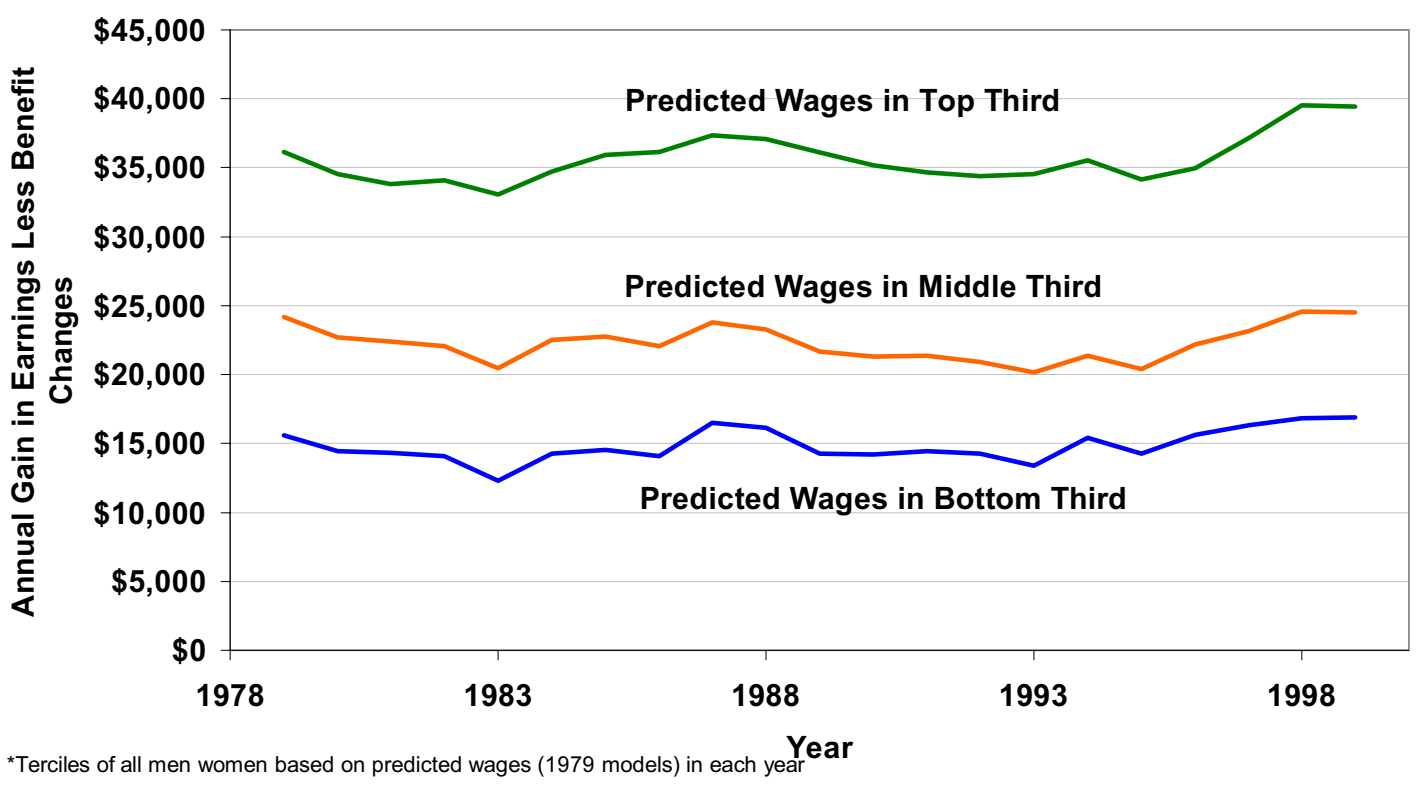


Figure 25

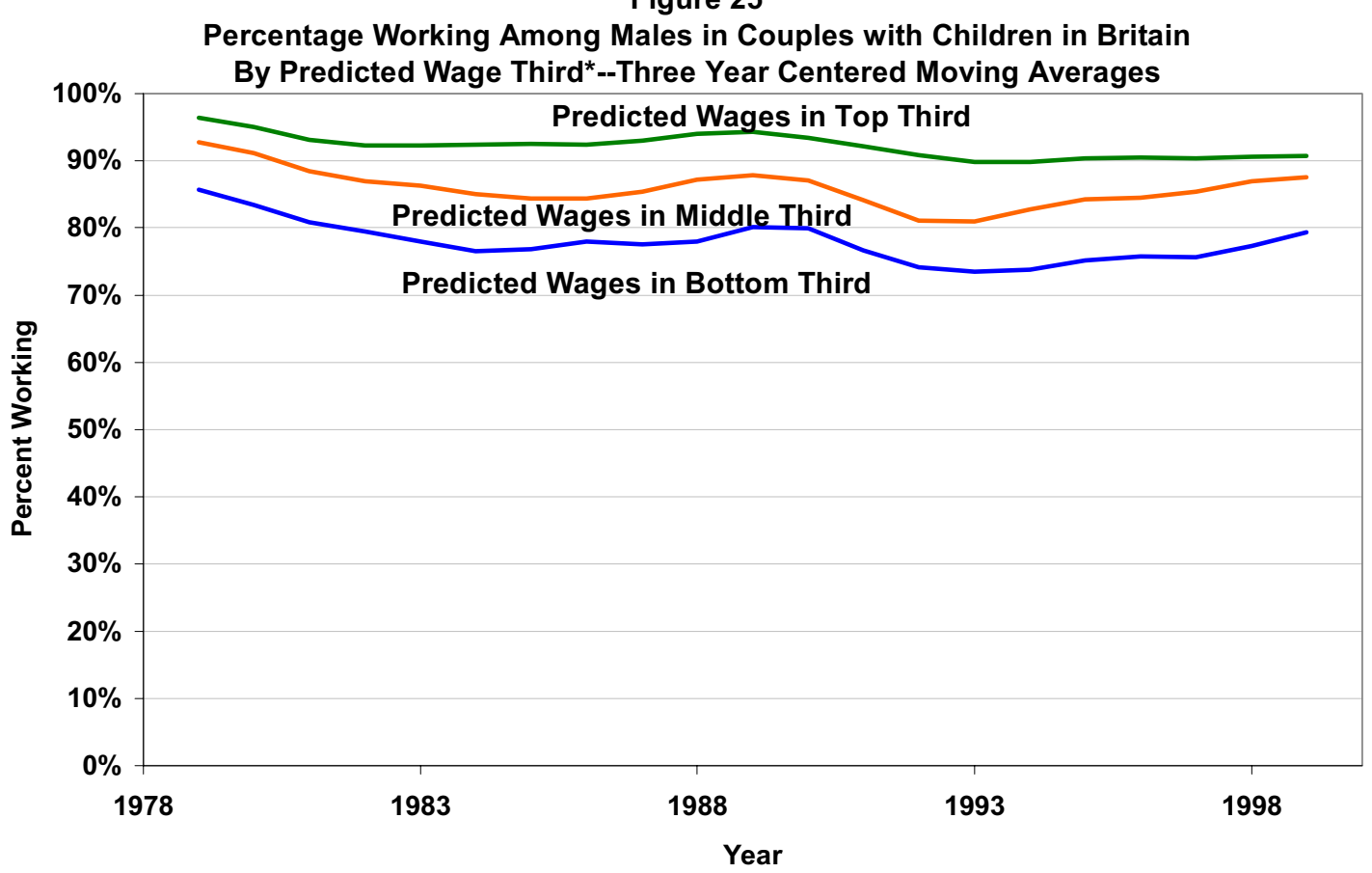

*Terciles of all men based on predicted wages (1979 models) in each year

Figure 26

Percentage Working Among Husbands with Children in the US By Predicted Wage Third*

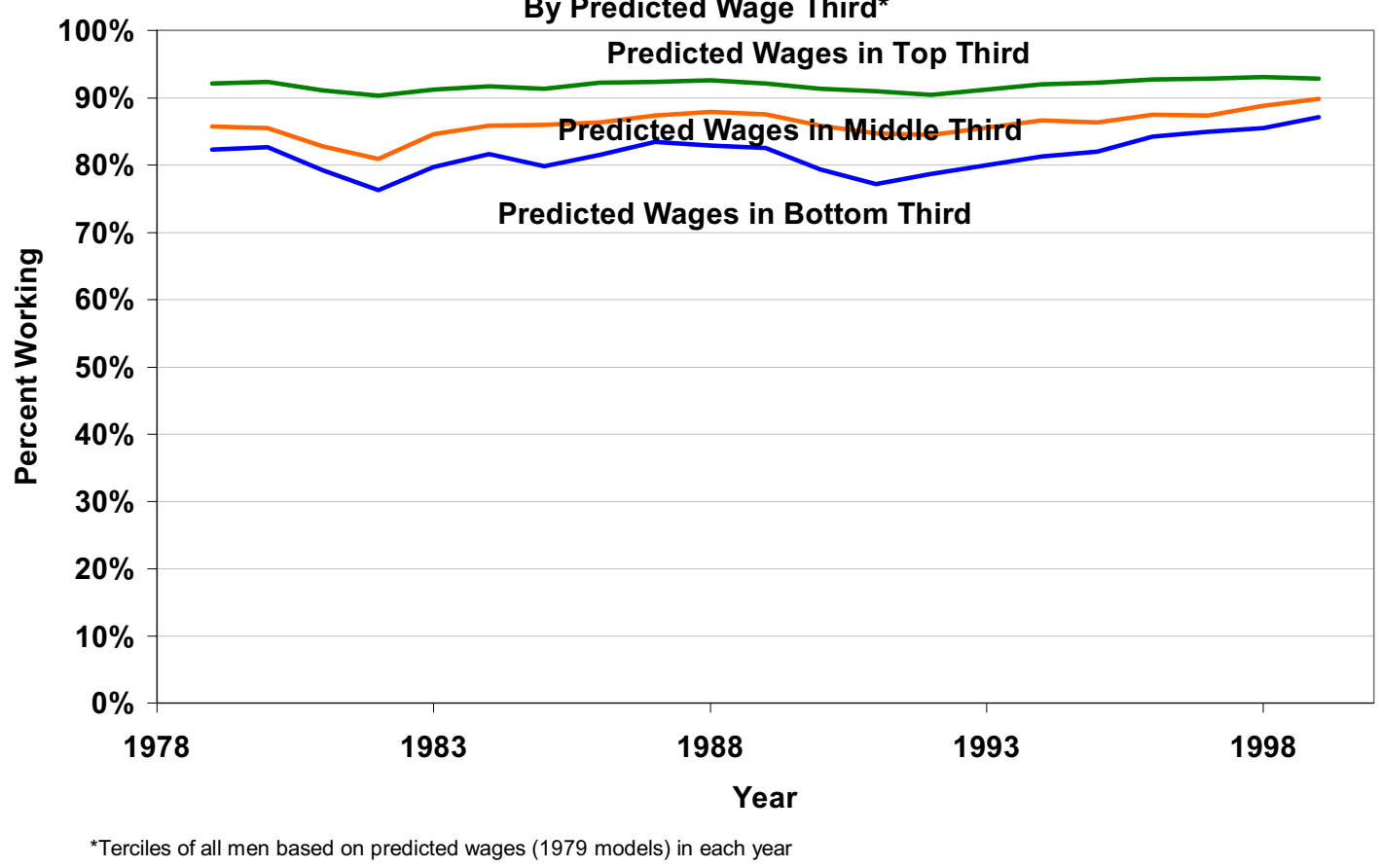


Figure 27

Predicted Gain in Earnings Less Benefit Changes for Full-Time Work: Women in Couples with Children in Britain By Predicted Wage Class* Assuming Partner Already Works Full-Time

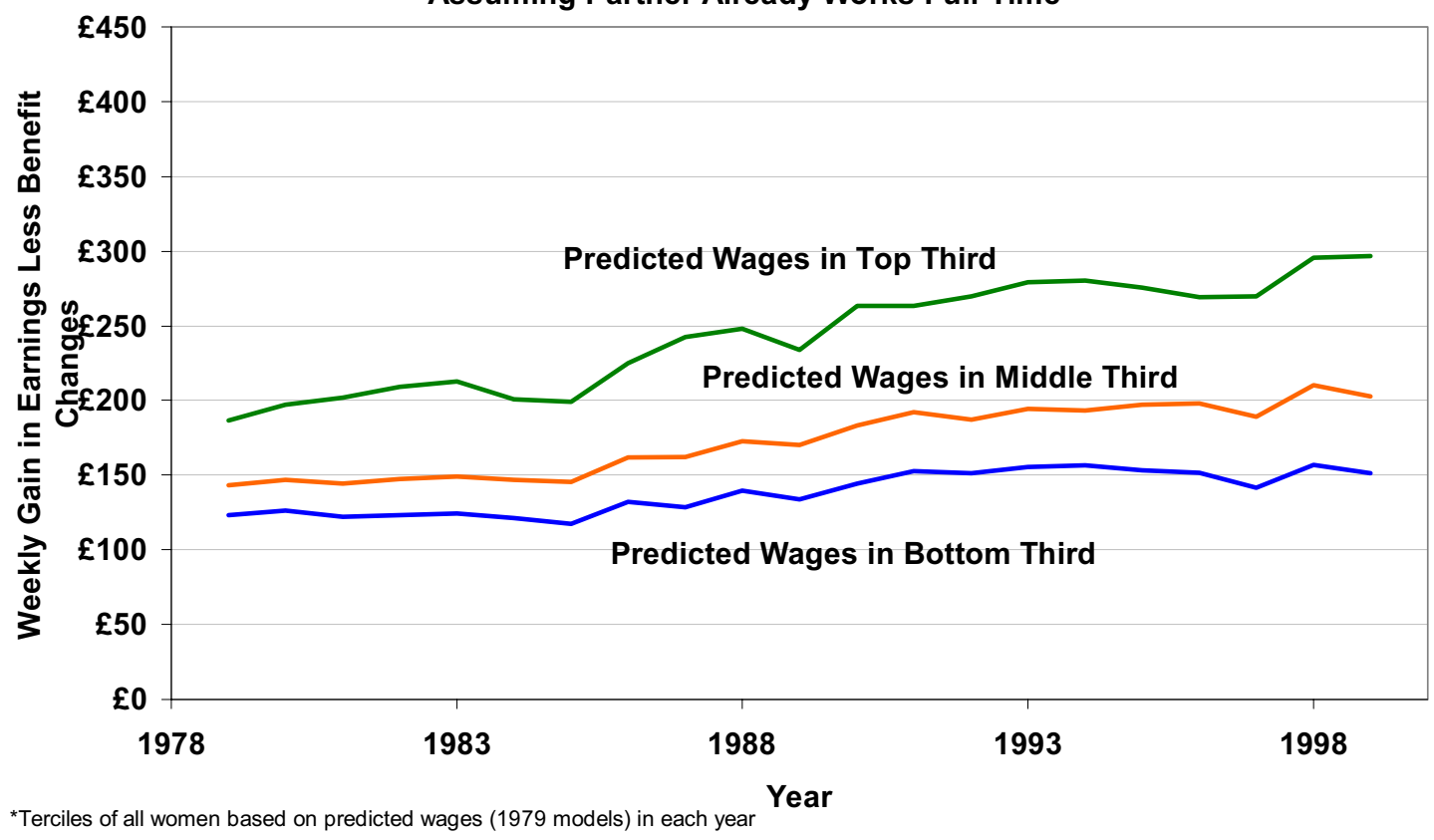

Figure 28

Predicted Gain in Earnings Less Benefit Changes for Full-Time Work: Wives with Children in US By Predicted Wage Class*

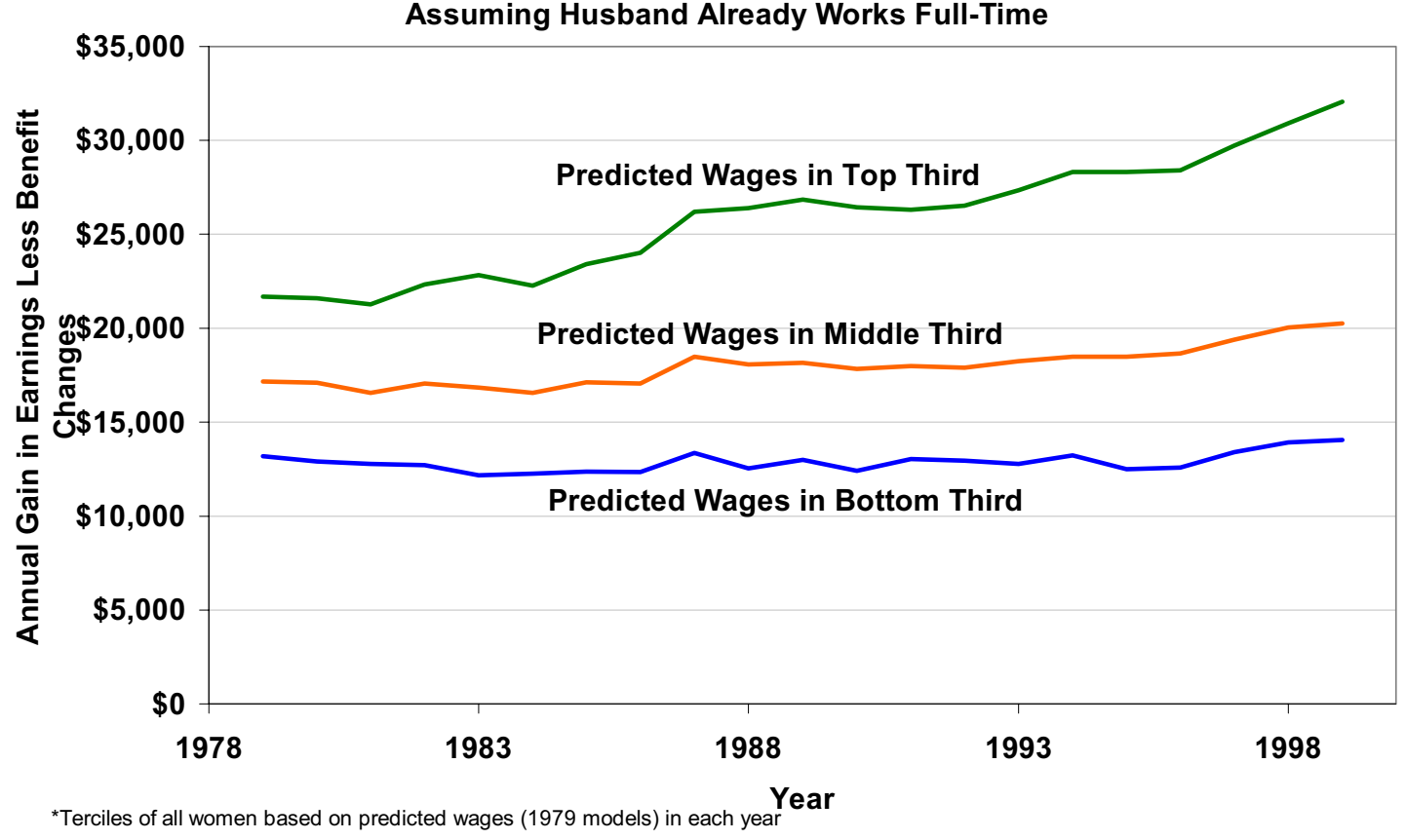


Figure 29

Percentage Working Among Women in Couples With Children in Britain By Predicted Wage Third*--Three Year Centered Moving Averages

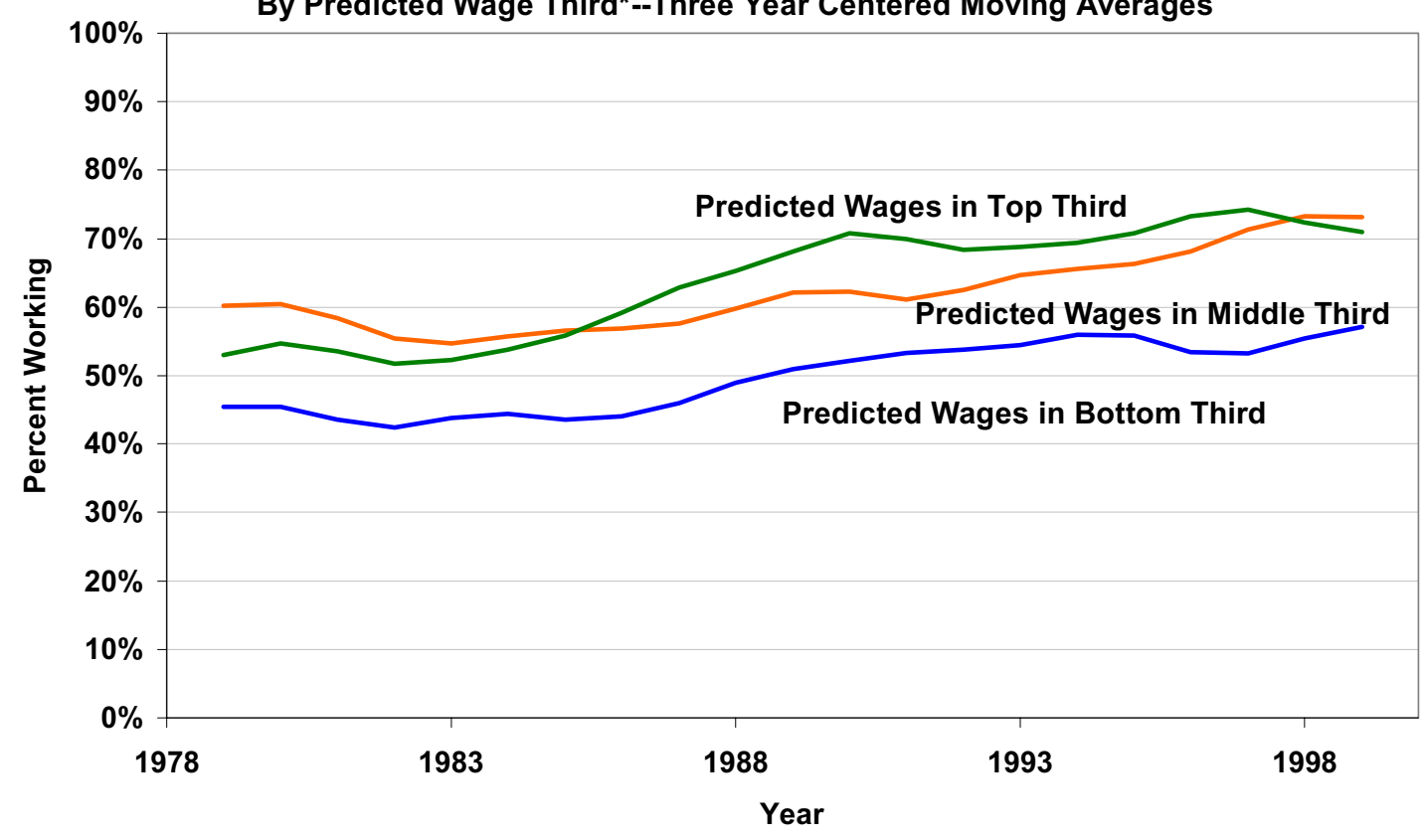

*Terciles of all women based on predicted wages (1979 models) in each year

Figure 30

Percentage Working Among Wives With Children in the US

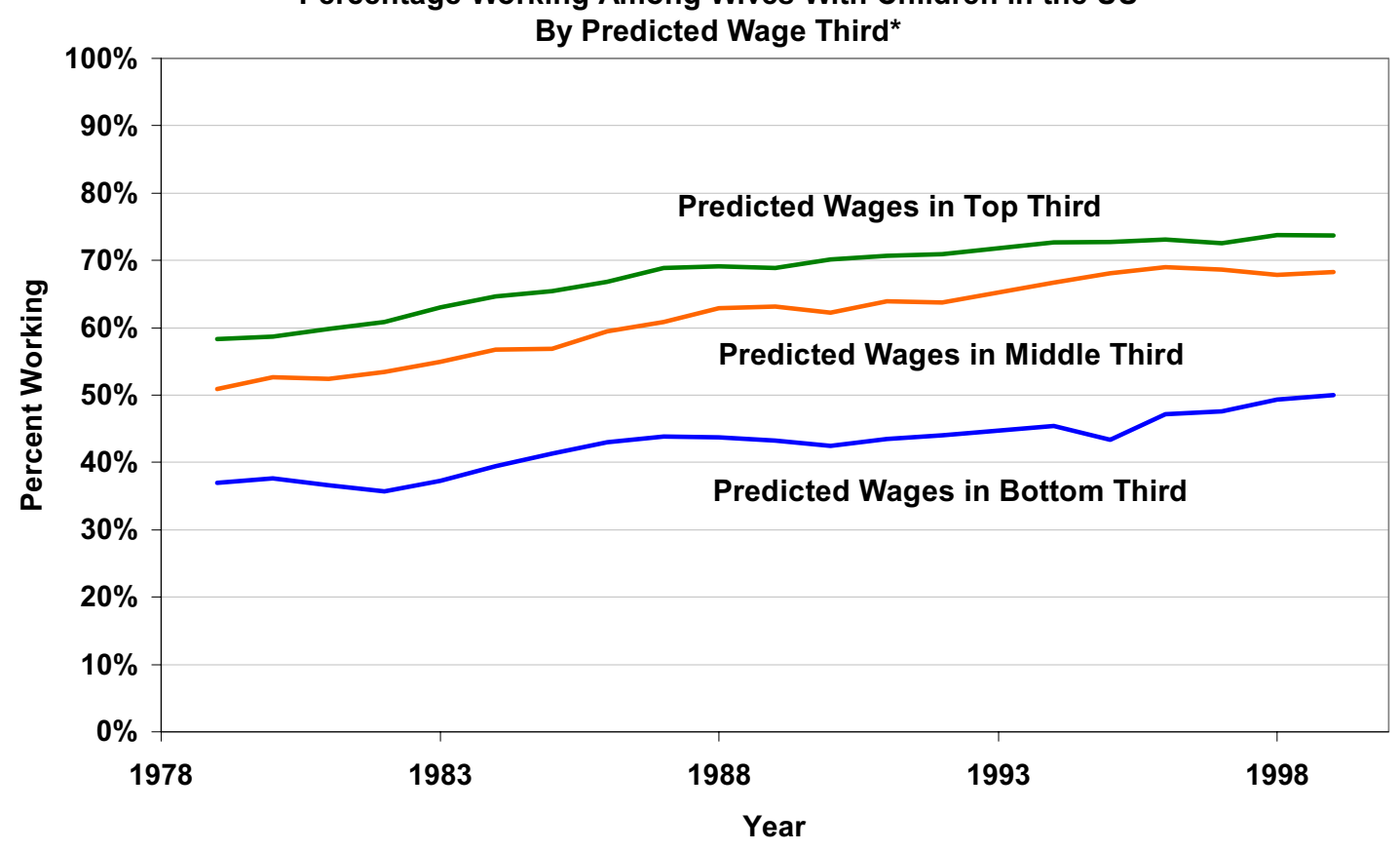

*Terciles of all women based on predicted wages (1979 models) in each year 
Table 1

Decomposition of Changes in Poverty Between 1979 and 1999 by Family Type

\begin{tabular}{|c|c|c|c|c|}
\hline & Gre & itain & $\mathbf{U n}$ & ates \\
\hline & Relative & Absolute & Relative & Absolute \\
\hline & Poverty & Poverty & Poverty & Poverty \\
\hline ALL PERSONS & & & & \\
\hline Poverty in 1979 & $13.0 \%$ & $13.0 \%$ & $26.2 \%$ & $10.4 \%$ \\
\hline + Demographics & $+5.4 \%$ & $+1.2 \%$ & $+3.3 \%$ & $+1.2 \%$ \\
\hline+ Wages & $+4.6 \%$ & $+0.7 \%$ & $+1.3 \%$ & $+1.2 \%$ \\
\hline + Work Patterns & $+5.1 \%$ & $+6.3 \%$ & $-0.8 \%$ & $-2.3 \%$ \\
\hline+ Government Benefits & $\underline{-3.7 \%}$ & $\underline{-6.8 \%}$ & $+0.0 \%$ & $+0.3 \%$ \\
\hline$=$ Poverty in 1999 & $24.4 \%$ & $14.5 \%$ & $30.0 \%$ & $10.9 \%$ \\
\hline Couples With Children & & & & \\
\hline Poverty in 1979 & $13.1 \%$ & $13.1 \%$ & $23.4 \%$ & $6.4 \%$ \\
\hline + Demographics & $+2.7 \%$ & $-2.2 \%$ & $+2.7 \%$ & $+0.8 \%$ \\
\hline + Wages & $+5.3 \%$ & $+0.8 \%$ & $+2.2 \%$ & $+1.4 \%$ \\
\hline + Work Patterns & $+3.8 \%$ & $+5.4 \%$ & $-1.7 \%$ & $-2.4 \%$ \\
\hline+ Government Benefits & $\underline{-2.3 \%}$ & $\underline{-3.4 \%}$ & $+0.1 \%$ & $+0.0 \%$ \\
\hline$=$ Poverty in 1999 & $22.6 \%$ & $13.7 \%$ & $26.8 \%$ & $6.4 \%$ \\
\hline Couples Without Children & & & & \\
\hline Poverty in 1979 & $3.5 \%$ & $3.5 \%$ & $9.5 \%$ & $2.5 \%$ \\
\hline + Demographics & $+0.9 \%$ & $+0.3 \%$ & $+2.3 \%$ & $+0.4 \%$ \\
\hline + Wages & $+2.8 \%$ & $+0.4 \%$ & $+0.7 \%$ & $+0.3 \%$ \\
\hline + Work Patterns & $+3.7 \%$ & $+3.7 \%$ & $-0.5 \%$ & $-0.3 \%$ \\
\hline+ Government Benefits & $\underline{-1.9 \%}$ & $\underline{-3.1 \%}$ & $\underline{-0.3 \%}$ & $\underline{-0.0 \%}$ \\
\hline$=$ Poverty in 1999 & $9.0 \%$ & $4.9 \%$ & $11.7 \%$ & $2.8 \%$ \\
\hline Singles With Children & & & & \\
\hline Poverty in 1979 & $48.3 \%$ & $48.3 \%$ & $63.9 \%$ & $36.9 \%$ \\
\hline + Demographics & $+11.9 \%$ & $+2.5 \%$ & $-2.3 \%$ & $-5.1 \%$ \\
\hline + Wages & $+6.9 \%$ & $+0.8 \%$ & $-0.6 \%$ & $+2.3 \%$ \\
\hline + Work Patterns & $+8.4 \%$ & $+12.0 \%$ & $-0.2 \%$ & $-6.5 \%$ \\
\hline+ Government Benefits & $\underline{-10.9 \%}$ & $\underline{-26.5 \%}$ & $+0.3 \%$ & $+1.4 \%$ \\
\hline = Poverty in 1999 & $64.7 \%$ & $37.2 \%$ & $61.1 \%$ & $29.0 \%$ \\
\hline Singles Without Children & & & & \\
\hline Poverty in 1979 & $13.3 \%$ & $13.3 \%$ & $26.6 \%$ & $15.0 \%$ \\
\hline + Demographics & $+3.8 \%$ & $+1.0 \%$ & $+2.6 \%$ & $+0.3 \%$ \\
\hline+ Wages & $+2.7 \%$ & $+0.2 \%$ & $+0.9 \%$ & $+0.9 \%$ \\
\hline + Work Patterns & $+10.5 \%$ & $+10.6 \%$ & $+0.7 \%$ & $-0.5 \%$ \\
\hline+ Government Benefits & $-6.5 \%$ & $-10.2 \%$ & $\underline{-0.1 \%}$ & $+0.4 \%$ \\
\hline$=$ Poverty in 1999 & $23.9 \%$ & $\overline{15.0 \%}$ & $\overline{30.8 \%}$ & $\overline{16.0 \%}$ \\
\hline
\end{tabular}


Table 2

Distribution of Poor Children by Work Hours of Family:

Actual 1999 and Projected if Work Patterns Were Comparable to 1979

\begin{tabular}{||c||c|c||c|c||}
\hline \multirow{1}{*}{$\begin{array}{c}\text { Total Hours } \\
\text { Worked By All } \\
\text { Persons in the } \\
\text { Household }\end{array}$} & $\begin{array}{c}\text { \% distribution } \\
\text { of poor } \\
\text { children by } \\
\text { work hours of } \\
\text { the family. }\end{array}$ & $\begin{array}{c}\text { children who are } \\
\text { poor and living in } \\
\text { families with } \\
\text { given work hours } \\
\text { as a percentage } \\
\text { of all children }\end{array}$ & $\begin{array}{c}\text { Projections if Work Patterns in } \\
\text { distribution } \\
\text { of poor } \\
\text { children by } \\
\text { work hours of } \\
\text { the family. }\end{array}$ & $\begin{array}{c}\text { children who are } \\
\text { poor and living in } \\
\text { families with } \\
\text { given work hours } \\
\text { as a percentage } \\
\text { of all children }\end{array}$ \\
\hline \hline No Work Hours & $51.1 \%$ & $17.6 \%$ & $37.7 \%$ & $11.0 \%$ \\
$1-29$ hours & $16.1 \%$ & $5.5 \%$ & $12.4 \%$ & $3.6 \%$ \\
30 hours and over & $32.8 \%$ & $11.3 \%$ & $49.9 \%$ & $14.5 \%$ \\
\hline \hline All Work Levels & $\mathbf{1 0 0 . 0 \%}$ & $\mathbf{3 4 . 5 \%}$ & $\mathbf{1 0 0 . 0 \%}$ & $\mathbf{2 9 . 1 \%}$ \\
\hline \hline
\end{tabular}


Figure A1

Components of Change in Absolute Poverty in the US Since 1979 Using $60 \%$ Median 79 Income Standard

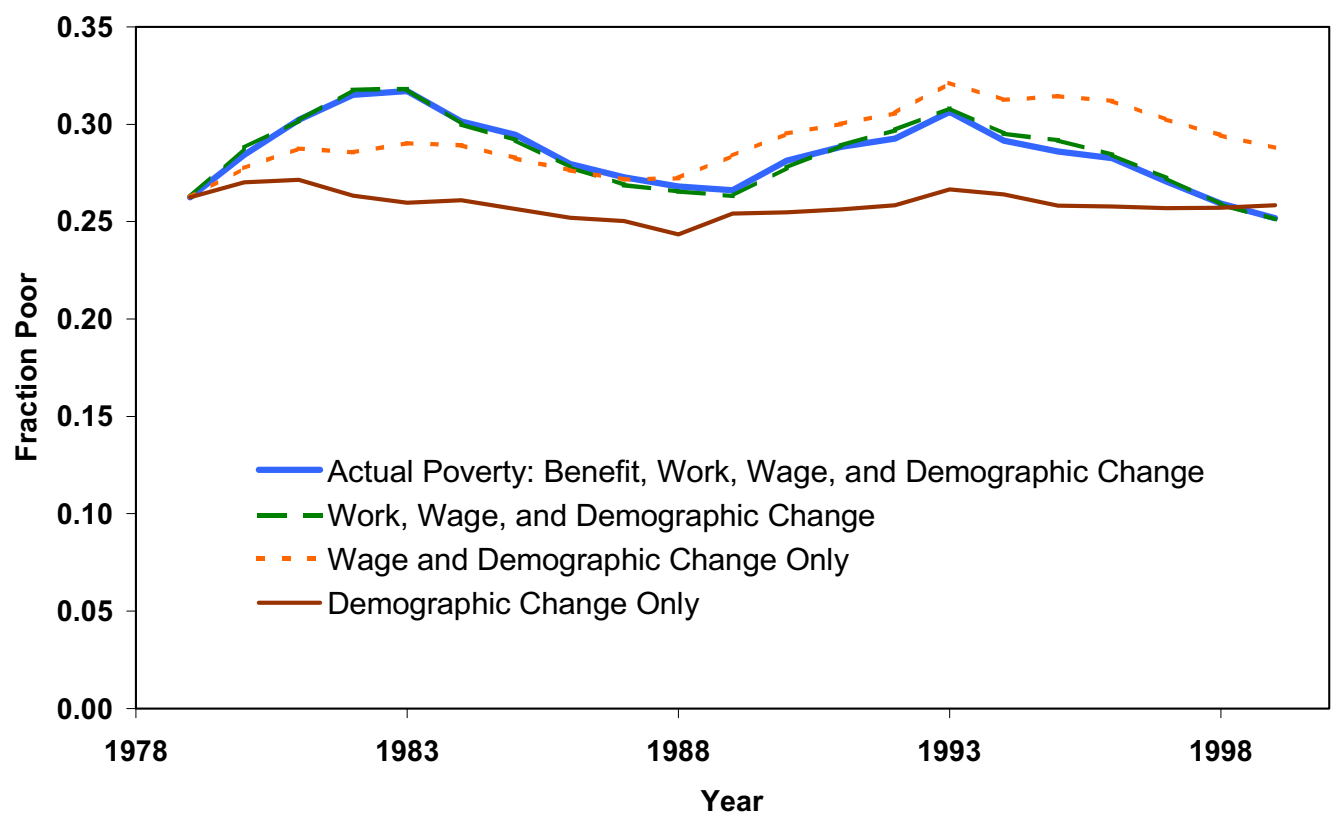


Table A1

Composition of Change in Absolute Poverty Since 1979 by Family Type: Britain

\begin{tabular}{|c|c|c|c|c|}
\hline & $\begin{array}{c}\text { Demographic } \\
\text { Changes }\end{array}$ & $\begin{array}{l}\text { Demographic } \\
\text { and Wage } \\
\text { Changes } \\
\end{array}$ & $\begin{array}{c}\text { Demographic, } \\
\text { Wage and Work } \\
\text { Changes }\end{array}$ & $\begin{array}{l}\text { Actual Poverty: } \\
\text { Demographic, } \\
\text { Wage, Work and } \\
\text { Benefit Changes }\end{array}$ \\
\hline \multicolumn{5}{|c|}{ Couples With Children } \\
\hline 1979 & $13.1 \%$ & $13.1 \%$ & $13.1 \%$ & $13.1 \%$ \\
\hline 1984 & $11.3 \%$ & $10.8 \%$ & $20.0 \%$ & $18.7 \%$ \\
\hline 1989 & $11.3 \%$ & $10.7 \%$ & $15.3 \%$ & $14.9 \%$ \\
\hline 1994 & $12.3 \%$ & $13.9 \%$ & $21.6 \%$ & $19.9 \%$ \\
\hline 1999 & $10.9 \%$ & $11.7 \%$ & $17.1 \%$ & $13.7 \%$ \\
\hline \multicolumn{5}{|c|}{ Couples Without Children } \\
\hline 1979 & $3.5 \%$ & $3.5 \%$ & $3.5 \%$ & $3.5 \%$ \\
\hline 1984 & $3.3 \%$ & $3.5 \%$ & $8.5 \%$ & $7.0 \%$ \\
\hline 1989 & $2.4 \%$ & $2.6 \%$ & $6.8 \%$ & $4.9 \%$ \\
\hline 1994 & $2.5 \%$ & $3.0 \%$ & $9.6 \%$ & $7.1 \%$ \\
\hline 1999 & $3.8 \%$ & $4.3 \%$ & $8.0 \%$ & $4.9 \%$ \\
\hline \multicolumn{5}{|c|}{ Singles With Children } \\
\hline 1979 & $48.3 \%$ & $48.3 \%$ & $48.3 \%$ & $48.3 \%$ \\
\hline 1984 & $48.7 \%$ & $51.7 \%$ & $62.9 \%$ & $53.2 \%$ \\
\hline 1989 & $46.8 \%$ & $47.5 \%$ & $59.4 \%$ & $50.2 \%$ \\
\hline 1994 & $48.9 \%$ & $47.5 \%$ & $65.1 \%$ & $51.1 \%$ \\
\hline 1999 & $50.9 \%$ & $51.7 \%$ & $63.7 \%$ & $37.2 \%$ \\
\hline \multicolumn{5}{|c|}{ Singles Without Children } \\
\hline 1979 & $13.3 \%$ & $13.3 \%$ & $13.3 \%$ & $13.3 \%$ \\
\hline 1984 & $14.3 \%$ & $14.9 \%$ & $26.7 \%$ & $21.4 \%$ \\
\hline 1989 & $11.7 \%$ & $12.0 \%$ & $20.0 \%$ & $15.9 \%$ \\
\hline 1994 & $14.3 \%$ & $13.9 \%$ & $26.9 \%$ & $19.0 \%$ \\
\hline 1999 & $14.3 \%$ & $14.6 \%$ & $25.1 \%$ & $15.0 \%$ \\
\hline
\end{tabular}


Table A2

Composition of Change in Relative Poverty Since 1979 by Family Type: Britain

\begin{tabular}{|c|c|c|c|c|}
\hline & $\begin{array}{c}\text { Demographic } \\
\text { Changes }\end{array}$ & $\begin{array}{l}\text { Demographic } \\
\text { and Wage } \\
\text { Changes }\end{array}$ & $\begin{array}{c}\text { Demographic, } \\
\text { Wage and Work } \\
\text { Changes }\end{array}$ & $\begin{array}{l}\text { Actual Poverty: } \\
\text { Demographic, } \\
\text { Wage, Work and } \\
\text { Benefit Changes }\end{array}$ \\
\hline \multicolumn{5}{|c|}{ Couples With Children } \\
\hline 1979 & $13.1 \%$ & $13.1 \%$ & $13.1 \%$ & $13.1 \%$ \\
\hline 1984 & $13.6 \%$ & $14.7 \%$ & $20.5 \%$ & $19.1 \%$ \\
\hline 1989 & $14.3 \%$ & $18.4 \%$ & $22.0 \%$ & $21.5 \%$ \\
\hline 1994 & $16.4 \%$ & $21.8 \%$ & $25.1 \%$ & $24.3 \%$ \\
\hline 1999 & $15.8 \%$ & $21.1 \%$ & $24.9 \%$ & $22.6 \%$ \\
\hline \multicolumn{5}{|c|}{ Couples Without Children } \\
\hline 1979 & $3.5 \%$ & $3.5 \%$ & $3.5 \%$ & $3.5 \%$ \\
\hline 1984 & $3.8 \%$ & $4.6 \%$ & $8.6 \%$ & $7.1 \%$ \\
\hline 1989 & $3.2 \%$ & $4.8 \%$ & $9.1 \%$ & $7.5 \%$ \\
\hline 1994 & $3.3 \%$ & $5.7 \%$ & $11.6 \%$ & $9.4 \%$ \\
\hline 1999 & $4.4 \%$ & $7.2 \%$ & $10.9 \%$ & $9.0 \%$ \\
\hline \multicolumn{5}{|c|}{ Singles With Children } \\
\hline 1979 & $48.3 \%$ & $48.3 \%$ & $48.3 \%$ & $48.3 \%$ \\
\hline 1984 & $53.2 \%$ & $58.0 \%$ & $63.3 \%$ & $54.4 \%$ \\
\hline 1989 & $55.2 \%$ & $61.9 \%$ & $70.1 \%$ & $66.7 \%$ \\
\hline 1994 & $56.4 \%$ & $65.5 \%$ & $72.9 \%$ & $63.7 \%$ \\
\hline 1999 & $60.2 \%$ & $67.1 \%$ & $75.5 \%$ & $64.7 \%$ \\
\hline \multicolumn{5}{|c|}{ Singles Without Children } \\
\hline 1979 & $13.3 \%$ & $13.3 \%$ & $13.3 \%$ & $13.3 \%$ \\
\hline 1984 & $15.4 \%$ & $16.9 \%$ & $26.7 \%$ & $22.0 \%$ \\
\hline 1989 & $14.9 \%$ & $18.5 \%$ & $25.6 \%$ & $23.2 \%$ \\
\hline 1994 & $16.5 \%$ & $19.2 \%$ & $30.3 \%$ & $25.3 \%$ \\
\hline 1999 & $17.1 \%$ & $19.9 \%$ & $30.4 \%$ & $23.9 \%$ \\
\hline
\end{tabular}


Table A3

Composition of Change in Absolute Poverty Since 1979 by Family Type: US

\begin{tabular}{|c|c|c|c|c|}
\hline & $\begin{array}{c}\text { Demographic } \\
\text { Changes }\end{array}$ & $\begin{array}{c}\text { Demographic } \\
\text { and Wage } \\
\text { Changes }\end{array}$ & $\begin{array}{c}\text { Demographic, } \\
\text { Wage and Work } \\
\text { Changes }\end{array}$ & $\begin{array}{c}\text { Actual Poverty: } \\
\text { Demographic, } \\
\text { Wage, Work and } \\
\text { Benefit Changes }\end{array}$ \\
\hline \multicolumn{5}{|c|}{ Couples With Children } \\
\hline 1979 & $6.4 \%$ & $6.4 \%$ & $6.4 \%$ & $6.4 \%$ \\
\hline 1984 & $7.5 \%$ & $9.1 \%$ & $10.4 \%$ & $10.4 \%$ \\
\hline 1989 & $7.9 \%$ & $9.7 \%$ & $7.8 \%$ & $8.0 \%$ \\
\hline 1994 & $7.6 \%$ & $10.1 \%$ & $9.0 \%$ & $8.1 \%$ \\
\hline 1999 & $7.3 \%$ & $8.7 \%$ & $6.3 \%$ & $6.4 \%$ \\
\hline \multicolumn{5}{|c|}{ Couples Without Children } \\
\hline 1979 & $2.5 \%$ & $2.5 \%$ & $2.5 \%$ & $2.5 \%$ \\
\hline 1984 & $2.8 \%$ & $3.3 \%$ & $3.9 \%$ & $3.8 \%$ \\
\hline 1989 & $2.5 \%$ & $2.8 \%$ & $2.5 \%$ & $2.9 \%$ \\
\hline 1994 & $2.5 \%$ & $2.7 \%$ & $2.6 \%$ & $3.1 \%$ \\
\hline 1999 & $2.9 \%$ & $3.2 \%$ & $2.8 \%$ & $2.8 \%$ \\
\hline \multicolumn{5}{|c|}{ Singles With Children } \\
\hline 1979 & $36.9 \%$ & $36.9 \%$ & $36.9 \%$ & $36.9 \%$ \\
\hline 1984 & $38.0 \%$ & $39.5 \%$ & $42.0 \%$ & $45.2 \%$ \\
\hline 1989 & $35.5 \%$ & $37.5 \%$ & $38.4 \%$ & $41.5 \%$ \\
\hline 1994 & $37.1 \%$ & $40.4 \%$ & $40.8 \%$ & $39.5 \%$ \\
\hline 1999 & $31.8 \%$ & $34.1 \%$ & $27.6 \%$ & $29.0 \%$ \\
\hline \multicolumn{5}{|c|}{ Singles Without Children } \\
\hline 1979 & $15.0 \%$ & $15.0 \%$ & $15.0 \%$ & $15.0 \%$ \\
\hline 1984 & $15.0 \%$ & $16.1 \%$ & $17.8 \%$ & $17.9 \%$ \\
\hline 1989 & $14.4 \%$ & $15.3 \%$ & $15.0 \%$ & $15.3 \%$ \\
\hline 1994 & $15.4 \%$ & $17.5 \%$ & $18.3 \%$ & $18.2 \%$ \\
\hline 1999 & $15.3 \%$ & $16.2 \%$ & $15.7 \%$ & $16.0 \%$ \\
\hline
\end{tabular}


Table A4

Composition of Change in Relative Poverty Since 1979 by Family Type: US

\begin{tabular}{|c|c|c|c|c|}
\hline & $\begin{array}{c}\text { Demographic } \\
\text { Changes }\end{array}$ & $\begin{array}{l}\text { Demographic } \\
\text { and Wage } \\
\text { Changes }\end{array}$ & $\begin{array}{l}\text { Demographic, } \\
\text { Wage and Work } \\
\text { Changes }\end{array}$ & $\begin{array}{l}\text { Actual Poverty: } \\
\text { Demographic, } \\
\text { Wage, Work and } \\
\text { Benefit Changes }\end{array}$ \\
\hline \multicolumn{5}{|c|}{ Couples With Children } \\
\hline 1979 & $23.4 \%$ & $23.4 \%$ & $23.4 \%$ & $23.4 \%$ \\
\hline 1984 & $25.2 \%$ & $26.0 \%$ & $26.8 \%$ & $26.6 \%$ \\
\hline 1989 & $26.0 \%$ & $27.8 \%$ & $26.4 \%$ & $26.4 \%$ \\
\hline 1994 & $25.3 \%$ & $27.4 \%$ & $26.6 \%$ & $26.5 \%$ \\
\hline 1999 & $26.2 \%$ & $28.4 \%$ & $26.7 \%$ & $26.8 \%$ \\
\hline \multicolumn{5}{|c|}{ Couples Without Children } \\
\hline 1979 & $9.5 \%$ & $9.5 \%$ & $9.5 \%$ & $9.5 \%$ \\
\hline 1984 & $10.8 \%$ & $11.0 \%$ & $11.5 \%$ & $11.6 \%$ \\
\hline 1989 & $10.7 \%$ & $11.3 \%$ & $11.1 \%$ & $11.1 \%$ \\
\hline 1994 & $10.9 \%$ & $11.0 \%$ & $11.0 \%$ & $11.0 \%$ \\
\hline 1999 & $11.8 \%$ & $12.5 \%$ & $12.0 \%$ & $11.7 \%$ \\
\hline \multicolumn{5}{|c|}{ Singles With Children } \\
\hline 1979 & $63.9 \%$ & $63.9 \%$ & $63.9 \%$ & $63.9 \%$ \\
\hline 1984 & $65.0 \%$ & $64.7 \%$ & $65.1 \%$ & $66.2 \%$ \\
\hline 1989 & $63.4 \%$ & $63.2 \%$ & $65.3 \%$ & $65.6 \%$ \\
\hline 1994 & $63.4 \%$ & $63.3 \%$ & $65.7 \%$ & $64.6 \%$ \\
\hline 1999 & $61.6 \%$ & $61.0 \%$ & $60.7 \%$ & $61.1 \%$ \\
\hline \multicolumn{5}{|c|}{ Singles Without Children } \\
\hline 1979 & $26.6 \%$ & $26.6 \%$ & $26.6 \%$ & $26.6 \%$ \\
\hline 1984 & $27.3 \%$ & $27.7 \%$ & $28.4 \%$ & $28.6 \%$ \\
\hline 1989 & $27.1 \%$ & $28.2 \%$ & $28.5 \%$ & $28.7 \%$ \\
\hline 1994 & $28.6 \%$ & $29.6 \%$ & $30.7 \%$ & $30.7 \%$ \\
\hline 1999 & $29.2 \%$ & $30.2 \%$ & $30.9 \%$ & $30.8 \%$ \\
\hline
\end{tabular}

